\title{
Exercise and type 2 diabetes
}

Citation for published version (APA):

Borghouts, L. (2000). Exercise and type 2 diabetes. [Doctoral Thesis, Maastricht University]. Universiteit Maastricht. https://doi.org/10.26481/dis.20000211lb

Document status and date:

Published: 01/01/2000

DOI:

10.26481/dis.20000211lb

Document Version:

Publisher's PDF, also known as Version of record

\section{Please check the document version of this publication:}

- A submitted manuscript is the version of the article upon submission and before peer-review. There can be important differences between the submitted version and the official published version of record.

People interested in the research are advised to contact the author for the final version of the publication, or visit the DOI to the publisher's website.

- The final author version and the galley proof are versions of the publication after peer review.

- The final published version features the final layout of the paper including the volume, issue and page numbers.

Link to publication

\footnotetext{
General rights rights.

- You may freely distribute the URL identifying the publication in the public portal. please follow below link for the End User Agreement:

www.umlib.nl/taverne-license

Take down policy

If you believe that this document breaches copyright please contact us at:

repository@maastrichtuniversity.nl

providing details and we will investigate your claim.
}

Copyright and moral rights for the publications made accessible in the public portal are retained by the authors and/or other copyright owners and it is a condition of accessing publications that users recognise and abide by the legal requirements associated with these

- Users may download and print one copy of any publication from the public portal for the purpose of private study or research.

- You may not further distribute the material or use it for any profit-making activity or commercial gain

If the publication is distributed under the terms of Article $25 \mathrm{fa}$ of the Dutch Copyright Act, indicated by the "Taverne" license above, 
Exercise and Type 2 Diabetes 
(c) 2000 L.B. Borghouts, Maastricht, Nederland.

ISBN 90-9013501-4

Omslag: Lars Borghouts.

Druk: Datawyse Maastricht/Krips Repro Meppel.

The studies described in this thesis were financially supported by the Diabetes Fund Netherlands (DFN).

Printing of this thesis was financially supported by the Diabetes Fund Netherlands (DFN), the Dr. Ir. J.H. van der Laarstichting, Servier Nederland BV, 


\section{Exercise and Type 2 Diabetes}

\section{PROEFSCHRIFT}

ter verkrijging van de graad van doctor aan de Universiteit Maastricht, op gezag van de Rector Magnificus, Prof. dr. A.C. Nieuwenhuijzen Kruseman, volgens het besluit van het College van Decanen, in het openbaar te verdedigen op vrijdag 11 februari 2000

om 16.00 uur

door

Laurentius Bartholomeus Borghouts

geboren te Breda op 29 juni 1972 


\section{Promotor:}

Prof. Dr. H. Kuipers

\section{Co-promotor:}

Dr. H.A. Keizer

\section{Beoordelingscommissie:}

Prof. Dr. Ir. W.H.M. Saris (voorzitter)

Prof. Dr. R.J. Heine

Prof. Dr. G.J. van der Vusse

Dr. A.J.M. Wagenmakers

Dr. B.H. Wolffenbuttel 


\section{Contents}

Chapter 1 Introduction

Chapter 2 Exercise and Insulin Sensitivity: A Review

Chapter 3 Type 2 Diabetes and Exercise: General

Materials and Methods

Chapter 4 Substrate Utilisation in Type 2 Diabetes at Rest and During Exercise

Chapter 5 Effect of Training Intensity on Insulin Sensitivity Evaluated by Insulin Tolerance Test

Chapter 6 No Effect of Training on Glucose Homeostasis during Acute Exercise to Exhaustion in Type 2 Diabetes

Chapter 7 Effects of Long-Term Physical Training on Type 2 Diabetes

Chapter 8 Physical Training Reduces Oral AntiHyperglycaemic Drug Requirements in Type 2 Diabetes

Chapter 9 GLUT-4 Expression in Different Skeletal Muscle Fibre Types (Evidence for Intermuscular Differences)

Chapter 10 General Discussion

Samenvatting

Alfabetische Dankwoordenlijst

Curriculum Vitae

Publications 


\section{Introduction}

\section{Chapter}

\section{Type 2 Diabetes: What is the Problem?}

The population of our Western society has become increasingly sedentary over the last decades, largely due to the advancing industrialisation and automation of both our occupational and leisure time activities. Together with the affluence that is characteristic for welfare states, this has lead to an increasing prevalence of pathological conditions such as coronary heart disease, obesity, and insulin resistance. The association of each of the above-mentioned conditions with sedentary living habits has been firmly established $(11,13)$. Quantitative estimates indicate that sedentary living is responsible for about one-third of deaths due to coronary heart disease and type 2 diabetes (11), It has been estimated that in the United States, a relatively small increase in physical activity of the general population would result in a decrease in overall mortality by about 1 . $1.5 \%(11)$.

Type 2 diabetes (formerly called non-insulin dependent diabetes mellitus) is a common disorder which is underdiagnosed, and therefore often undertreated. Besides physical inactivity, risk factors for type 2 diabetes include older age, obesity, family history of diabetes, and ethnicity (2). It is the most prevalent form of diabetes mellitus (about $90-95 \%$ of all diagnosed cases diabetes), and affects an estimated 110 million people world-wide (17). In the Netherlands, the prevalence of type 2 diabetes has been estimated to be $7-8 \%$ (10). Consequently, the health care costs associated with type 2 diabetes, and its clinical complications, are substantial; in the UK, it has been calculated that diabetes accounts for $\sim 5 \%$ of total health care costs, while the annual health care expenditure per head is seven times greater for someone with diabetes than for the non-diabetic person (1). In the US, the total health care costs for diabetes have been estimated to be between $\$ 91.8$ billion and $\$ 105$ billion (1). From these impressive figures, and given the fact that the prevalence of type 2 diabetes is expected only to rise in future years, it has become clear that prevention and treatment of this metabolic disorder is presently one of the major challenges in medical research. 


\section{Pathogenesis of Type 2 Diabetes}

Type 2 diabetes mellitus is diagnosed as an elevated fasting plasma glucose level (>11 mmol// once, or $>7 \mathrm{mmol} / \mathrm{l}$ on two separate occasions), or in case of mildly elevated fasting plasma glucose $(>6 \mathrm{mmol} / \mathrm{l})$ by an oral glucose tolerance test.

Several factors are responsible for maintaining a normal glucose tolerance (table 1.1). These factors will subsequently be discussed briefly, together with their possible roles in the

Table 1.1: Factors responsible for maintenance of a normal glucose tolerance.

\begin{tabular}{|c|}
\hline Insulin secretion \\
First phase \\
Second phase \\
Tissue glucose uptake \\
Peripheral (primarily muscle) \\
Splanchnic (primarily liver) \\
Suppression of hepatic glucose output \\
\hline
\end{tabular}

pathofysiology of type 2 diabetes. For a more comprehensive review, the reader is referred to the papers of Defronzo (3-5). Insulin secretion:

Fasting concentrations of plasma insulin have been found to be normal or increased in type 2 diabetes patients. Although it could be

argued that enhanced insulin secretion by the pancreatic $\beta$-cells is a primary lesion of type 2 diabetes, with the subsequent development of insulin resistance secondary to hyperinsulinaemia, there is little evidence to support such a pathological sequence. Most of the available evidence suggests that insulin resistance is the primary disturbance. However, insulin secretion in response hyperglycaemia is usually deficient in type 2 diabetics. In response to an oral or intravenous glucose load, insulin is secreted in a biphasic pattern. The acute phase is a burst of insulin secretion within the first ten minutes, followed by the second phase of progressively increasing insulin secretion that persists as long as hyperglycaemia is present. A longitudinal investigation by Weyer et al. (15) in Pima Indians, a population in which type 2 diabetes is highly prevalent, has suggested that a blunted first phase insulin response occurs early in the development of type 2 diabetes. It was found by these authors that this deficiency is already present at the transition from normal glucose tolerance (NGT) to impaired glucose tolerance (IGT). In contrast, insulin levels $30 \mathrm{~min}$ after glucose administration were decreased only in those individuals who had developed frank type 2 diabetes (15).

Tissue glucose uptake: During euglycaemic insulin clamp, the major part of the infused glucose is disposed in skeletal muscle. From figure 1.1, it can be seen that under these conditions, skeletal muscle is almost solely responsible for the insulin resistance present in type 2 diabetes. Under the same conditions, it has been shown by Kelley et al. (8) that insulin stimulated translocation of the glucose transporter GLUT-4 to the plasma membrane is attenuated in skeletal muscle of type 2 diabetes patients. Since glucose transport is thought to be the rate limiting step for insulin stimulated glucose uptake, this attenuated GLUT-4 translocation in skeletal muscle may be a primary cause of insulin resistance in type 2 diabetes. Splanchnic glucose uptake is not thought to be significantly affected in type 2 diabetes (3-5), however, insulin resistance does play a role with regard to hepatic glucose output. 


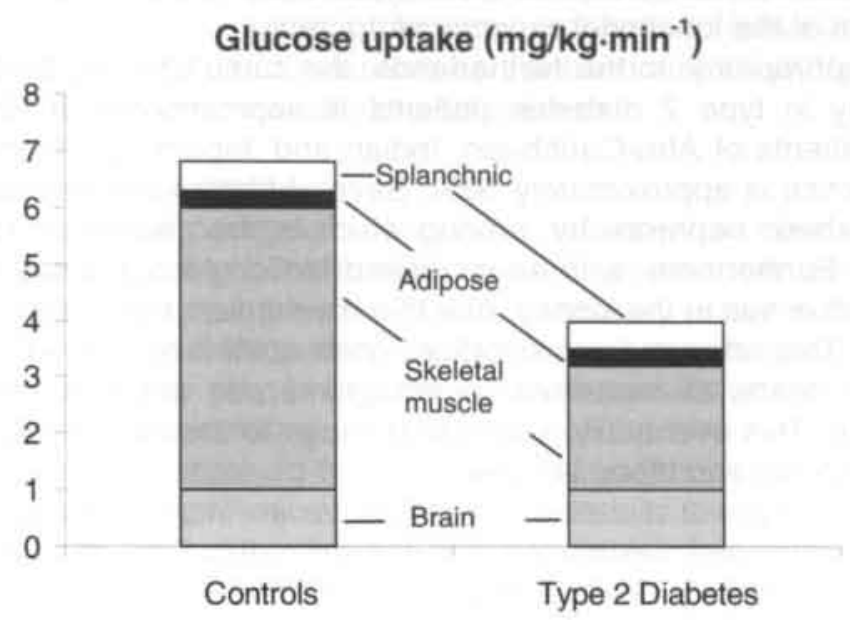

Figure 1.1: Glucose uptake in different tissues during euglycemic insulin clamp studies in type 2 diabetics and controls. Adapted from (3).

Hepatic glucose production: During euglycaemic insulin clamp studies, when blood glucose concentration is maintained by glucose infusion, and hepatic glucose production is largely or completely suppressed, the liver does not contribute significantly to the abnormalities found in type 2 diabetes. However, the elevated plasma glucose levels found in these patients during an oral glucose tolerance test (OGTT) are caused in part by hepatic insulin resistance. Insulin inhibits hepatic glucose output, and the diminished inhibition in type 2 diabetics accounts for approximately one-third of the abnormal plasma glucose levels found during an OGTT. The other two-thirds are caused by peripheral insulin resistance. The study by Weyer et al. (15) mentioned earlier, suggested that the increased endogenous glucose output occurs during the transition from IGT to type 2 diabetes. In other words, increased hepatic glucose output is probably not the primary lesion in the aetiology of type 2 diabetes.

\section{Complications of Type 2 Diabetes.}

Type 2 diabetes is associated with several long-term complications, that can seriously affect the well-being of type 2 diabetes patients. Moreover, these complications are responsible for the increased mortality observed in patients with type 2 diabetes. The major complications associated with type 2 diabetes (2) will subsequently be described briefly.

Diabetic retinopathy: The retinovascular complications associated with diabetes mellitus are currently the major cause of blindness in adults. They are probably the result of several factors impairing blood supply and oxygen delivery to the retina. These factors include an increase in glycosylated haemoglobin (HbA1c) and thickening of the retina's basal membrane. This can lead to a progressive deterioration of the blood-retina barrier, causing leakage through the vessel 
wall, and focal retinal ischaemia. Both these occurrences lead to a progressive deterioration of the functional capacity of the retina.

Diabetic nephropathy: In the Netherlands, the cumulative incidence of diabetic nephropathy in type 2 diabetes patients is approximately $5-10 \%$. In type 2 diabetes patients of Afro-Caribbean, Indian and Japanese ethnicity, the cumulative incidence is approximately $50 \%$. Several factors are involved in the aetiology of diabetic nephropathy, among which is the disposition to develop hypertension. Furthermore, with an increased blood glucose level, afferent vasodilatation will ensue in the kidney, due to a mechanism that is not yet completely elucidated. This afferent vasodilatation, often combined with an efferent vasoconstriction, leads to increases in intraglomerular pressure and glomerular filtration rate. This eventually results in damage to the glomerulus, and to other tubular structures and blood vessels.

Hypertension: Type 2 diabetes patients have an increased prevalence of hypertension. It has been estimated that approximately $50 \%$ of all type 2 diabetes patients will ultimately develop hypertension. The underlying pathogenesis of this association is largely unknown. However, possible important factors are increased sodium retention and hyperinsulinaemia. Furthermore, an increased sensitivity of the blood vessel wall to vaso-active substances has been demonstrated in type 2 diabetics.

Diabetic neuropathy: Estimates of the prevalence of diabetic neuropathy are highly variable, due to lack of consensus about diagnostic criteria, and suboptimal sensitivity of the diagnostic methods currently in use. It is clear however, that the prevalence of neuropathy is strongly increased in type 2 diabetic patients compared to age-matched non-diabetics, up to an age of approximately 70 years. Diabetic neuropathy can occur in the brain, in proximal motor nerves, and as distal symmetrical polyneuropathy. In the brain, ischaemia of the nerves due to changes in the vasa nervorum are probably the cause of neuropathy. However, the causes of proximal motor neuropathy and distal symmetrical polyneuropathy are largely unknown. One of the hypothesised mechanisms again involves the glycosylation of proteins, and herewith associated vascular adaptations.

Dyslipidaemia: Insulin resistance, hypertension, and dyslipidaemia are clustered in what has been called Syndrome X, the Pluri-Metabolic Syndrome, or Reaven's Syndrome. The underlying mechanisms causing this syndrome are under much debate. However, what is clear is that type 2 diabetics often exhibit hyperlipidaemia, characterised by increased plasma low-density lipoprotein cholesterol levels, decreased high-density lipoprotein cholesterol levels, and increased plasma free fatty acid concentrations. These abnormalities are associated with an increased risk of atherogenesis.

Cardiovascular pathology: Cardiovascular disease is the major cause of mortality in type 2 diabetic patients. The prevalence of cardiovascular pathology is 1.5-3.5 times higher in type 2 diabetic patients compared to non-diabetics. These pathologies are strongly associated with dyslipidaemia, hyperinsulinaemia, and hyperglycaemia. All these disturbances adversely affect endothelial function and other structures of the vessel wall, causing increased risk of atherosclerosis, cardiomyopathy and myocardial infarction.

Diabetic foot: It is estimated that approximately $25 \%$ of all diabetes patients (type 1 and 2) will need medical care for problems of the foot at least once in 
their life. The interaction of angiopathy and neuropathy can lead to a multitude of abnormalities of the foot, varying from nail problems to infections of muscle and bone structures. Small foot trauma can subsequently lead to ulcerations and gangrene, not seldom necessitating amputation.

\section{Exercise and Type 2 Diabetes}

As indicated in the first paragraph of this chapter, physical inactivity is an important risk factor for type 2 diabetes. Several large-scale epidemiological studies have confirmed that people who are physically active have a reduced risk for developing type 2 diabetes $(7,9)$. Chapter 2 of this thesis reviews the role physical activity can play in improving insulin sensitivity, together with the possible underlying mechanisms. A great deal of the knowledge about these mechanisms has been obtained from animal studies (principally mouse and rat studies). Although the conclusions drawn from these studies have undoubtedly been invaluable to our understanding of the interplay between exercise and muscle glucose uptake, it is essential to confirm these in human studies, since extrapolation from one species to another is not always valid. Furthermore, regarding training intervention studies it must be noted that effects of training on insulin sensitivity have been reported after training periods as brief as a few weeks $(12,14,16)$. However, from an exercise physiological point of view one can hardly consider an individual "trained" who, after a lifetime of inactivity, has undergone a training program of several weeks or months. These considerations have brought us to the project described in this thesis: a two-year intervention study into whole body and skeletal muscle adaptations to physical training in type 2 diabetes patients. This enabled us not only to study the effects of prolonged training, but also the feasibility of such a "life style" intervention in this patient group.

Our main objectives were to study:

1) if substrate utilisation during moderate intensity exercise is different between type 2 diabetes patients and healthy controls.

2) whether low intensity and high intensity training are equally effective in improving insulin sensitivity.

3) glucoregulation during acute exhaustive exercise in type 2 diabetes patients.

4) to what extend a long-term training program can improve insulin stimulated glucose disposal and glycaemic control in type 2 diabetes patients.

5) if physical training in type 2 diabetes patients results in an increased expression of skeletal muscle GLUT-4 protein, and an increased translocation of GLUT-4 to the sarcolemma after stimulation with insulin and/or contractions.

6) if the level of physical training remains adequate to maintain possible training-induced improvements, when training supervision is minimised after an initial training period of 12 months.

Our study into the effect of training on GLUT-4 translocation in human skeletal muscle were carried out making use of immuno-electronmicroscopy. Unfortunately, these investigations were still in progress at the completion of this thesis. Therefore, their results will be published a separate paper. 
The emphasis of our studies has been on skeletal muscle metabolism. Although peripheral insulin resistance is a key factor in type 2 diabetes (6), it should be made clear here that this should not be taken to indicate that the effect of physical training on splanchnic glucose metabolism is negligible. Indeed, these effects can be profound, as will be described in the next chapter, but they are beyond the direct scope of the studies presented in this thesis. 


\section{References}

1. Alberti, K. G. The costs of noninsulin-dependent diabetes mellitus [editorial]. Diabet Med 14: 7-9, 1997.

2. Ballegooie, E. v., and R. J. Heine. Diabetes Mellitus. Utrecht: Bunge, 1995.

3. DeFronzo, R. A. Lilly lecture 1987. The triumvirate: beta-cell, muscle, liver. A collusion responsible for NIDDM. Diabetes 37: 667-87, 1988.

4. DeFronzo, R. A. Pathogenesis of type-2 diabetes: metabolic and molecular implications for identifying diabetes genes. Diabetes-Rev 5: 177 269, 1997.

5. DeFronzo, R. A., R. C. Bonadonna, and E. Ferrannini. Pathogenesis of NIDDM. A balanced overview. Diabetes-Care 15: 318-68, 1992.

6. DeFronzo, R. A., R. Gunnarsson, 0. Bjorkman, M. Olsson, and J. Wahren. Effects of insulin on peripheral and splanchnic glucose metabolism in noninsulin-dependent (type 2) diabetes mellitus. $J$ Clin Invest 76 : 149-55, 1985.

7. Helmrich, S. P., D. R. Ragland, R. W. Leung, and R. S. Paffenbarger, Jr. Physical activity and reduced occurrence of non-insulin-dependent diabetes mellitus [see comments]. $\mathrm{N}$ Engl-J-Med 325: 147-52, 1991.

8. Kelley, D. E., M. A. Mintun, S. C. Watkins, J. A. Simoneau, F. Jadali, A. Fredrickson, J. Beattie, and R. Theriault. The effect of non-insulindependent diabetes mellitus and obesity on glucose transport and phosphorylation in skeletal muscle. $J$ Clin Invest 97: 2705-13, 1996.

9. Manson, J. E., E. B. Rimm, M. J. Stampfer, G. A. Colditz, W. C. Willett, A. S. Krolewski, B. Rosner, C. H. Hennekens, and F. E. Speizer. Physical activity and incidence of noninsulin-dependent diabetes mellitus in women. Lancet 338: 774-8, 1991.

10. Mooy, J. M., P. A. Grootenhuis, H. de Vries, H. A. Valkenburg, L. M. Bouter, P. J. Kostense, and R. J.
Heine. Prevalence and determinants of glucose intolerance in a Dutch caucasian population. The Hoorn Study. Diabetes Care 18: 1270-3, 1995.

11. Powell, K. E., and S. N. Blair. The public health burdens of sedentary living habits: theoretical but realistic estimates. Med-Sci-Sports-Exerc 26: 851-6, 1994.

12. Schneider, S. H., L. F. Amorosa, A. K. Khachadurian, and N. B. Ruderman. Studies on the mechanism of improved glucose control during regular exercise in type 2 (noninsulin-dependent) diabetes. Diabetologia 26: 355-60, 1984.

13. Seidell, J. C., and K. M. Flegal. Assessing obesity: classification and epidemiology. Br Med Bull 53: 23852, 1997.

14. Trovati, M., Q. Carta, F. Cavalot, S. Vitali, C. Banaudi, P. G. Lucchina, F. Fiocchi, G. Emanuelli, and G. Lenti. Influence of physical training on blood glucose control, glucose tolerance, insulin secretion, and insulin action in non-insulin-dependent diabetic patients. Diabetes Care 7: 416-20, 1984.

15. Weyer, C., C. Bogardus, D. M. Mott, and R. E. Pratley. The natural history of insulin secretory dysfunction and insulin resistance in the pathogenesis of type 2 diabetes mellitus. J Clin Invest 104: 787-794, 1999.

16. Yamanouchi, K., T. Shinozaki, K. Chikada, T. Nishikawa, K. Ito, S. Shimizu, N. Ozawa, Y. Suzuki, H. Maeno, K. Kato, and et al. Daily walking combined with diet therapy is a useful means for obese NIDDM patients not only to reduce body weight but also to improve insulin sensitivity. Diabetes Care 18: 775-8, 1995.

17. Zimmet, P., and D. McCarthy. The NIDDM epidemic: global estimates and projections-a look into the crystal ball. IDF Bulletin 40: 8-16, 1995. 


\section{Exercise and Insulin Sensitivity: A Review}

\section{L.B. Borghouts, H.A. Keizer}

International Journal of Sports Medicine (In Print)

\section{Summary}

Physical activity has a beneficial effect on insulin sensitivity in normal as well as insulin resistant populations. A distinction should be made between the acute effects of exercise and genuine training effects. Up to two hours after exercise, glucose uptake is in part elevated due to insulin independent mechanisms, probably involving a contraction-induced increase in the amount of GLUT-4 associated with the plasma membrane and T-tubules. However, a single bout of exercise can increase insulin sensitivity for at least $16 \mathrm{~h}$ post exercise in healthy as well as type 2 diabetes populations. Recent studies have accordingly shown that acute exercise also enhances insulin stimulated GLUT-4 translocation. Increases in muscle GLUT-4 protein content contribute to this effect, and in addition it has been hypothesized that the depletion of muscle glycogen stores with exercise plays a role herein. Physical training potentiates the effect of exercise on insulin sensitivity through multiple adaptations in glucose transport and metabolism. In addition, training may elicit favorable changes in lipid metabolism and can bring about improvements in the regulation of hepatic glucose output, which is especially relevant to type 2 diabetes. It is concluded that physical training can be considered to play an important, if not essential role in the treatment and prevention of insulin insensitivity. 
Physical activity has been advocated in the treatment of diabetes mellitus from as early as the 5th century (115). More recent epidemiological studies have provided evidence that the level of physical activity is associated with the incidence of type 2 diabetes $(34,51,82)$. Indeed, the risk for developing type 2 diabetes in women who engage in exercise at least once a week has been estimated to be $33 \%$ lower than for their sedentary counterparts (82). Crosssectional studies have shown that trained subjects are more insulin sensitive than untrained subjects $(48,67,79,121)$ and that, although ageing is associated with declining insulin sensitivity, endurance trained elderly subjects are more insulin sensitive than young, sedentary subjects (110). The mechanisms by which training improves insulin sensitivity have been investigated extensively over the last two decades. However, just as it is impossible to attribute type 2 diabetes to one single cause, the effects of physical training on insulin resistance/sensitivity can not be ascribed to a single mechanism. Furthermore, studies have been carried out on in vitro muscle preparations, animal models of type 2 diabetes and obesity, healthy subjects, type 2 diabetic and obese subjects. This makes a general interpretation of this field of research complicated.

Although aerobic exercise is usually considered the most adequate mode of exercise for improving insulin sensitivity, little attention has been directed toward the issue of minimal or optimal exercise requirements. A training program can vary in its duration, frequency and intensity, and for example muscle mass involved in the exercise. Furthermore, effects of acute exercise and long-term training should be distinguished, since the mechanism by which they influence glucose uptake are distinct. This review on the effect of exercise on insulin sensitivity will therefore summarise current literature subdivided in studies carried out both in healthy and type 2 diabetic subjects, and effects of acute exercise versus physical training. Mechanisms underlying these effects will be discussed together with their importance with regard to type 2 diabetes.

\section{Acute exercise in healthy man}

Carbohydrates and lipids are generally considered the most important substrates during exercise. Although amino acids are utilised during exercise as well, their quantitative role in the energy provision to exercising muscle is limited under most circumstances (77). In the resting, postabsorbtive state, fat is the predominant energy source, as indicated by respiratory exchange ratio's of around 0.75 , both at whole body level and in arterio-venous balance studies of the leg (65). Substrate metabolism during exercise depends on the intensity and duration of exercise, together with the training status of the exercising individual. Muscle and liver glycogen become more important to energy provision with increasing exercise intensity, while the relative contribution of plasma free fatty acids (FFA) decreases (102). In addition, intramuscular triglycerides (IMTG) 
play a role in muscle metabolism during moderate to intense exercise, but probably not at very low intensities (102). When exercise is prolonged (>60 $\mathrm{min}$ ), muscle glycogen stores eventually become depleted, and consequently the contribution of plasma substrates to total energy expenditure must increase if power output is to be sustained. Despite this fact, plasma glucose concentration remains quite stable during exercise of moderate duration because hepatic glucose output increases in proportion to the increased muscle glucose uptake (102). Hepatic glucose production constitutes of glycogenolysis and gluconeogenesis from the precursors lactate, pyruvate, glycerol and amino acids (mainly alanine). Liver glycogenolysis accounts for approximately $75 \%$ of glucose output at the onset of exercise. Since liver glycogen stores after an overnight fast are approximately $75-100 \mathrm{~g}$, after $40 \mathrm{~min}$ of strenuous exercise as much as $20-25 \%$ of pre-exercise liver glycogen will have been mobilised. As liver glycogen becomes increasingly depleted, the rate of glycogenolysis will fall, and gluconeogenesis will contribute up to $50 \%$ of total glucose output. However, this increase in gluconeogenesis fails to fully compensate for decreased liver glycogen breakdown, and therefore after approximately $90 \mathrm{~min}$ of exercise without glucose ingestion, blood glucose will fall (37). Hepatic glucose output is stimulated by afferent neural feedback from contracting muscle and by unidentified substances released from the muscle into the blood (70). Subsequently, a decline in plasma insulin levels is probably the most important factor stimulating glucose production by the liver, whereas adrenaline has an additional stimulating effect during intense exercise (70). These same conditions (sympathetic stimulation and hormonal shifts) regulate mobilisation of fatty acids from the adipose tissue. Circulating lipids that can be used as an energy source are free fatty acids (FFA) and triglycerides (TG). FFA in plasma are bound to albumin, while TG are incorporated in lipoproteins by the liver. Although the amount of TG in the circulation outweighs that of FFA, FFA probably play a predominant role in energy metabolism during exercise (120). Shortly after the onset of exercise, a small drop in FFA concentration is usually seen, due to an increased muscle uptake. This mismatch between uptake and mobilisation of FFA is gradually corrected by the before-mentioned stimulation of lipolysis, and with prolonged exercise, markedly elevated FFA concentrations are present. The degree of fat oxidation during exercise is largely determined by exercise intensity, and not duration, since human lipid stores are in theory sufficient for several days of exercise. At exercise of $25 \% \mathrm{VO}_{2} \max$ almost all energy is derived from fat, and its relative contribution declines with increasing exercise intensity (102). Absolute rates of fat oxidation start to decrease at exercise intensities exceeding approximately $70 \% \mathrm{VO}_{2}$ max, when turnover and plasma levels of FFA fall rapidly $(4,102)$ (figure 2.1$)$.

A single bout of exercise has been shown to increase insulin stimulated whole body glucose uptake, as measured by glucose clamp, for at least 16 hours postexercise $(11,89)$. In addition, acute exercise has been shown to decrease the insulin response to an oral glucose tolerance test (OGTT) (128), suggesting that peripheral insulin sensitivity is increased. The magnitude of this acute exercise effect probably depends on the mode of exercise and its duration, but to our knowledge no well-controlled studies have been conducted on this topic. The current literature on the importance of exercise intensity in relation to insulin 


\section{Glossary}

Insulin sensitivity

Insulin resistance

Insulin responsiveness

Glucose clamp technique

M

Glucose tolerance

OGTT

IVGTT

Impaired glucose tolerance

Glucose-mass action
The insulin concentration that elicits a halfmaximal response.

Diminished or attenuated effect of insulin on glucose uptake.

The effect of maximally stimulating, supraphysiological insulin levels on glucose uptake.

Method to quantify insulin stimulated glucose uptake. During insulin infusion, plasma glucose is maintained at a predetermined value by glucose infusion and frequent online plasma glucose monitoring.

The amount of glucose required to maintain fasting glucose values during a standardised insulin infusion.

The ability of the body to dispose of glucose after a glucose load.

Oral glucose tolerance test. Used generally for clinical diagnosis of diabetes. After an oral glucose load (usually $75 \mathrm{~g}$ ) plasma glucose levels are measured at specified times over 2 h. Diabetes is diagnosed when levels of venous plasma glucose are: fasting $>7.0 \mathrm{mM}$ and/or peak during OGTT $>11.0 \mathrm{mM}$ and/or $2 \mathrm{~h}$ value $>11.0 \mathrm{mM}$. Normal values are considered: fasting $<6.4 \mathrm{mM}$ and/or peak during OGTT $<11.1 \mathrm{mM}$ and/or $2 \mathrm{~h}$ value $<7.8 \mathrm{mM}$. Intravenous glucose tolerance test. Used to determine glucose tolerance for research purposes. Glucose is given intravenously, circumventing the effect of variable gastrointestinal absorption.

State diagnosed by OGTT, when levels are above normal but below diabetic. $2 \mathrm{~h}$ OGTT value 7.8-11.0.

The ability of glucose to stimulate its own uptake, through its concentration gradient over the plasma membrane. 


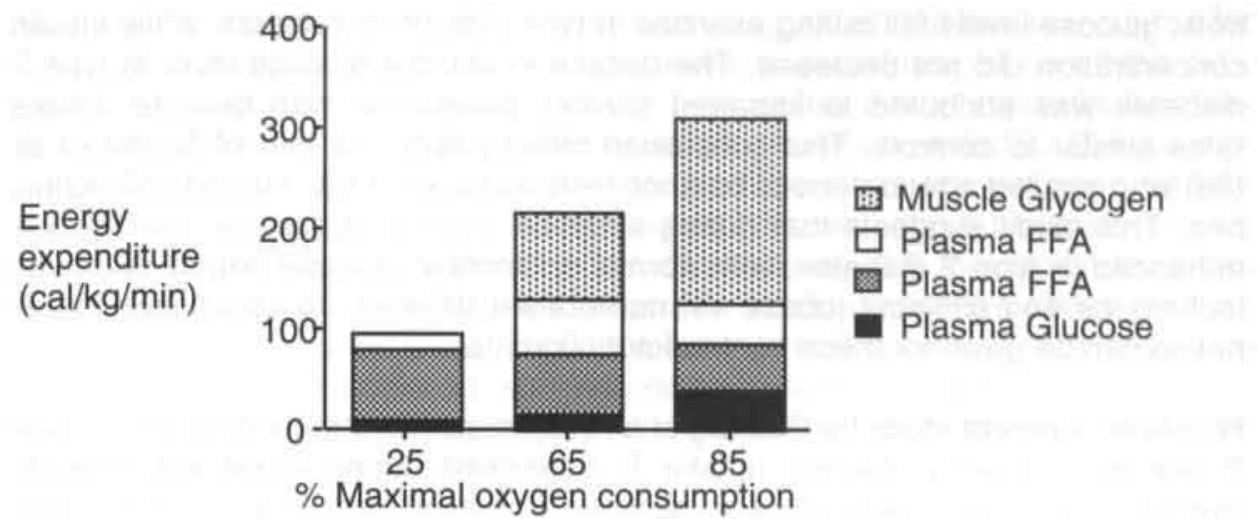

Figure 2.1: Substrate Utilisation during exercise of different intensities. Reprinted from Romiin et al. (102).

sensitivity is equivocal $(14,62,128)$. The general opinion seems to be that not exercise intensity, but the total amount of work performed is of prime importance (14).

In healthy man more than $80 \%$ of an intravenous glucose load (24) is taken up by skeletal muscle, and thus an increase in skeletal muscle glucose uptake after exercise can have a major impact on whole body level. Skeletal muscle becomes more insulin sensitive after acute exercise which has been shown both in rat $(100,123)$ and man $(99)$. Adipose tissue and the liver also exhibit insulin stimulated glucose uptake. However, adipose tissue only accounts for 1$2 \%$ of glucose clearance after an intravenous glucose load in normal man (8), and $3-4 \%$ in obese subjects $(8,84)$. Therefore, its role in glucose uptake after exercise will be small. It has been shown that after acute exercise a smaller portion of an ingested glucose load is taken up by the liver, apparently favouring skeletal muscle glycogen replenishment (81).

From these considerations, it follows that skeletal muscle is the major organ for exercise induced stimulation of glucose uptake. One-legged exercise models have demonstrated that this effect is predominantly restricted to the exercised muscles (99). The possible mechanisms explaining enhanced insulin stimulated glucose uptake will be discussed subsequently.

\section{Acute exercise in type 2 diabetes}

In type 2 diabetes patients, fuel utilisation during exercise is probably altered. In contrast to normal man, blood glucose declines during prolonged exercise in type 2 diabetes patients $(86,93)$. In theory, this could reflect inadequate liver glucose output (glycogenolysis or gluconeogenesis), a disproportional use of plasma glucose during exercise, or both. Unfortunately, few studies have addressed the metabolic response of type 2 diabetes patients to acute exercise $(19,86,93)$. Minuk et al. (93) studied several metabolic aspects of acute exercise in type 2 diabetic subjects, applying stable isotope techniques. Relatively little differences from body-composition matched controls were found. Plasma levels of lactate, pyruvate, alanine and FFA increased similarly in type 2 diabetes and controls during $45 \mathrm{~min}$ of exercise at $60 \% \mathrm{VO}_{2} \max$. In contrast to con- 
trols, glucose levels fell during exercise in type 2 diabetic subjects, while insulin concentration did not decrease. The decline in plasma glucose level in type 2 diabetes was attributed to impaired glucose production with glucose uptake rates similar to controls. This conclusion directly opposes that of Martin et al. (86) who applied arterio-venous balance techniques over the leg and splanchnic bed. This study suggests that during exercise peripheral glucose utilisation is enhanced in type 2 diabetes, with normal splanchnic glucose output. Although techniques and subjects (obese vs. non-obese) differed, no conclusive explanation can be given for these contradictory findings.

However, a recent study by Colberg et al. (19), supports the concept that in type 2 diabetes, plasma glucose uptake is increased during moderate intensity exercise. Glycogen oxidation was reduced however, resulting in similar total carbohydrate oxidation rates in type 2 diabetic and control subjects.

From the cited studies, it is concluded that the impairment in insulin stimulated glucose uptake at rest, characteristic for type 2 diabetes, does not prevail during exercise. Hyperglycaemia in these subjects probably even leads to increased plasma glucose disappearance during exercise, due to mass action of glucose (19).

Although there is evidence that the rate of lipid oxidation by muscle under resting conditions in type 2 diabetes is reduced $(63,65)$, to our knowledge muscle lipid oxidation during exercise has never been investigated. However, overall fat utilisation, as determined by RER measurements, seems to be similar in type 2 diabetic and healthy subjects during exercise (19).

As in healthy subjects, it has been shown that acute exercise can stimulate insulin mediated glucose uptake in type 2 diabetes. Devlin et al. $(32,33)$ have found an effect of a single bout of high-intensity exercise on insulin stimulated glucose uptake, measured after 12-14 h after exercise, in obese (33) and type 2 diabetic (32) subjects. However, in contrast to most studies $(11,89,128)$, no significant effect was found in lean, normal subjects (33). The absolute increase in insulin stimulated glucose uptake was similar however, implying that acute exercise is able to stimulate glucose uptake to a certain extent, but that this increase is of relevance especially when insulin sensitivity is already impaired.

\section{How acute exercise can improve insulin sensitivity}

A distinction should be made between the early and late phase of exercise stimulated glucose uptake. Exercise requires an increase in plasma glucose uptake by skeletal muscle. Upon cessation of exercise, the rate of glycolysis will immediately decrease, while glucose transport is still elevated due to increased membrane glucose transport capacity and blood flow. Blood flow decreases quite rapidly after exercise (15-45 $\mathrm{min})$, depending on the workload (3). In incubated rat epitrochlearis muscle, glucose transport after swimming exercise remains elevated for approximately 2 hours (127). This effect was not dependent on insulin or other hormones, since these were not added to the incubation medium. A similar time course was found for the decline in plasma membrane associated glucose transporter number after treadmill exercise (41). In muscle from rats sacrificed $30 \mathrm{~min}$ after exercise, glucose transporter protein in plasma membrane was elevated, but it had returned to pre-exercise values in rats 
sacrificed $2 \mathrm{~h}$ after exercise (41). It has been suggested that the time course for return of glucose uptake to pre-exercise levels is dependent on fibre type (94). Using sarcolemmal giant vesicles derived from vastus lateralis muscle, Kristiansen et al. (73) have shown that exercise also increases muscle GLUT-4 translocation in humans, but how long this effect remains has not yet been investigated. The late phase of exercise stimulated glucose uptake however, can be attributed to enhanced post-exercise insulin sensitivity. It is this prolonged effect that is especially of importance with regard to insulin insensitive states such as type 2 diabetes, and will therefore be the focus of this review. The mechanisms involved may be associated with exercise induced glycogen depletion, and involve effects on insulin stimulated glucose transporter capacity, as will be described in the following paragraphs.

\section{Glycogen repletion}

When glucose is ingested under postabsorbtive conditions, a large portion will be stored in the liver $(23,38)$. Post-exercise, this glucose load will almost entirely serve to replenish muscle glycogen stores (81). The rate limiting step in the formation of glycogen is considered to be the transfer of glucose from UDPglucose to glycogen, catalysed by the enzyme glycogen synthase. In accordance, it was postulated that glycogen synthase (GS) could play an important role in the exercise induced rise in insulin sensitivity. Indeed, glycogen synthase activity was found to be increased after exercise $(32,71)$. However, glycogen formation remains elevated long after glycogen synthase activity has returned to normal, and glycogen stores are repleted to levels above pre-exercise levels with adequate food intake (58). It should be pointed out that although glycogen synthase is the rate limiting enzyme for glycogen formation, glycogen formation can only proceed when glucose is available. In accordance, it has been shown that glucose transport, not glycogen synthase activity, is rate limiting for glycogen formation $(9,95,96)$. This precludes a prominent role for GS in the improved insulin sensitivity after exercise. Recently, other mechanisms through which glycogen depletion could play a role in insulin sensitivity after acute exercise have been suggested, being through the putative association of GLUT4 with the glycogen stores (17), or through its effect on the hexosamine biosynthesis pathway (85). These mechanisms will subsequently be described.

\section{Insulin signalling}

Increased insulin sensitivity after exercise has been suggested to involve enhanced insulin signalling. However, insulin receptor binding in skeletal muscle is not improved by acute exercise $(12,118)$. Furthermore, although insulin stimulated muscle glucose uptake is increased in human skeletal muscle after exercise, IRS1-phosphorylation and PI 3-kinase activity are unaltered (124) (see figure 2.1). This would indicate that prior exercise does not increase tyrosine kinase activity of the insulin receptor. These results are supported by several studies in rat hindlimb muscles $(39,118)$, but using different analytical methods, Zhou et al. (129) reported a 6-fold increase in insulin stimulated PI 3-kinase activity after treadmill running.

With regard to type 2 diabetes, the cellular insulin resistance that characterises this disease is thought to lie distally from insulin receptor binding $(16,60)$. 
Therefore, it is questionable if (yet undiscovered) exercise effects on insulin binding could favourably affect insulin resistance in type 2 diabetes. It has been suggested however, that insulin could prolong the effect of exercise-induced glucose transporter translocation by slowing internalisation of GLUT-4 (127).

\section{Glucose transport}

A large body of evidence is available showing that glucose transport into the muscle cell is enhanced by acute exercise. Directly after exercise, the number of glucose transporters associated with the plasma membrane and transverse tubules is increased dramatically $(41,43,103)$ with a concomitant rise in glucose uptake. However, glucose transporter level in the plasma membrane returns to resting values within 2 hours after cessation of exercise (41), and can therefore not be responsible for the prolonged exercise effect on insulin stimulated glucose uptake. The response of glucose transporters to insulin stimulation after exercise is of more importance in this respect. Hansen et al. (47) have

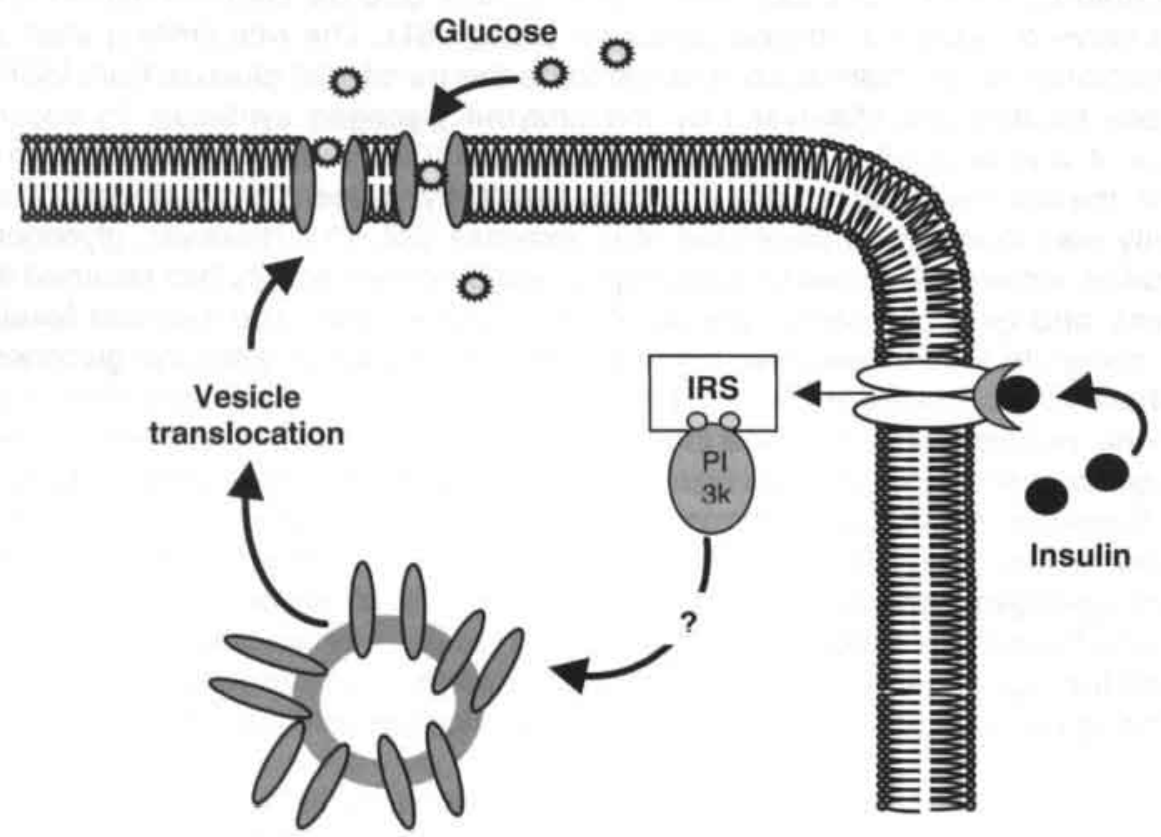

Figure 2.2: Insulin Stimulated GLUT-4 Translocation in Muscle Cells.

GLUT-4 is stored in intracellular vesicles. After insulin binding to its receptor, receptor autophosphorylation results in phosphorylation of insulin receptor substrates (IRS). These form complexes with various docking proteins, such as $\mathrm{PI}-3$ kinase (PI3k). Activation of PI3k is a major pathway in the activation of glucose uptake. It activates several phosphoinositide-dependent kinases that participate in the GLUT-4 translocation process. The exact mechanisms are as yet unknown (?). Exercise stimulates glucose uptake independent of PI3k. 
recently shown that $3.5 \mathrm{hr}$ after $30 \mathrm{~min}$ of exercise, glucose transport and GLUT-4 translocation were both, and to a similar magnitude, increased in response to a submaximal insulin stimulation. This occurred despite unaltered total GLUT-4 content. It is as yet unknown how long this effect persists, and if it plays a role in the increased insulin sensitivity up to $16 \mathrm{hr}$ after exercise. Interestingly, rats show large increases in muscle GLUT-4 mRNA and GLUT-4 protein expression 16h (97), and even immediately after prolonged exercise (58). Since GLUT-4 protein concentration and insulin-stimulated glucose transport are positively correlated (52) this rise in total GLUT-4 may well contribute to the prolonged acute exercise effect.

As already mentioned, a major portion of glucose ingested after exercise is taken up by skeletal muscle to replenish glycogen stores (81). Therefore, it is interesting that a functional association between muscle glycogen and GLUT-4 has recently been suggested (17). These authors hypothesise that glycogen depletion would result in a larger available pool of free GLUT-4 vesicles. This hypothesis is supported by the observation that mice over-expressing GLUT1, having dramatically increased muscle glycogen levels, are insulin resistant (45). An alternative (or additional) mechanism by which glycogen depletion might indirectly stimulate GLUT-4 translocation was put forward by Ivy and Kuo (58) extending the findings of others $(85,101)$ on the effect of glucosamine on glucose transport. Fructose-6-phosphate can be converted to glucosamine-6phosphate by the rate limiting enzyme glutamine:fructose-6-phosphate amidotransferase (GFAT) (Figure 2.3). Glucosamine-6-phosphate enters the hexosamine-biosynthetic pathway eventually forming glycolipids, glycoproteins, and other products. Although this pathway is thought to represent only $2-3 \%$ of total glucose flux, it may play an important regulatory role. It has been shown, that incubation with glucosamine, which enters hexosamine-biosynthetic pathway

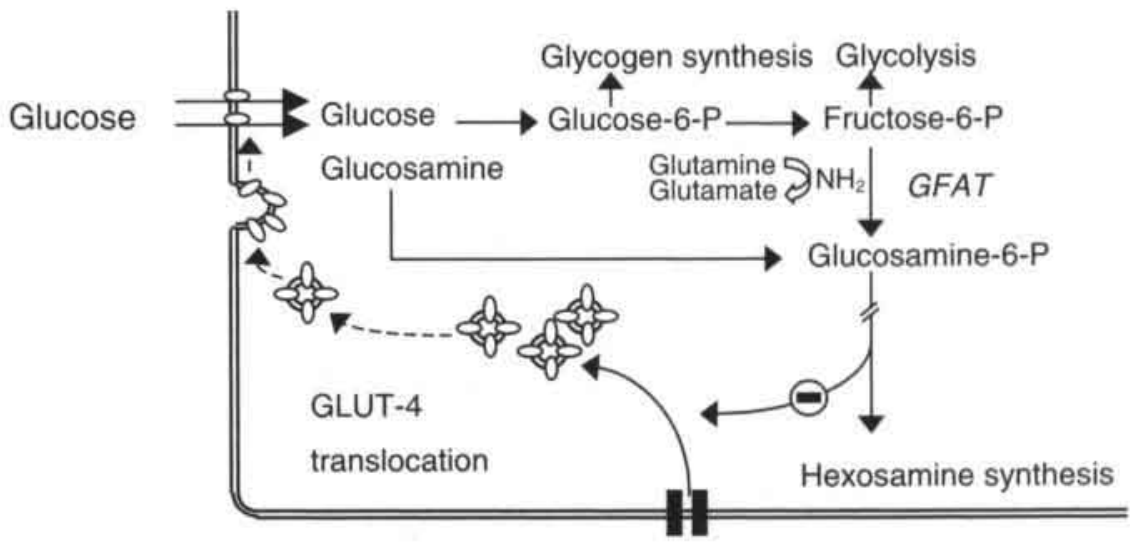

Insulin

Figure 2.3: Possible mechanism by which glucose entering the hexosamine biosynthetic pathway could affect insulin sensitivity. Please refer to the text for further details. 
distal from GFAT, inhibits insulin stimulated glucose transport in both adipocytes (85) and muscle preparations (101). This desensitisation of insulin signal transduction possibly arises from altered glycosylation of GLUT-4, or vesicleassociated proteins. Under circumstances when insulin stimulated glucose uptake is increased after exercise, but glucose disposal to glycolysis and glycogenesis has returned to near pre-exercise levels, more glucose would enter the hexosamine pathway, and this would subsequently inhibit glucose uptake. Conversely, when glycogen levels are low, GFAT activity would be low, and glucose uptake would not be restrained by the products of the hexosamine pathway (58). It is interesting in this respect, that it has been found that GFAT activity in human muscle biopsies was increased by $46 \%$ in type 2 diabetes patients compared with normal subjects (126).

\section{Physical training in healthy man}

Exercise training induces a variety of metabolic adaptations, enabling welltrained subjects to exercise at a high performance level. In addition, these adaptations to exercise elicit profound changes in resting metabolism. Several of these mechanisms potentially improve insulin sensitivity, and enhance glucose disposal. Studies comparing trained with untrained individuals provide insight into the magnitude of this effect, although they do not rule out population differences due to natural selection mechanisms. These (mostly early) studies showed that trained subjects, compared with matched untrained subjects have a diminished insulin response to a glucose load (7), a lower basal insulin level (79) and $50 \%$ lower insulin levels during constant glucose infusion (79). Applying the euglycaemic clamp, trained individuals were found to be more insulin sensitive (submaximal insulin stimulation) and have either equal (67) or increased $(28,91)$ insulin responsiveness (maximal insulin stimulation). It seems that physical activity counteracts the decline in insulin sensitivity associated with ageing, since lean, older athletes show similar glucose and insulin responses to young athletes during an oral glucose tolerance test, and lower responses compared with older lean untrained subjects (110).

Intervention studies have provided more direct evidence for the beneficial effect of physical training on insulin sensitivity. Training interventions have ranged from a few days to several months, and healthy subjects as well as subjects with varying degrees of insulin insensitivity have been studied. The hyperinsulinaemic euglycaemic clamp has been applied to quantify whole body insulin stimulated glucose uptake in young subjects after 6 weeks of endurance training (113). With submaximal insulin infusion, glucose uptake was increased $30 \%$ after training. Similar results have been obtained after 7 weeks of daily treadmill running in rats (59) and after 16 weeks of strength training in older subjects (92). In the latter study, glucose uptake was increased to the same extent ( \pm $23 \%$ ) at both physiological and supraphysiological hyperinsulinaemia.

Several studies have investigated the effect of a physical training program in healthy, older subjects $(60-80 \mathrm{yr}$.) $(61,111,117)$. The long term programs, lasting 6-12 months $(61,111)$, indicate that in these subjects with normal initial glucose tolerance, glucose tolerance remains unchanged after training, but with reduced insulin responses and reduced basal insulin levels. The observed 
effect is still evident at least 60 hours after the last exercise bout (61). In the 3 month intervention study of Tonino (117), glucose uptake during a euglycaemic clamp remained elevated even after 7 days of detraining. Therefore, these studies suggest a genuine training effect. In conclusion, it is clear that physical training increases insulin sensitivity in healthy subjects, and reverses the adverse effects of ageing on insulin sensitivity. Data suggests that the main training effect in healthy subjects is that normal glucose tolerance can be maintained with reduced insulin levels.

\section{Physical training in type 2 diabetes patients}

Studies on the effect of exercise training in IGT- or type 2 diabetic subjects are abundant. Table 2.1 summarises a number of these studies. Those that have applied the oral glucose tolerance test have obtained variable results. Some investigators have found no effect of training on OGTT $(104,109,119)$, others report improved glucose tolerance with lower $(54,106)$ or unchanged $(75)$ insulin response. Decreased fasting levels of blood glucose $(10,119,125)$ and insulin $(10,25,28,119,125)$ after training were found in some, but not all studies. This discrepancy between studies may result from differences in training duration, frequency and intensity, but this is not readily apparent when the applied training programs are examined. However, there can be significant differences between study populations, even within groups of type 2 diabetes patients. For example, type 2 diabetic subjects with an insulin deficiency are unlikely to respond to physical training with a reduced insulin secretion to an oral glucose load. Differences in the degree of insulin resistance of the subjects could also account for differences in the effect of training. Furthermore, although it is clear that the OGTT may be suitable as a clinical tool for diagnosis of type 2 diabetes, its use to evaluate insulin sensitivity within a research setting is limited (108). It is notable therefore, that all studies applying the glucose clamp technique (as described by DeFronzo (26)) have reported whole body glucose uptake $(M)$ to increase drastically after exercise training $(10,25,75$, $119,125)$. However, insulin stimulated glucose uptake never increases to normal levels with euglycaemic clamps, indicating that the applied training programs have not been able to fully overcome or compensate insulin resistance. Unfortunately, of the cited studies, only two mention $\mathrm{HbA1c}$ levels, an indication of long term glucose homeostasis. Both studies however, find very similar decreases $(\approx 15 \%)$ after six weeks of training $(109,119)$.

On the whole, type 2 diabetes patients and healthy subjects seem equally responsive to physical exercise, with the expected difference that oral glucose tolerance has been found to improve in type 2 diabetes only.

\section{How physical training can improve insulin sensitivity}

Before going into the mechanism by which training could improve insulin sensitivity, it is important to consider whether a genuine training effect exists or whether the reported effects of training could merely be a residual effect of the last exercise bout. Furthermore, a distinction should be made between insulin sensitivity and insulin responsiveness. Insulin sensitivity is determined, usually with the glucose clamp technique, at a submaximal insulin level, while insulin 
Next page

Table 2.1: Training intervention studies performed in populations with decreased insulin sensitivity.

IGT: impaired glucose tolerance; HRmax: maximal heart rate ; BEGP: basal endogenous glucose production ; $\mathrm{M}_{\mathrm{s}}$ : submaximally insulin stimulated whole body glucose uptake ; $\mathrm{M}_{\mathrm{m}}$ : maximally stimulated whole body glucose uptake ; leg $\mathrm{GCR}_{\mathrm{s}}$ : submaximally insulin stimulated leg glucose clearance ; leg $\mathrm{GCR}_{\mathrm{m}}$ : maximally insulin stimulated leg glucose clearance. With training programs building up in intensity in time, or applying interval protocols, the highest exercise intensity achieved is re-

responsiveness is determined at supraphysiological, maximally stimulating insulin levels.

To investigate the effect of a single bout of exercise versus physical training, trained subjects have been compared with untrained subjects, both $15 \mathrm{~h}$ after an exercise session (90). Under these conditions, insulin sensitivity was higher in the trained subjects. However the last exercise bout before the experiment was not controlled in the trained group, and therefore not identical in both groups. In a subsequent study, trained subjects were studied again $15 \mathrm{~h}$ after their last habitual exercise bout, immediately after $60 \mathrm{~min}$ of exercise at $64 \%$ $\mathrm{VO}_{2} \max$, and after 5 days of detraining. Insulin sensitivity was similar directly and $15 \mathrm{~h}$ after exercise, but decreased to near untrained levels after 5 days of detraining (91). The increased insulin sensitivity found in trained subjects would therefore be a residual effect of the last exercise session. In contrast, it was found that insulin responsiveness was the same in all three conditions, which led the authors to conclude that the alteration in maximal insulin action with prolonged endurance training cannot be ascribed to the effect of the last exercise bout. These findings were extended to a one-legged exercise training model with measurement of glucose clearance of the leg (LGC) by Dela et al $(27,28)$. In these studies, subjects followed one-legged training programs for 10 weeks on a bicycle ergometer, and insulin stimulated glucose uptake was measured over the trained leg $16 \mathrm{~h}$ after the last exercise bout. Subsequently, a single exercise bout was performed with the untrained leg, and again insulin stimulated glucose uptake was measured over the trained leg $16 \mathrm{~h}$ later. It was found in type 2 diabetes and control subjects that training increases LGC at both maximal and submaximal insulin stimulation, but contrary to the whole body studies, no effect was detected of a single bout of one-legged exercise. This finding therefore supports the concept that training causes an increase in muscle insulin sensitivity that cannot be achieved by acute exercise. It should be noted that with one-legged exercise models, the muscle mass involved in exercise is smaller than with bicycling. Consequently, systemic adaptations (e.g. On liver glucose output) may be less pronounced, and therefore these studies should be interpreted accordingly.

It seems that the above mentioned studies are unequivocal in their findings with regard to an additional effect of training compared to acute exercise on insulin sensitivity. This may stem from misinterpretation of detraining effects. Cessation of training may rapidly reverse the training associated increase in insulin sensitivity $(15,50,88,91)$. However, this does not exclude the possibility that longterm training elicits a stronger effect than does acute exercise. Thus, an acute 


\begin{tabular}{|c|c|c|c|c|}
\hline Study & Subjects & Training & Results & Remarks \\
\hline (106) & Type 2 DM & $\begin{array}{l}6 \mathrm{mo} / 5 \cdot \mathrm{wk} / 30 \\
\mathrm{~min} \\
\text { cycling at } 100 \mathrm{w}\end{array}$ & $\begin{array}{l}\text { OGTT: unaltered } \\
\text { IVGTT: improved, } \\
\text { with insulin } \leftrightarrow\end{array}$ & $\begin{array}{l}5 \text { subjects, all } \\
\text { insulin deficient, } \\
\text { were tested }\end{array}$ \\
\hline (104) & IGT & $\begin{array}{l}12 \mathrm{mo} / 2 \cdot \mathrm{wk} / 60 \\
\mathrm{~min} \text { various at? }\end{array}$ & $\begin{array}{l}\text { OGTT: improved, } \\
\text { with insulin } \downarrow\end{array}$ & 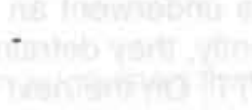 \\
\hline (109) & Type 2 DM & $\begin{array}{l}6 \mathrm{wk} / 3 \cdot \mathrm{wk} / 44 \\
\min \\
\text { various at } 70 \% \\
\mathrm{VO}_{2} \max \end{array}$ & $\begin{array}{l}\text { OGTT: unaltered } \\
\text { IVGTT: unaltered } \\
\mathrm{HbA}_{1} 14 \% \downarrow\end{array}$ & $\begin{array}{l}\text { OGT better } 12 \mathrm{~h} \\
\text { than } 72 \mathrm{~h} \text { after } \\
\text { exercise }\end{array}$ \\
\hline (10) & $\begin{array}{l}\text { Type } 2 \text { DM, } \\
\text { IGT }\end{array}$ & $\begin{array}{l}3 \text { mo/3.wk/30 } \\
\text { min } \\
\text { various at } 75 \% \\
\text { HRmax } \\
\text { combined with } \\
\text { diet }\end{array}$ & $\begin{array}{l}\text { IVGTT: unaltered } \\
\text { BEGP: } 17 \% \downarrow \\
M_{5}: 30 \% \uparrow\end{array}$ & $\begin{array}{l}\text { exercise + diet } \\
\text { intervention } \\
\text { more effective } \\
\text { than diet alone }\end{array}$ \\
\hline (119) & Type 2 DM & $\begin{array}{l}6 \mathrm{wk} / 7 \cdot \mathrm{wk} / 60 \\
\text { min } \\
\text { cycling at } 55 \% \\
\mathrm{VO}_{2} \text { max }\end{array}$ & $\begin{array}{l}\text { OGTT: unaltered } \\
\text { IVGTT: improved, } \\
\text { with insulin } \leftrightarrow \\
M_{s}: 28 \% \uparrow \\
\mathrm{HbA}_{1} 16 \% \downarrow\end{array}$ & $\begin{array}{l}5 \text { subjects } \\
\text { tested }\end{array}$ \\
\hline (75) & Type 2 DM & $\begin{array}{l}3 \text { mo/3.wk/50 } \\
\text { min } \\
\text { cycling at } 85 \% \\
\mathrm{VO}_{2} \text { max }\end{array}$ & $\begin{array}{l}\text { OGTT: improved } \\
\text { with insulin } \leftrightarrow \\
M_{s}: 22 \% \uparrow \\
M_{m}: 24 \% \uparrow\end{array}$ & $\begin{array}{l}\text { subjects with } \\
\text { unaltered } \mathrm{VO}_{2-} \\
\text { max excluded }\end{array}$ \\
\hline (54) & $\begin{array}{l}\text { Type } 2 \text { DM, } \\
\text { IGT }\end{array}$ & $\begin{array}{l}12 \mathrm{mo} / 4 \cdot \mathrm{wk} / 60 \\
\text { min } \\
\text { cycling \& run- } \\
\text { ning at } 80 \% \\
\mathrm{VO}_{2} \text { max }\end{array}$ & $\begin{array}{l}\text { OGTT: improved, } \\
\text { with insulin } \downarrow\end{array}$ & - \\
\hline (25) & Obese & $\begin{array}{l}6 \text { wk/ } 5 \cdot \text { wk/ } 50 \\
\text { min } \\
\text { cycling \& run- } \\
\text { ning at } 65 \% \\
\mathrm{VO}_{2} \max \end{array}$ & $\begin{array}{l}\text { insulin } \downarrow \text { during } \\
\text { hyperglycaemia } \\
M_{\mathrm{s}}: 24 \% \uparrow\end{array}$ & - \\
\hline (27) & Type 2 DM & $\begin{array}{l}10 \mathrm{wk} / 6 \cdot \mathrm{wk} / 30 \\
\text { min } \\
\text { one-leg cycling } \\
\text { at } 70 \% \text { one- } \\
\text { legged } \mathrm{VO}_{2} \text { max }\end{array}$ & $\begin{array}{l}M_{s}: 31 \% \uparrow \\
M_{m}: 19 \% \uparrow \\
\text { leg GCR }: 58 \% \uparrow \\
\text { leg GCR }: 39 \% \uparrow\end{array}$ & $\begin{array}{l}\text { with acute } \\
\text { exercise no } \\
\text { increase in leg } \\
\text { GCR }\end{array}$ \\
\hline (125) & Type 2 DM & $\begin{array}{l}7 \text { wk/6 wk/13 km } \\
\text { walking at? } \\
\text { combined with } \\
\text { diet }\end{array}$ & $M_{5}: 47 \% \uparrow$ & $\begin{array}{l}\mathrm{M}_{\mathrm{s}} \text { : did not } \\
\text { change with diet } \\
\text { alone }\end{array}$ \\
\hline
\end{tabular}


bout of exercise could have less impact on insulin sensitivity in untrained than trained subjects. This view is supported by the one-legged exercise data, finding an increased glucose uptake over the leg $16 \mathrm{~h}$ after the last exercise bout in trained, but not untrained leg $(27,28)$. Additional evidence for the idea that acute exercise in the trained state is more potent that acute exercise in the untrained state comes from a study by Heath et al. (50), in which trained subjects underwent an OGTT the morning after their last training session. Subsequently, they detrained for 10 days, after which they were subjected to a second OGTT. On the next day, a single training session comparable to their last training was performed, and on the morning thereafter, a third OGTT was applied. Detraining caused markedly elevated insulin levels during the OGTT. With one bout of exercise the insulin response was blunted compared to detraining, but still elevated compared to before the detraining period (Figure 2.4) (50). This again indicates that insulin sensitivity after acute exercise is higher in the trained state than in the detrained or untrained state.

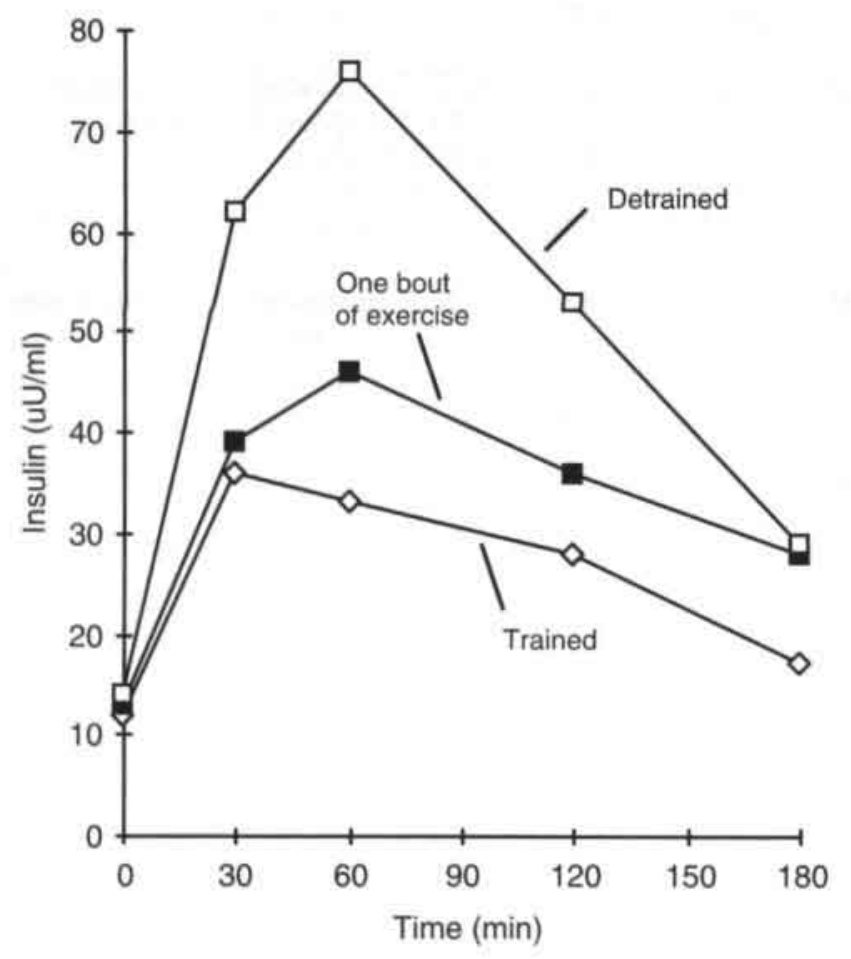

Figure 2.4: Plasma insulin concentration during an oral $100-\mathrm{g}$ glucose tolerance test in the trained state, after no exercise for 10 days, and one day after a single bout of exercise following 11 days without exercise. Adapted from Heath et al., 1983. 
Due to differences in study protocols it is precarious to make comparisons between studies, but it seems that values of insulin stimulated glucose uptake obtained during euglycaemic clamps after training interventions in previously sedentary subjects $(92,113,117)$ are still lower compared with values measured in athletes $(91,121,122)$, which also suggests long term adaptations to training.

We therefore conclude that although it has repeatedly been suggested that the effect of training on insulin sensitivity is rapidly lost, training probably does potentiate the acute effect of exercise on insulin sensitivity. The possible mechanisms underlying this effect will be discussed subsequently, together with several other beneficial effects of long-term training that are of special importance for glucose intolerant populations.

\section{Insulin signalling}

Defects in the insulin signal transduction pathway have been shown in skeletal muscle of both obese (40) and type 2 diabetic subjects (5). Specifically, insulin receptor substrate-1(IRS-1) phosphorylation and phosphatidylinositol 3-kinase activity were decreased with insulin stimulation. Endurance training in rats has been shown to enhance gene expression (mRNA levels) of the insulin receptor, IRS-1 and ERK1 in skeletal muscle (66). ERK1 is a MAP kinase isoform, and the MAP kinase pathway is involved in several insulin post-receptor effects, possibly including regulation of glycogen synthase activity (22). Whether, and to what extent, exercise training could alter insulin signalling to improve insulin stimulated glucose uptake remains to be elucidated.

\section{Glucose transport and metabolism}

Muscle blood flow is not limiting to muscle glucose utilisation under physiological conditions, although it may be at supraphysiological insulin stimulation (13). However, muscle capillary density in men and women with type 2 diabetes is decreased compared to controls (83). This decreased capillarisation could be attributed to a high waist-hip ratio in women, but not men with type 2 diabetes (83). It is conceivable therefore, that if training is capable of increasing glucose transport and metabolism, adaptive increases in muscle blood flow should also occur to ensure adequate supply of glucose. Indeed, capillary density increases with endurance training in both healthy individuals (2) and type 2 diabetes patients (1). Insulin is a potent stimulator of muscle blood flow, and endurance training enhances this capability (35). So, irrespective of the question whether glucose supply limits glucose disposal under physiological conditions, muscle blood flow increases with training in concert with the adaptations at the level of glucose transport and metabolism.

As mentioned earlier, glucose transport is usually the rate limiting factor in muscle glucose disposal. Glucose transport over the sarcolemma relies on the amount of glucose transporters associated with the plasma membrane and the T-tubules. Therefore, glucose transport capacity increases if the total amount of GLUT-4 protein increases, and/or if the portion of GLUT-4 that translocates in response to insulin stimulation would increase. Conversely, insulin resistance 
might be explained by insufficient amounts of GLUT-4 in skeletal muscle, or any process causing impaired GLUT-4 translocation. With regard to the former, muscle biopsy studies have clearly shown that the amount of GLUT-4 in skeletal muscle of type 2 diabetes patients is not different from healthy controls (29, $80,107)$. The study of the latter, GLUT-4 translocation in skeletal muscle, has been complicated by difficulties inherent to the study of membrane proteins. This often involves isolation of membranes using subcellular fractionation, with the chance of cross-contamination. The methods currently available to (semi-) quantitate membrane-associated GLUT-4, with their specific advantages and disadvantages have been recently reviewed (78).

In the obese Zucker rat, an animal model commonly used in the study of insulin resistance, there is an indication that insulin stimulated GLUT-4 translocation is defect (69), while exercise stimulates translocation normally (68). Similar to the findings in the Zucker rat, confocal laser scanning microscopy in humans has revealed that upon insulin stimulation, GLUT-4 translocation to the plasma membrane is attenuated in obese and type 2 diabetes patients compared with healthy subjects (64).

GLUT-4 is muscle group-specifically upregulated in endurance trained individuals (48), and GLUT-4 content has been shown to increase by training in skeletal muscle of healthy subjects $(46,55,56)$, IGT-subjects (57), and type 2 diabetes patients (29). However, since translocation of GLUT-4 in response to exercise and insulin is thought to rely on distinct mechanisms, upregulation of GLUT-4 by training does not necessarily have to lead to increased translocation in response to insulin. Applying an exofacial photolabelling technique (ATB-BMPA), and thus avoiding subcellular fractionation, Etgen et al. (36) have shown that in the obese Zucker rat, training improves insulin sensitivity by enhanced recruitment of glucose transporters to the plasma membrane, but only in predominantly fast-twitch muscle. To our knowledge, such evidence is lacking in humans. In the rat, glucose uptake is lower in fast-twitch muscles than in slowtwitch oxidative muscles (42), and training has been shown to convert glycolytic fast-twitch fibres (type 2b) into more oxidative fast-twitch (type 2a) fibres. It is therefore conceivable that in this species, training effects are more pronounced in fast twitch muscle than in slow-twitch muscle.

Type 2 diabetes has been associated with fibre type abnormalities, specifically an elevated number of fast-twitch glycolytic fibres and a decreased number of slow-twitch oxidative fibres (83). Similarly, the ratio of glycolytic to oxidative enzymes in vastus lateralis muscle of type 2 diabetes patients is higher than in controls (112). This ratio was found to correlate negatively with insulin sensitivity. Although glucose transport is normally the rate limiting step for glucose disposal in skeletal muscle, enzyme deficiencies of oxidative or non-oxidative glucose disposal could lead to impaired glucose uptake. The concentration gradient for glucose over the sarcolemma is maintained through glucose phosphorylation by hexokinase, forming glucose-6-phosphate. If, by a downstream defect in glucose metabolism, glucose-6-phosphate accumulates, hexokinase will be inhibited and glucose transport into the cell impaired. Physical training leads to an increase in enzyme capacity in skeletal muscle not only in normo- 
glycaemic subjects (53) but also in type 2 diabetes patients (1). Thus, the capacity for glucose metabolism increases in concert with changes in glucose transport, thereby contributing to improved insulin sensitivity after training.

\section{Body composition and lipid metabolism}

Obesity is a clear risk factor for the development of insulin resistance $(51,72)$. Particularly visceral obesity could lead to a cluster of metabolic derangements, among which insulin resistance and hyperinsulinaemia $(20,30,74)$. Given the importance of skeletal muscle for insulin stimulated glucose uptake, a body composition high in muscle mass and low in body fat would clearly be favourable to insulin sensitivity.

Plasma FFA levels are increased in type 2 diabetes, caused by increased fasting lipolysis, insulin resistance in suppression of lipolysis (44), as well as impaired clearance of FFA from plasma (116). High levels of FFA can impair glucose uptake and metabolism in skeletal muscle $(49,105)$, and may lead to increased hepatic glucose output (21). Visceral adipocytes have a low responsiveness to the anti-lipolytic effect of insulin, which could explain the derangement in lipid profiles found in obesity and obese forms of type 2 diabetes (6). Since physical training can significantly reduce visceral body fat $(31,74)$, this could induce a reduction in plasma FFA levels. Both fat cell size and lipoprotein lipase (LPL) activity have been shown to be lower in the subcutaneous abdominal depot of trained women compared with controls (87), and trained rats show an increase in the anti-lypolitic effect of insulin $(76,114)$. Taken together, these effects might improve glycaemic control in type 2 diabetes patients with disturbed lipid metabolism.

\begin{tabular}{|llc|}
\hline Insulin signalling & Insulin receptor mRNA & $\uparrow$ \\
& IRS-1 mRNA & $\uparrow$ \\
Glucose transport and & ERK1 mRNA & $\uparrow$ \\
metabolism & Capillary density & $\uparrow$ \\
& Insulin stimulated muscle blood flow & $\uparrow$ \\
& GLUT-4 protein & $\uparrow$ \\
& GLUT-4 translocation & $\uparrow$ \\
& Enzymes (non-)oxidative glucose & $\uparrow$ \\
Body composition and lipid & disposal & Whole body fat free mass \\
metabolism & Whole body fat mass & $\uparrow$ \\
& Visceral body fat & $\downarrow$ \\
Hepatic glucose output & FFA levels & $\downarrow$ \\
& Basal glucose production & $\downarrow$ \\
& Inhibition glucose output by insulin & $\uparrow$ \\
\hline
\end{tabular}

Table 2.2:

Potentially beneficial effects of training for type 2 diabetes. 


\section{Hepatic glucose output}

Although peripheral insulin resistance is the key defect in type 2 diabetes, a secondary derangement is an increased basal hepatic glucose output and impaired suppression of hepatic glucose output by insulin. This adds to hyperglycaemia caused by peripheral insulin resistance, and elevates plasma glucose concentration to a level at which glucose-mass action is sufficient to normalise insulin-stimulated glucose uptake in type 2 diabetes $(63,98)$. In healthy subjects, a training program can lead to decreased hepatic glucose output during exercise both by reducing glycogenolysis and gluconeogenesis, but without altering glucose kinetics at rest (18). In contrast, in obesity, 6 weeks of endurance training is effective in enhancing suppression of hepatic glucose output by insulin (25). Similar findings have been reported in type 2 diabetes patients in whom 12 weeks of training induced significant reductions in basal glucose production (17\%) and hepatic glucose output during insulin stimulation (25\%) (10).

Thus, in addition to enhancing peripheral insulin sensitivity, physical training has been shown to bring about improvements in the regulation of hepatic glucose output, thereby further underscoring the potential of physical training to normalise metabolic control.

\section{Conclusions}

Although type 2 diabetes is characterised by peripheral insulin resistance, plasma glucose utilisation during exercise is probably increased compared to healthy controls. This is caused by glucose-mass action together with unimpaired contraction-stimulated glucose uptake, leading to declining glucose levels during prolonged exercise in type 2 diabetes. During and immediately after acute exercise, glucose uptake in skeletal muscle is enhanced through increased glucose supply and an increase in plasma membrane associated GLUT-4. These effects disappear within 2 hours after exercise is discontinued. However, there remains a prolonged effect of acute exercise on glucose uptake through an increased insulin sensitivity. This effect is present in both type 2 diabetic and healthy subjects. From animal studies, it is known that after exercise, more GLUT-4 translocates to the plasma membrane upon insulin stimulation, possibly involving mechanisms initiated by glycogen depletion.

In their habitual state, physically trained subjects are more insulin responsive and sensitive than untrained subjects. Despite the fact that with several days of detraining this enhanced insulin sensitivity rapidly wanes, acute exercise enhances insulin stimulated glucose uptake more in trained than untrained muscle. Therefore, to optimise insulin sensitivity, it is advisable to perform exercise on a regular basis. Since skeletal muscle is responsible for a major portion of glucose uptake after exercise, large muscle groups should be exercised. This view is supported by the observation that acute exercise with one leg does not improve whole-body insulin sensitivity in untrained subjects.

Physical training causes multiple adaptations in skeletal muscle that contribute to increased insulin sensitivity, including upregulation of muscle GLUT-4 protein, increased enzyme capacities and muscle capillarisation. In addition, in populations with elevated resting hepatic glucose output, training leads to decreased basal glucose production and increased suppression of liver glucose 
output by insulin. These effects contribute to improved glycaemic control. With obesity or other disturbances of lipid metabolism, physical training induces changes in blood lipid profiles, lipid metabolism and body composition, that are known to positively correlate with insulin sensitivity.

Thus, although various underlying mechanisms remain to be elucidated, physical training can be considered an important, if not essential part of the treatment and prevention of insulin insensitivity. 
References

1. Allenberg, K., K. Johansen, and B. Saltin. Skeletal muscle adaptations to physical training in type 2 (non-insulin-dependent) diabetes mellitus. Acta Med Scand 223: 36573, 1988.

2. Andersen, P., and J. Henriksson. Capillary supply of the quadriceps femoris muscle of man: adaptive response to exercise. J-PhysiolLond 270: 677-90, 1977.

3. Bangsbo, J., P. D. Gollnick, T. E. Graham, C. Juel, B. Kiens, M. Mizuno, and B. Saltin. Anaerobic energy production and $\mathrm{O} 2$ deficit-debt relationship during exhaustive exercise in humans. J Physiol Lond 422: 539-59, 1990.

4. Bjorkman, O. Fuel metabolism during exercise in normal and diabetic man. Diabetes Metab Rev 1: 319-57, 1986.

5. Bjornholm, M., Y. Kawano, M. Lehtihet, and J. R. Zierath. Insulin receptor substrate-1 phosphorylation and phosphatidylinositol 3kinase activity in skeletal muscle from NIDDM subjects after in vivo insulin stimulation. Diabetes 46: 524-7, 1997.

6. Bjorntorp, P. Metabolic implications of body fat distribution. DiabetesCare 14: 1132-43, 1991.

7. Bjorntorp, P., M. Fahlen, G. Grimby, A. Gustafson, J. Holm, P. Renstrom, and T. Schersten. Carbohydrate and lipid metabolism in middle-aged, physically well-trained men. Metabolism 21: 1037-44, 1972.

8. Bjorntorp, P., and L. Sjostrom. Carbohydrate storage in man: speculations and some quantitative considerations. Metabolism 27: 1853-65, 1978.

9. Bloch, G., J. R. Chase, D. B. Meyer, M. J. Avison, G. I. Shulman, and R. G. Shulman. In vivo regulation of rat muscle glycogen resynthesis after intense exercise. Am J Physiol 266: E85-91, 1994.
10. Bogardus, C., E. Ravussin, D. C. Robbins, R. R. Wolfe, E. S. Horton, and E. A. Sims. Effects of physical training and diet therapy on carbohydrate metabolism in patients with glucose intolerance and noninsulin-dependent diabetes mellitus. Diabetes 33: 311-8, 1984.

11. Bogardus, C., P. Thuillez, E. Ravussin, B. Vasquez, M. Narimiga, and S. Azhar. Effect of muscle glycogen depletion on in vivo insulin action in man. $\mathrm{J}$-ClinInvest 72: 1605-10, 1983.

12. Bonen, A., M. H. Tan, P. Clune, and R. L. Kirby. Effects of exercise on insulin binding to human muscle. Am-J-Physiol 248: E403-8, 1985.

13. Bourey, R. E., A. R. Coggan, W. M. Kohrt, J. P. Kirwan, D. S. King, and J. O. Holloszy. Effect of exercise on glucose disposal: response to a maximal insulin stimulus. $J$ Appl-Physiol 69: 1689-94, 1990.

14. Braun, B., M. B. Zimmermann, and $\mathrm{N}$. Kretchmer. Effects of exercise intensity on insulin sensitivity in women with non-insulin-dependent diabetes mellitus. J Appl Physiol 78: 300-6, 1995.

15. Burstein, R., C. Polychronakos, C. J. Toews, J. D. MacDougall, $\mathbf{H}$. J. Guyda, and B. I. Posner. Acute reversal of the enhanced insulin action in trained athletes. Association with insulin receptor changes. Diabetes 34: 756-60, 1985.

16. Clauser, E., I. Leconte, and C. Auzan. Molecular basis of insulin resistance. Horm Res 38: 5-12, 1992.

17. Coderre, L., K. V. Kandror, G. Vallega, and P. F. Pilch. Identification and characterization of an exercise-sensitive pool of glucose transporters in skeletal muscle. J Biol Chem 270: 27584-8, 1995.

18. Coggan, A. R., S. C. Swanson, L. A. Mendenhall, D. L. Habash, and C. L. Kien. Effect of endurance training on hepatic glycogenolysis and gluconeogenesis during pro- 
longed exercise in men. Am-JPhysiol 268: E375-83, 1995.

19. Colberg, S. R., J. M. Hagberg, S. D. McCole, J. M. Zmuda, P. D. Thompson, and D. E. Kelley. Utilisation of glycogen but not plasma glucose is reduced in individuals with NIDDM during mild-intensity exercise. J-Appl-Physiol 81: 202733, 1996.

20. Colberg, S. R., J. A. Simoneau, F. L. Thaete, and D. E. Kelley. Skeletal muscle utilisation of free fatty acids in women with visceral obesity [see comments]. J-ClinInvest 95: 1846-53, 1995.

21. Consoli, A. Role of liver in pathophysiology of NIDDM. Diabetes Care 15: 430-41, 1992.

22. Davis, R. J. The mitogen-activated protein kinase signal transduction pathway. J-Biol-Chem 268: 145536, 1993 .

23. DeFronzo, R. A., E. Ferrannini, R. Hendler, J. Wahren, and P. Felig. Influence of hyperinsulinemia, hyperglycaemia, and the route of glucose administration on splanchnic glucose exchange. Proc Natl Acad Sci U S A 75: 5173-7, 1978.

24. Defronzo, R. A., E. Jacot, E. Jequier, E. Maeder, J. Wahren, and J. P. Felber. The effect of insulin on the disposal of intravenous glucose. Results from indirect calorimetry and hepatic and femoral venous catheterization. Diabetes 30 : 1000-7, 1981.

25. DeFronzo, R. A., R. S. Sherwin, and N. Kraemer. Effect of physical training on insulin action in obesity. Diabetes 36: 1379-85, 1987.

26. DeFronzo, R. A., J. D. Tobin, and R. Andres. Glucose clamp technique: a method for quantifying insulin secretion and resistance. AmJ-Physiol 237: E214-23, 1979.

27. Dela, F., J. J. Larsen, K. J. Mikines, T. Ploug, L. N. Petersen, and $\mathbf{H}$. Galbo. Insulin-stimulated muscle glucose clearance in patients with NIDDM. Effects of onelegged physical training. Diabetes 44: 1010-20, 1995.
28. Dela, F., K. J. Mikines, M. von Linstow, N. H. Secher, and H. Galbo. Effect of training on insulinmediated glucose uptake in human muscle. Am-J-Physiol 263: E113443, 1992.

29. Dela, F., T. Ploug, A. Handberg, L. N. Petersen, J. J. Larsen, K. J. Mikines, and H. Galbo. Physical training increases muscle GLUT4 protein and mRNA in patients with NIDDM. Diabetes 43: 862-5, 1994.

30. Despres, J. P. Visceral obesity, insulin resistance, and dyslipidemia: contribution of endurance exercise training to the treatment of the plurimetabolic syndrome. Exerc Sport Sci Rev 25: 271-300, 1997.

31. Despres, J. P., M. C. Pouliot, S. Moorjani, A. Nadeau, A. Tremblay, P. J. Lupien, G. Theriault, and C. Bouchard. Loss of abdominal fat and metabolic response to exercise training in obese women. Am J Physiol 261: E159-67, 1991.

32. Devlin, J. T., M. Hirshman, E. D. Horton, and E. S. Horton. Enhanced peripheral and splanchnic insulin sensitivity in NIDDM men after single bout of exercise. Diabetes 36: 434-9, 1987.

33. Devlin, J. T., and E. S. Horton. Effects of prior high-intensity exercise on glucose metabolism in normal and insulin-resistant men. Diabetes 34: 973-9, 1985.

34. Eriksson, K. F., and F. Lindgarde. Prevention of type 2 (non-insulindependent) diabetes mellitus by diet and physical exercise. The 6-year Malmo feasibility study. Diabetologia 34: 891-8, 1991.

35. Eriksson, K. F., B. Saltin, and F. Lindgarde. Increased skeletal muscle capillary density precedes diabetes development in men with impaired glucose tolerance. A 15-year follow-up. Diabetes 43: 805-8, 1994.

36. Etgen, G. J., Jr., J. Jensen, C. M. Wilson, D. G. Hunt, S. W. Cushman, and J. L. Ivy. Exercise training reverses insulin resistance in muscle by enhanced recruitment of 
GLUT-4 to the cell surface. Am-JPhysiol 272: E864-9, 1997.

37. Felig, P., A. Cherif, A. Minagawa, and J. Wahren. Hypoglycemia during prolonged exercise in normal men. N Engl J Med 306: 895-900, 1982.

38. Ferrannini, E., J. Wahren, P. Felig, and R. A. DeFronzo. The role of fractional glucose extraction in the regulation of splanchnic glucose metabolism in normal and diabetic man. Metabolism 29: 28-35, 1980.

39. Goodyear, L. J., P. Y. Chang, D. J. Sherwood, S. D. Dufresne, and D. E. Moller. Effects of exercise and insulin on mitogen-activated protein kinase signaling pathways in rat skeletal muscle. Am-J-Physiol 271: E403-8, 1996.

40. Goodyear, L. J., F. Giorgino, L. A. Sherman, J. Carey, R. J. Smith, and G. L. Dohm. Insulin receptor phosphorylation, insulin receptor substrate-1 phosphorylation, and phosphatidylinositol 3-kinase activity are decreased in intact skeletal muscle strips from obese subjects. J-Clin-Invest 95: 2195-204, 1995.

41. Goodyear, L. J., M. F. Hirshman, P. A. King, E. D. Horton, C. M. Thompson, and E. S. Horton. Skeletal muscle plasma membrane glucose transport and glucose transporters after exercise. J-ApplPhysiol 68: 193-8, 1990.

42. Goodyear, L. J., M. F. Hirshman, R. J. Smith, and E. S. Horton. Glucose transporter number, activity, and isoform content in plasma membranes of red and white skeletal muscle. Am-J-Physiol 261: E55661, 1991.

43. Goodyear, L. J., P. A. King, M. F. Hirshman, C. M. Thompson, E. D. Horton, and E. S. Horton. Contractile activity increases plasma membrane glucose transporters in absence of insulin. Am-J-Physiol 258: E667-72, 1990.

44. Groop, L. C., R. C. Bonadonna, S. DelPrato, K. Ratheiser, K. Zyck, E. Ferrannini, and R. A. DeFronzo. Glucose and free fatty acid metabo- lism in non-insulin-dependent diabetes mellitus. Evidence for multiple sites of insulin resistance. $\mathrm{J}$-ClinInvest 84: 205-13, 1989.

45. Gulve, E. A., J. M. Ren, B. A. Marshall, J. Gao, P. A. Hansen, J. O. Holloszy, and M. Mueckler. Glucose transport activity in skeletal muscles from transgenic mice overexpressing GLUT1. Increased basal transport is associated with a defective response to diverse stimuli that activate GLUT4. J Biol Chem 269: 18366-70, 1994.

46. Gulve, E. A., and R. J. Spina. Effect of 7-10 days of cycle ergometer exercise on skeletal muscle GLUT-4 protein content. J Appl Physiol 79: 1562-6, 1995.

47. Hansen, P. A., L. A. Nolte, M. M. Chen, and J. O. Holloszy. Increased GLUT-4 translocation mediates enhanced insulin sensitivity of muscle glucose transport after exercise. Journal of Applied Physiology 85: 1218-1222, 1998.

48. Hardin, D. S., B. Azzarelli, J. Edwards, J. Wigglesworth, L. Maianu, G. Brechtel, A. Johnson, A. Baron, and W. T. Garvey. Mechanisms of enhanced insulin sensitivity in endurance-trained athletes: effects on blood flow and differential expression of GLUT 4 in skeletal muscles. J Clin Endocrinol Metab 80: 2437-46, 1995.

49. Hargreaves, M., B. Kiens, and E. A. Richter. Effect of increased plasma free fatty acid concentrations on muscle metabolism in exercising men. J-Appl-Physiol 70: 194201, 1991.

50. Heath, G. W., J. R. d. Gavin, J. M. Hinderliter, J. M. Hagberg, S. A. Bloomfield, and J. O. Holloszy. Effects of exercise and lack of exercise on glucose tolerance and insulin sensitivity. J Appl Physiol 55: 512-7, 1983.

51. Helmrich, S. P., D. R. Ragland, R. W. Leung, and R. S. Paffenbarger, Jr. Physical activity and reduced occurrence of non-insulindependent diabetes mellitus [see 
comments]. N-Engl-J-Med 325: 147 52, 1991.

52. Henriksen, E. J., R. E. Bourey, K. J. Rodnick, L. Koranyi, M. A. Permutt, and J. O. Holloszy. Glucose transporter protein content and glucose transport capacity in rat skeletal muscles. Am J Physiol 259: E593-8, 1990.

53. Holloszy, J. O., and E. F. Coyle. Adaptations of skeletal muscle to endurance exercise and their metabolic consequences. J-App/-Physiol 56: 831-8, 1984.

54. Holloszy, J. O., J. Schultz, J. Kusnierkiewicz, J. M. Hagberg, and A. A. Ehsani. Effects of exercise on glucose tolerance and insulin resistance. Brief review and some preliminary results. Acta Med Scand Supp/ 711: 55-65, 1986.

55. Houmard, J. A., M. S. Hickey, G. L. Tyndall, K. E. Gavigan, and G. L. Dohm. Seven days of exercise increase GLUT-4 protein content in human skeletal muscle. J Appl Physiol 79: 1936-8, 1995.

56. Houmard, J. A., M. H. Shinebarger, P. L. Dolan, N. Leggett Frazier, R. K. Bruner, M. R. McCammon, R. G. Israel, and G. L. Dohm. Exercise training increases GLUT-4 protein concentration in previously sedentary middle-aged men. Am J Physiol 264: E896-901, 1993.

57. Hughes, V. A., M. A. Fiatarone, R. A. Fielding, B. B. Kahn, C. M. Ferrara, P. Shepherd, E. C. Fisher, R. R. Wolfe, D. Elahi, and W. J. Evans. Exercise increases muscle GLUT-4 levels and insulin action in subjects with impaired glucose tolerance. Am J Physiol 264: E855-62, 1993.

58. Ivy, J. L., and C. H. Kuo. Regulation of GLUT4 protein and glycogen synthase during muscle glycogen synthesis after exercise. Acta Physiol Scand 162: 295-304, 1998.

59. James, D. E., E. W. Kraegen, and D. J. Chisholm. Effects of exercise training on in vivo insulin action in individual tissues of the rat. J-ClinInvest 76: 657-66, 1985.
60. Kahn, C. R. Banting Lecture. Insulin action, diabetogenes, and the cause of type 2 diabetes. Diabetes 43: 1066-84, 1994.

61. Kahn, S. E., V. G. Larson, J. C. Beard, K. C. Cain, G. W. Fellingham, R. S. Schwartz, R. C. Veith, J. R. Stratton, M. D. Cerqueira, and I. B. Abrass. Effect of exercise on insulin action, glucose tolerance, and insulin secretion in aging. $A m-\mathrm{J}$ Physiol 258: E937-43, 1990.

62. Kang, J., R. J. Robertson, J. M. Hagberg, D. E. Kelley, F. L. Goss, S. G. DaSilva, R. R. Suminski, and A. C. Utter. Effect of exercise intensity on glucose and insulin metabolism in obese individuals and obese NIDDM patients. Diabetes-Care 19: 341-9, 1996.

63. Kelley, D. E., and L. J. Mandarino. Hyperglycaemia normalizes insulinstimulated skeletal muscle glucose oxidation and storage in noninsulindependent diabetes mellitus. J-ClinInvest 86: 1999-2007, 1990.

64. Kelley, D. E., M. A. Mintun, S. C. Watkins, J. A. Simoneau, F. Jadali, A. Fredrickson, J. Beattie, and R. Theriault. The effect of noninsulin-dependent diabetes mellitus and obesity on glucose transport and phosphorylation in skeletal muscle. J Clin Invest 97: 2705-13, 1996.

65. Kelley, D. E., and J. A. Simoneau. Impaired free fatty acid utilisation by skeletal muscle in non-insulindependent diabetes mellitus. J-ClinInvest 94: 2349-56, 1994.

66. Kim, Y., T. Inoue, R. Nakajima, K. Nakae, T. Tamura, K. Tokuyama, and M. Suzuki. Effects of endurance training on gene expression of insulin signal transduction pathway. Biochem-Biophys-Res-Commun 210: 766-73, 1995.

67. King, D. S., G. P. Dalsky, M. A. Staten, W. E. Clutter, D. R. Van Houten, and J. O. Holloszy. Insulin action and secretion in endurancetrained and untrained humans. $J$ Appl-Physiol 63: 2247-52, 1987. 
68. King, P. A., J. J. Betts, E. D. Horton, and E. S. Horton. Exercise, unlike insulin, promotes glucose transporter translocation in obese Zucker rat muscle. Am J Physiol 265: R447-52, 1993.

69. King, P. A., E. D. Horton, M. F. Hirshman, and E. S. Horton. Insulin resistance in obese Zucker rat ( $\mathrm{fa} / \mathrm{fa}$ ) skeletal muscle is associated with a failure of glucose transporter translocation. J Clin Invest 90: 1568-75, 1992.

70. Kjaer, M. Hepatic glucose production during exercise. In: Skeletal muscle metabolism in exercise and diabetes, edited by E. A. e. a. Richter. New York: Plenum Press, 1998, p. 117-127.

71. Kochan, R. G., D. R. Lamb, S. A. Lutz, C. V. Perrill, E. M. Reimann, and K. K. Schlender. Glycogen synthase activation in human skeletal muscle: effects of diet and exercise. Am-J-Physiol 236: E6606. 1979.

72. Kohrt, W. M., J. P. Kirwan, M. A. Staten, R. E. Bourey, D. S. King, and J. O. Holloszy. Insulin resistance in aging is related to abdominal obesity. Diabetes 42: 273-81, 1993.

73. Kristiansen, S., M. Hargreaves, and E. A. Richter. Exerciseinduced increase in glucose transport, GLUT-4, and VAMP-2 in plasma membrane from human muscle. Am-J-Physiol 270: E197201, 1996.

74. Krotkiewski, M., and P. Bjorntorp. Muscle tissue in obesity with different distribution of adipose tissue. Effects of physical training. Int $J$ Obes 10: 331-41, 1986.

75. Krotkiewski, M., P. Lonnroth, K. Mandroukas, Z. Wroblewski, M. Rebuffe Scrive, G. Holm, U. Smith, and P. Bjorntorp. The effects of physical training on insulin secretion and effectiveness and on glucose metabolism in obesity and type 2 (non-insulin-dependent) diabetes mellitus. Diabetologia 28 : 881-90, 1985.
76. Lavoie, J. M., J. Bongbele, S. Cardin, M. Belisle, J. Terrettaz, and G. Van de Werve. Increased insulin suppression of plasma free fatty acid concentration in exercisetrained rats. J Appl Physiol 74: 293 6, 1993.

77. Lemon, P. W., and F. J. Nagle. Effects of exercise on protein and amino acid metabolism. Med Sci Sports Exerc 13: 141-9, 1981.

78. Lí, W. M., and J. H. McNeill. Quantitative methods for measuring the insulin-regulatable glucose transporter (Glut4). J-PharmacolToxicol-Methods 38: 1-10, 1997.

79. Lohmann, D., F. Liebold, W. Heilmann, H. Senger, and A. Pohl. Diminished insulin response in highly trained athletes. Metabolism 27: 521-4, 1978.

80. Lund, S., H. Vestergaard, P. H. Andersen, O. Schmitz, L. B. Gotzsche, and $O$. Pedersen. GLUT-4 content in plasma membrane of muscle from patients with non-insulin-dependent diabetes mellitus. Am-J-Physiol 265: E88997, 1993.

81. Maehlum, S., P. Felig, and J. Wahren. Splanchnic glucose and muscle glycogen metabolism after glucose feeding during postexercise recovery. Am-J-Physiol 235: E25560, 1978.

82. Manson, J. E., E. B. Rimm, M. J. Stampfer, G. A. Colditz, W. C. Willett, A. S. Krolewski, B. Rosner, C. H. Hennekens, and F. E. Speizer. Physical activity and incidence of non-insulin-dependent diabetes mellitus in women. Lancet 338: 774-8, 1991.

83. Marin, P., B. Andersson, M. Krotkiewski, and P. Bjorntorp. Muscle fiber composition and capillary density in women and men with NIDDM. Diabetes Care 17: 382-6, 1994.

84. Marin, P., M. Rebuffe Scrive, U. Smith, and P. Bjorntorp. Glucose uptake in human adipose tissue. Metabolism 36: 1154-60, 1987. 
85. Marshall, S., W. T. Garvey, and R. R. Traxinger. New insights into the metabolic regulation of insulin action and insulin resistance: role of glucose and amino acids. Faseb $J 5$ : 3031-6, 1991.

86. Martin, I. K., A. Katz, and J. Wahren. Splanchnic and muscle metabolism during exercise in NIDDM patients. Am-J-Physiol 269: E583-90, 1995.

87. Mauriege, P., D. Prud'Homme, M. Marcotte, M. Yoshioka, A. Tremblay, and J. P. Despres. Regional differences in adipose tissue metabolism between sedentary and endurance-trained women. $A m$ J Physiol 273: E497-506, 1997.

88. McCoy, M., J. Proietto, and M. Hargreaves. Effect of detraining on GLUT-4 protein in human skeletal muscle. J Appl Physiol 77: 1532-6, 1994.

89. Mikines, K. J., B. Sonne, P. A. Farrell, B. Tronier, and H. Galbo. Effect of physical exercise on sensitivity and responsiveness to insulin in humans. Am-J-Physiol 254: E248-59, 1988.

90. Mikines, K. J., B. Sonne, P. A. Farrell, B. Tronier, and H. Galbo. Effect of training on the doseresponse relationship for insulin action in men. J Appl Physiol 66: 695703, 1989.

91. Mikines, K. J., B. Sonne, B. Tronier, and $\mathbf{H}$. Galbo. Effects of training and detraining on doseresponse relationship between glucose and insulin secretion. Am-JPhysiol 256: E588-96, 1989.

92. Miller, J. P., R. E. Pratley, A. P. Goldberg, P. Gordon, M. Rubin, M. S. Treuth, A. S. Ryan, and B. F. Hurley. Strength training increases insulin action in healthy 50 - to 65 -yrold men. J Appl Physiol 77: 1122-7, 1994.

93. Minuk, H. L., M. Vranic, E. B. Marliss, A. K. Hanna, A. M. Albisser, and B. Zinman. Glucoregulatory and metabolic response to exercise in obese noninsulin- dependent diabetes. Am J Physiol 240: E458-64, 1981.

94. Ploug, T., H. Galbo, J. Vinten, M. Jorgensen, and E. Richter. Kinetics of glucose transport in rat muscle: effects of insulin and contractions. Am-J-Physiol 253: E12-E20, 1987.

95. Price, T. B., G. Perseghin, A. Duleba, W. Chen, J. Chase, D. L. Rothman, R. G. Shulman, and G. I. Shulman. NMR studies of muscle glycogen synthesis in insulinresistant offspring of parents with non-insulin-dependent diabetes mellitus immediately after glycogendepleting exercise. Proc Natl Acad Sci U S A 93: 5329-34, 1996.

96. Ren, J. M., B. A. Marshall, E. A. Gulve, J. Gao, D. W. Johnson, J. O. Holloszy, and M. Mueckler. Evidence from transgenic mice that glucose transport is rate-limiting for glycogen deposition and glycolysis in skeletal muscle. J Biol Chem 268: 16113-5, 1993.

97. Ren, J. M., C. F. Semenkovich, E. A. Gulve, J. Gao, and J. O. Holloszy. Exercise induces rapid increases in GLUT4 expression, glucose transport capacity, and insulinstimulated glycogen storage in muscle. J Biol Chem 269: 14396401, 1994.

98. Revers, R. R., R. Fink, J. Griffin, J. M. Olefsky, and O. G. Kolterman. Influence of hyperglycaemia on insulin's in vivo effects in type 2 diabetes. J Clin Invest 73: 664-72, 1984.

99. Richter, E. A., K. J. Mikines, H. Galbo, and B. Kiens. Effect of exercise on insulin action in human skeletal muscle. J Appl Physiol 66: 876-85, 1989.

100. Richter, E. A., T. Ploug, and H. Galbo. Increased muscle glucose uptake after exercise. No need for insulin during exercise. Diabetes 34 : 1041-8, 1985.

101. Robinson, K. A., D. A. Sens, and M. G. Buse. Pre-exposure to glucosamine induces insulin resistance of glucose transport and glycogen 
synthesis in isolated rat skeletal muscles. Study of mechanisms in muscle and in rat-1 fibroblasts overexpressing the human insulin receptor [published erratum appears in Diabetes 1993 Oct;42(10):1547]. Diabetes 42: 1333-46, 1993.

102. Romijn, J. A., E. F. Coyle, L. S. Sidossis, A. Gastaldelli, J. F. Horowitz, E. Endert, and R. R. Wolfe. Regulation of endogenous fat and carbohydrate metabolism in relation to exercise intensity and duration. Am-J-Physiol 265: E380-91, 1993.

103. Roy, D., and A. Marette. Exercise induces the translocation of GLUT4 to transverse tubules from an intracellular pool in rat skeletal muscle. Biochem Biophys Res Commun 223: 147-52, 1996.

104. Ruderman, N. B., O. P. Ganda, and $K$. Johansen. The effect of physical training on glucose tolerance and plasma lipids in maturityonset diabetes. Diabetes 28 Suppl 1: 89-92, 1979.

105. Saloranta, C., V. Koivisto, E. Widen, K. Falholt, R. A. DeFronzo, M. Harkonen, and L. Groop. Contribution of muscle and liver to glucose-fatty acid cycle in humans. Am-J-Physiol 264: E599-605, 1993.

106. Saltin, B., F. Lindgarde, M. Houston, R. Horlin, E. Nygaard, and P. Gad. Physical training and glucose tolerance in middle-aged men with chemical diabetes. Diabetes 28 Suppl 1: 30-2, 1979.

107. Scheck, S. H., R. J. Barnard, L. O. Lawani, J. F. Youngren, D. A. Martin, and R. Singh. Effects of NIDDM on the glucose transport system in human skeletal muscle. Diabetes Res 16: 111-9, 1991.

108. Scheen, A. J., and P. J. Lefebvre. Assessment of insulin resistance in vivo: application to the study of type 2 diabetes. Horm Res 38: 19-27, 1992.

109. Schneider, S. H., L. F. Amorosa, A. K. Khachadurian, and N. B. Ruderman. Studies on the mechanism of improved glucose control during regular exercise in type 2 (non-insulin-dependent) diabetes. Diabetologia 26: 355-60, 1984.

110. Seals, D. R., J. M. Hagberg, W. K. Allen, B. F. Hurley, G. P. Dalsky, A. A. Ehsani, and J. O. Holloszy. Glucose tolerance in young and older athletes and sedentary men. $J$ Appl Physiol 56: 1521-5, 1984.

111. Seals, D. R., J. M. Hagberg, B. F. Hurley, A. A. Ehsani, and J. O. Holloszy. Effects of endurance training on glucose tolerance and plasma lipid levels in older men and women. Jama 252: 645-9, 1984.

112. Simoneau, J. A., and D. E. Kelley. Altered glycolytic and oxidative capacities of skeletal muscle contribute to insulin resistance in NIDDM. $J$ Appl Physiol 83: 166-71, 1997.

113. Soman, V. R., V. A. Koivisto, D. Deibert, P. Felig, and R. A. DeFronzo. Increased insulin sensitivity and insulin binding to monocytes after physical training. $N$ Engl $J$ Med 301: 1200-4, 1979.

114. Suda, K., T. Izawa, T. Komabayashi, M. Tsuboi, and S. Era. Effect of insulin on adipocyte lipolysis in exercise-trained rats. J Appl Physiol 74: 2935-9, 1993.

115. Sushruta, S. . Varanasi: Vidya Vilas Press, 1963, p. 361-87.

116. Taskinen, M. R., C. Bogardus, A. Kennedy, and B. V. Howard. Multiple disturbances of free fatty acid metabolism in noninsulin-dependent diabetes. Effect of oral hypoglycemic therapy. J-Clin-Invest 76: 63744, 1985.

117. Tonino, R. P. Effect of physical training on the insulin resistance of aging. Am J Physiol 256: E352-6, 1989.

118. Treadway, J. L., D. E. James, E. Burcel, and N. B. Ruderman. Effect of exercise on insulin receptor binding and kinase activity in skeletal muscle. Am J Physiol 256: E138-44, 1989.

119. Trovati, M., Q. Carta, F. Cavalot, S. Vitali, C. Banaudi, P. G. Lucchina, F. Fiocchi, G. Emanuelli, and G. Lenti. Influence of physical 
training on blood glucose control, glucose tolerance, insulin secretion, and insulin action in non-insulindependent diabetic patients. Diabetes Care 7: 416-20, 1984.

120. Van der Vusse, G. J., and R. S. Reneman. Lipid metabolism in muscle. In: Exercise: regulation and integration of multiple systems, edited by L. B. Rowell and J. T. Sheperd. Oxford: Oxford University Press, 1996, p. 953-994.

121. Vestergaard, H., P. H. Andersen, S. Lund, O. Schmitz, S. Junker, and $\mathbf{O}$. Pedersen. Pre- and posttranslational upregulation of musclespecific glycogen synthase in athletes. Am J Physiol 266: E92-101, 1994.

122. Vukovich, M. D., P. J. Arciero, W. M. Kohrt, S. B. Racette, P. A. Hansen, and J. O. Holloszy. Changes in insulin action and GLUT-4 with 6 days of inactivity in endurance runners. $J$ Appl Physiol 80: 240-4, 1996.

123. Wallberg Henriksson, H., S. H. Constable, D. A. Young, and J. $O$. Holloszy. Glucose transport into rat skeletal muscle: interaction between exercise and insulin. J-Appl-Physiol 65: 909-13, 1988.

124. Wojtaszewski, J. F., B. F. Hansen, B. Kiens, and E. A. Richter. Insulin signaling in human skeletal muscle: time course and effect of exercise. Diabetes 46: 1775-81, 1997.

125. Yamanouchi, K., T. Shinozaki, K. Chikada, T. Nishikawa, K. Ito, S. Shimizu, N. Ozawa, Y. Suzuki, H. Maeno, K. Kato, and et al. Daily walking combined with diet therapy is a useful means for obese NIDDM patients not only to reduce body weight but also to improve insulin sensitivity. Diabetes Care 18: 775-8, 1995.

126. Yki Jarvinen, H., M. C. Daniels, A. Virkamaki, S. Makimattila, R. A. DeFronzo, and D. McClain. Increased glutamine:fructose-6phosphate amidotransferase activity in skeletal muscle of patients with NIDDM. Diabetes 45: 302-7, 1996.
127. Young, D. A., H. Wallberg Henriksson, M. D. Sleeper, and J. O. Holloszy. Reversal of the exercise-induced increase in muscle permeability to glucose. $A m-J$ Physiol 253: E331-5, 1987.

128. Young, J. C., J. Enslin, and B. Kuca. Exercise intensity and glucose tolerance in trained and nontrained subjects. J-Appl-Physiol 67: 39-43, 1989.

129. Zhou, Q., and G. L. Dohm. Treadmill running increases phosphatidylinostol 3-kinase activity in rat skeletal muscle. Biochem Biophys Res Commun 236: 647-50, 1997. 


\section{Type 2 Diabetes and Exercise:}

\section{General Materials \& Methods}

\section{Chapter}

All experiments described in this thesis, save for those in Chapter 4 and 5, were performed in subjects, and according to procedures, described below. Subjects were recruited for this study in several ways. The majority of type 2 diabetes patients responded to an interview in a local newspaper. This resulted in over 150 telephone calls of potentially interested type 2 diabetes patients, of which about 60 visited a subsequent meeting in which the exact procedures were described. In addition, some patients were directed to us by the Department of Internal Medicine of the University Hospital Maastricht. Since the vast majority of all these volunteers were men, women were excluded from the study for the sake of homogeneity. A total of 51 men with type 2 diabetes were subsequently physically examined in collaboration with the before mentioned Department of Internal Medicine.

Inclusion criteria for the study were:

1) Male type 2 diabetes patients with moderately controlled metabolic regulation (Hba1c 7-9\%).

2) Age $35-60 \mathrm{yr}$.

3) Agreement to volunteer for the study by giving a written informed consent.

Exclusion criteria were:

1) Impaired renal function (creatinine $>140 \mu \mathrm{mol} / \mathrm{l}$, or creatinine clearance < $40 \mathrm{ml} / \mathrm{min}$.

2) Impaired liver function (ALAT, ASAT, gGT $>2 x$ standard value).

3) Usage of corticosteroids.

4) Cardiovascular disease (decompensatio cordis, angina pectoris, myocardial infarction).

5) Hypertension (SBP> $170 \mathrm{mmHg}, \mathrm{DBP}>100 \mathrm{mmHg}$ ).

6) Diabetic complications, such as proliferative retinopathy and proteinurea > $1.5 \mathrm{~g} /$ day.

7) Insulin therapy. 
After screening, 28 men eventually participated in the first test, the incremental bicycle ergometer test. In total, 15 of these patients completed the full two year training program. Drop out was caused by symptoms of cardiovascular pathology during the first exercise test $(n=2)$, rheumatic symptoms $(n=1)$ and various other causes all related to reported inability to continue the program because of lack of time. Chapters will report on subgroups of these patients of whom all concerning data was available.

A type 2 diabetic control group $(n=9)$ was recruited according to the same inand exclusion criteria at the Department of Internal Medicine of the University Hospital Leiden. These patients were to serve as a non-training control group. In addition, 8 age and body composition matched, healthy control subjects were recruited as a healthy, non-training control group. These groups underwent tests exactly similar to the type 2 diabetes group who were to follow the training program, at the start and end of the intervention period.

In the course of the project, approximately 18 months after the initial tests of the first type 2 diabetes group, an additional group of type 2 diabetes patients were included and tested $(n=12)$. Recruitment of this group was performed in collaboration with the Department of Internal Medicine of the St. Anna Hospital Geldrop, applying the before mentioned in- and exclusion criteria. This group was to follow a training program of one year, at the medical fitness centre of the St. Anna Hospital. They were again tested exactly similar to the other groups, and furthermore 8 of these subjects participated in the experiments described in Chapter 4. These stable isotope experiments were supposed to be repeated after one year of training, but of the 8 subjects that participated herein, only 2 had a substantially increased $\mathrm{VO}_{2} \max$ after training, and thus these experiments were not repeated.

\section{Medication at the onset of the study}

Of the 28 men starting the 2 year intervention study, 13 were taking oral sulfonylureas only, 6 were taking oral sulfonylureas in combination with biguanids, and 9 were not taking any blood glucose lowering medication.

In type 2 diabetes control group, 6 were taking oral sulfonylureas only, one was taking an oral sulfonylurea in combination with biguanids, and 2 were free of blood glucose lowering medication.

Of the group recruited in Geldrop, 5 were taking oral sulfonylureas only, 4 were taking oral sulfonylureas in combination with biguanids, one person was taking a combination of a sulfonylurea and an $\alpha$-glucosidase inhibitor, and two were not taking any blood glucose lowering medication.

\section{The incremental bicycle ergometer test}

At the start and every half year thereafter, a maximal bicycle test was performed in all subjects. They were asked to refrain from oral blood glucose lowering medication for 48 hours preceding the test. On the day of the test, subjects reported to the laboratory after an overnight fast when tested in the morning, or at least 6 hours of fasting when tested in the afternoon or evening. Repeated tests were always performed at the same time of day for each subject. Subjects were weighed and their body fat percentage and fat free mass (FFM) were estimated using a skinfold calliper. Skinfolds that were measured were located 
subscapular, suprailiac, and over the biceps and triceps of the upper arm. From the sum of skinfolds, the body fat percentage was calculated according to the method of Durnin and Womersley (4).

Patients were then placed in a supine position and a Teflon catheter was inserted into a brachial vein. Subsequently, preparations for taking a muscle biopsy from the $\mathrm{m}$. vastus lateralis were made. Approximately $15 \mathrm{~cm}$. from the patella, the skin and muscle fascia were anaesthetised using xylocaine (without adrenaline). Ten minutes hereafter, the first blood sample was drawn from the brachial catheter.

An incision of approximately $0.7-1 \mathrm{~cm}$ was made through skin and fascia, and a modified Bergström needle was used to take the biopsy. The modification to the needle consists of a rubber O-ring between the inner and outer bore of the needle, which considerably improves the effectiveness of suction applied to the inner bore. The technique of applying suction to increase muscle biopsy size has been described by Evans et al. (5).

Usually, repeated samples were taken to ensure an adequate sample size. Further procedures of biopsy sample treatment will be described subsequently.

The incision was closed using reinforced skin closures (Steri-Strip, 3M, St. Paul, Min., U.S.A.), covered with a sterilised gauze swab and an elastic, self-adhesive bandage (Acrylastic, Beiersdorf A.G., Hamburg, Germany).

Electrodes for a 12-lead ECG were applied, and the subject was placed on an electromagnetically braked bicycle ergometer (Lode, Groningen, The Netherlands). Open-circuit breath-by-breath spirometry commenced (Oxycon $\beta$, Mijnhardt-Jaeger, Mannheim, Germany) and the second blood sample was taken. After one minute, subjects started pedalling at a self-determined rate, but above $60 \mathrm{rpm}$, at a workload of $0.75 \mathrm{~W} \cdot \mathrm{kg} \mathrm{FFM}^{-1}$ for $3 \mathrm{~min}$. This marked the start of the incremental bicycle ergometer test. Blood was drawn in the last 30 seconds of this step, every 6 min hereafter and at exhaustion. After $3 \mathrm{~min}$, the workload was adjusted to $1.5 \mathrm{~W} \cdot \mathrm{kg} \mathrm{FFM}^{-1}$ and increased every 3 minutes by 0.5 $\mathrm{W} \cdot \mathrm{kg} \mathrm{FFM}^{-1}$ until subjects were no longer able to maintain a pedalling frequency above $60 \mathrm{rpm}$. Workload was then decreased to approx. $1 \mathrm{~W} / \mathrm{kg}$ body weight and subjects were encouraged to keep cycling for about one minute. In our experience, this decreases the risk of adverse vaso-vagal reactions after maximal exercise. Immediately after subjects stopped cycling, they were asked to lie down for the post-exercise muscle biopsy. This biopsy was taken from the same incision and according to the same procedures as the pre-exercise biopsy. To avoid effects of local tissue damage due to the first biopsy, the biopsy needle was inserted at a vertical angle (distally before exercise, proximally after exercise). Routinely, no anaesthesia was administered before taking the postexercise biopsy, but we estimate that with $\approx 5 \%$ of the biopsies subjects indicated sensitivity upon testing, and some additional xylocaine was given. After taking this biopsy, the incision was again appropriately covered and bandaged, and subjects could take a shower.

\section{Blood sampling and analysis}

With the two resting blood samples, $20 \mathrm{ml}$ of blood was drawn into glass tubes: $8 \mathrm{ml}$ for growth hormone binding protein (GHBP, data not available) determination in serum, $4 \mathrm{ml}$ for measurement of adrenaline and noradrenaline, to which were added heparin and glutathione (5.6 mg dissolved in $125 \mu \mathrm{l}$ of saline), $4 \mathrm{ml}$ 
for glucagon measurement, added were heparin and 2000 kallikrein inhibitor units in saline, and $4 \mathrm{ml}$ for determination of insulin, c-peptide, glucose and lactate, in a heparinised tube. With the first sample, an additional $1.5 \mathrm{ml}$ of blood was taken for $\mathrm{HbA1c}$ measurement in whole blood.

$12 \mathrm{ml}$ of blood was taken with the first and last exercise sample for determination of adrenaline, noradrenaline, glucagon, c-peptide, insulin, glucose and lactate. The same substances were measured in the remaining exercise samples, with the exception of the catecholamines. The catheter was kept patent by flushing with heparinised saline after sampling.

All tubes, except those for GHBP, were placed on ice before the test and promptly centrifuged after blood collection. Plasma was immediately placed at $70{ }^{\circ} \mathrm{C}$ (catecholamines) or at $-20^{\circ} \mathrm{C}$ (rest) until analysis. Blood plasma was analysed for glucose using the hexokinase method, and for lactate (6) on a COBAS FARA analyser (Roche, Basel, Switzerland). Glucagon and C-peptide were measured with radioimmunoassay (DPC, Los Angeles, USA and BykSangtec Diagnostica, Dietzenbach, Germany) and insulin with fluoroimmunoassay (EG\&G, Breda, The Netherlands). Catecholamines and $\mathrm{HbA1c}$ were measured with high-pressure liquid chromatography (Recipe, Munich, Germany and Bio-Rad Diamat, Munich, Germany).

\section{The hyperinsulinaemic euglycaemic clamp}

In a subgroup of 14 men of the type 2 diabetes patients recruited in Maastricht, in all men recruited in Geldrop, and in the control groups, a hyperinsulinaemic euglycaemic clamp was performed at the start of the project, and repeated after one and, where appropriate, two years.

The subjects reported to the laboratory at $9.00 \mathrm{~h}$ in the morning after an overnight fast. A Teflon catheter was introduced into an antecubital vein for infusions of both insulin and glucose. A retrogadely indwelling catheter was inserted into a dorsal hand vein of the contralateral arm. Subsequently the arm was kept in a heated air box (own fabricate), which was held at a constant temperature of $60^{\circ} \mathrm{C}$ to provide arterialised blood samples. After 30 minutes of warming up, two basal blood samples were drawn. Thereupon, the insulin infusion was started. Insulin (Actrapid, Novo Nordisk) was infused (Beckton-Dickinson Pilot C) at a rate of $8 \mathrm{mU} / \mathrm{kg} \mathrm{bwt} / \mathrm{min}$. The infusate was prepared diluting $50 \mathrm{U}(0.5 \mathrm{ml}$ Actrapid) of insulin per $47.5 \mathrm{ml}$ isotonic saline. To prevent insulin absorption to plastic tubing, $2 \mathrm{ml}$ of sterilised human albumin was added to the infusate. Blood for determination of blood glucose was drawn every 5 minutes and analysed immediately (Analox GM7, Meyvis, the Netherlands). During the clamp, catheters were flushed every 15 minutes with heparinised saline.

When blood glucose had reached $\approx 6 \mathrm{mmol}$, glucose infusion was started and adjusted when appropriate to achieve a euglycaemic steady state around 90 minutes after the start of the clamp. Glucose $(20 \%$ dextrose solution containing $5 \mathrm{mmol} \mathrm{KCl}$ per $500 \mathrm{ml}$ ) was infused using an IVAC 560 infusion pump. Euglycaemia was assumed when blood glucose was between 4.7 and $5.3 \mathrm{mmol} / \mathrm{l}$.

When euglycaemia was achieved, glucose infusion was maintained at the same rate until 6 consecutive euglycaemic values $(30 \mathrm{~min})$ had been measured. Hereafter, the insulin infusion was discontinued, but glucose infusion was continued lowering the infusion rate gradually for approximately 45 minutes, to prevent hypoglycaemia. 
As soon as the insulin infusion was discontinued, preparations for a muscle biopsy from the $\mathrm{m}$. vastus lateralis were made, as described before. After the biopsy, subjects were given breakfast. In repeated experiments, the time span of the clamp was kept as similar as possible, since glucose uptake during the hyperinsulinaemic clamp is known to increase in time (3).

\section{Muscle biopsy treatment}

Biopsies were divided into samples for immunoelectronmicroscopy (IEM), biochemistry and histology. IEM results will not be reported in this thesis. For biochemistry, the muscle samples were put in a screw-cap tubes and frozen in liquid nitrogen.

Muscle for histology was mounted on a thin piece of cork with a drop of embedding compound (Tissue-Tek, Miles Laboratories) and frozen in isopenthane cooled to its melting point with liquid nitrogen. These samples were subsequently put in an aluminium cryo-vial. Biochemistry and histology muscle pieces were stored at $-70^{\circ} \mathrm{C}$.

\section{Methods for muscle fibre typing}

Fibre typing was performed using the ATP-ase staining method. Muscle slides $(\approx 4 \mu \mathrm{m}$ ) were cryosectioned and thaw mounted on glass slides and air dried. Sections were immersed in acetate buffer at either $\mathrm{pH} 4.3, \mathrm{pH} 4.45$, or $\mathrm{pH} 4.6$ at room temperature for $45 \mathrm{sec}$, washed in 3 rinses of TRIS-buffer at $\mathrm{pH} 7.8$, and 3 rinses of distilled water. Sections were then incubated for 25 minutes in fresh ATP-glycine buffer of $\mathrm{pH} 9.4$, quenched 3 times in calciumchloride $1 \%$, washed in 3 rinses of distilled water, incubated $3 \mathrm{~min}$ in cobaltchloride $1 \%$, washed in 3 rinses of distilled water, incubated $1 \mathrm{~min}$ in ammoniumsulphide, washed in 3 rinses of distilled water. Slides were then dehydrated in an ethanol series of 50 $100 \%$ and two times xylol $100 \%$, and embedded in entallan.

Sections were photographed microscopically and the photographs were examined making a distinction between type $1,2 \mathrm{~A}$ and $2 \mathrm{~B}$ fibres.

\section{Methods for muscle enzyme capacity}

Muscle was analysed for protein content, citrate synthase (CS), glycogen synthase (GS), glycogen phosphorylase (GP), 3-hydroxyacyl-CoA dehydrogenase (HAD) and cytosolic fatty acid-binding protein (FABPC). Methods were as follows:

Citrate Synthase Muscle tissue was homogenised to a $5 \%$ solution in SET(sucrose, EDTA, Tris) buffer. This was centrifuged and the supernatant was diluted 3 times with SET-buffer. Measurement of CS activity is based on adding acetyl-CoA and oxaloacetate (at $\mathrm{pH} 8.0)$ to the sample, in the presence of 5,5'dithiobis(2-nitrobenzoic acid) (DTNB). CS converts acetyl-CoA and oxaloacetate to citrate and CoA-SH, and the latter binds with DTNB to form CoA-DTNB. The photospectrometric extinction of this complex was measured at $412 \mathrm{~nm}$ on a COBAS Fara analyser.

3-hydroxyacyl-CoA dehydrogenase Muscle tissue was homogenised to a $5 \%$ solution in SET- (sucrose, EDTA, Tris) buffer. This was centrifuged and the supernatant was diluted 3 times with SET-buffer. HAD activity was measured in tetra-sodiumpyrophosphate buffer at $\mathrm{pH}$ 7.3. Acetoacyl-CoA and NADH were added, which are converted by $H A D$ to 3 -hydroxybutyryl-CoA and NAD. The 
photospectrometric extinction of $\mathrm{NADH}$ was measured at $340 \mathrm{~nm}$ on a COBAS Fara analyser.

Cytoplasmic fatty acid binding protein This was measured with enzyme-linked immuno-sorbent assay. PVC microtiter plates (Beckton Dickinson, Oxnard, Ca, USA) were coated with the monoclonal human anti-FABP IgG 67D3 (HyCult Biotechnology, Uden, The Netherlands) diluted $1: 1000$ in $0.1 \mathrm{M}$ carbonate buffer $\left(\mathrm{pH}\right.$ 9.6) for $2 \mathrm{~h}$ at $37{ }^{\circ} \mathrm{C}$. Between consecutive steps, plates were washed 4 times in PBT (PBS with $0.1 \%$ BSA and $0.05 \%$ Tween $20, \mathrm{pH} 7.4$ ). Homogenates, as described above under "muscle enzyme analysis" were centrifuged and the supernatant diluted 1:100 in PBT. $50 \mu \mathrm{l}$ sample was pipetted into each well and incubated $60 \mathrm{~min}$ at room temperature. Subsequently plates were incubated with the monoclonal peroxidised human anti-FABP IgG 66E2-HRP (HyCult Biotechnology), diluted 1:1000 in PBT, overnight at $4{ }^{\circ} \mathrm{C}$. Bound 66E2-HRP was visualised with ortho-phenylenediamine dihydrochloride (Biozym, Landgraaf, The Netherlands) and $\mathrm{H}_{2} \mathrm{O}_{2}$ in citrate buffer of $\mathrm{pH}$ 5.0. After 5 min of incubation, the reaction was stopped with $5 \% \mathrm{H}_{2} \mathrm{SO}_{4}$. Plates were read at $450 \mathrm{~nm}$ using a Titertek Multiskan 2 microtiterplate reader (Flow Laboratories, Lugano, Switserland). Subsequently, the concentration of FABP in all samples was calculated.

GLUT-4 SDS-Page and Immunoblotting Muscle tissue was homogenised in icecold HES-buffer (50 mM Hepes, 10 mM EDTA, 250 mM sucrose, pH 7.4) containing $1 \mathrm{mM}$ phenylmethylsulfonylfluoride (Merck, Darmstadt, Germany) and $400 \mathrm{U} / \mathrm{ml}$ Trasylol (Bayer AG, Leverkusen, Germany), and centrifuged $15 \mathrm{~min}$ at $3000 \mathrm{xg}$. The pellet was resuspended in buffer and ultracentrifuged at $150,000 \mathrm{xg}$ for $90 \mathrm{~min}$ at $4^{\circ} \mathrm{C}$. The membrane fraction was suspended in PBS and stored at $-80{ }^{\circ} \mathrm{C}$ until further processing. For gel electrophoresis $25 \mu \mathrm{l}$ of membrane fraction was boiled $4 \mathrm{~min}$ in an equal volume of SDS-sample buffer containing $2.3 \%$ of sodium dodecylsulfate (SDS; BDH Chemicals Ltd, Poole, UK) and $5 \%$ $\beta$-mercaptoethanol (Bio-Rad Laboratories, Hercules, $\mathrm{Ca}, \mathrm{USA}$ ) and subsequently centrifuged for $5 \mathrm{~min}$. Polyacrylamide slab gels containing $0.1 \%$ SDS were loaded with the samples on a Mini Protean-3 Electrophoresis Cell (BioRad Laboratories). After electrophoretic separation, the proteins were subjected to immunoblotting using a Mini Trans-Blot Electrophoretic Transfer Cell (BioRad Laboratories). The separated polypeptides were transferred to a nitrocellulose membrane (Bio-Rad Laboratories) by blotting for $60 \mathrm{~min}$ at $100 \mathrm{~V}$ in cold $\left(4^{\circ} \mathrm{C}\right)$ buffer containing $25 \mathrm{mM}$ Tris (Merck), $192 \mathrm{mM}$ glycine (Merck), and 20\% methanol (Merck). For detection of GLUT-4 we used the polyclonal rabbit antiserum GLUT4-BW, that was raised against a synthetic peptide corresponding to a 12 amino-acid c-terminal sequence of human GLUT-4. Nitrocellulose sheets were pre-incubated with blocking buffer for $60 \mathrm{~min}$, containing $5 \%$ nonfat dry milk and $0.05 \%$ Tween20 (Sigma, St. Louis, Mo, USA) in PBS. Incubation with anti GLUT-4, diluted 1:1000 in block buffer, was carried out overnight at room temperature. After three washing steps with $0.05 \%$ Tween 20 in PBS, blots were incubated for $60 \mathrm{~min}$ at room temperature with horseradish peroxidase-conjugated swine anti-rabbit Ig (SWARPO, DAKO, Glostrup, Denmark), diluted $1: 10,000$ in 5\% non-fat dry milk with $0.05 \%$ Tween 20 in PBS. Blots were subsequently washed $90 \mathrm{~min}$ in $0.05 \%$ Tween20/PBS, and $10 \mathrm{~min}$ in PBS, Chemiluminescence was performed using a Super Signal West Dura Extended kit (Pierce, Rockford, IL, USA). 
GLUT-4 immunofluorescence assay Frozen muscle tissue was cryosectioned at $-20^{\circ} \mathrm{C}$ (CM3050, Leica, Nussloch, Germany). Transverse sections of $4 \mu \mathrm{m}$ were thaw-mounted on uncoated glass slides and air-dried. Labelling started with 5 min fixation in methanol followed by 1 'aceton fixation, and air dried. After each step, sections were washed 3 times for 5 min with PBS. Sections were incubated for $30 \mathrm{~min}$ with GLUT4-BW (1:10 in 1\% BSA/PBS). In a number of sections, GLUT4-BW was omitted as a negative control. Sections were subsequently incubated for $30 \mathrm{~min}$ with fluorescein isothiocyanate-conjugated goatanti-rabbit Ig (GARFITC, SBA Inc., Birmingham, AL, USA), and mounted in Mowiol (Hoechst, Frankfurt, Germany) containing $0.5 \mu \mathrm{g} / \mathrm{ml}$ 4'-6'-diamino-2phenylindole (DAPI, Merck) for DNA staining. Sections were examined using a Leica DM fluorescence microscope, coupled to a CCD camera and image processing system (MetaSystem, Heidelberg, Germany).

\section{Training intervention}

Subjects included in the training intervention followed an endurance training program based on individual maximal heart rate as determined in the incremental bicycle ergometer test. The majority of training sessions were performed on bicycle ergometers, but some subjects occasionally used treadmills or rowing machines. In addition, some low impact resistance training was performed. In the calculation of training time, only data from the endurance-type exercise was used. All subjects were provided with a heart rate monitor (Sporttester, Polar) with storage capacity, and training heart rate data was periodically downloaded into a personal computer for evaluation. All training sessions were performed under supervision at our human performance laboratory and at selected fitness centres during the first year. The second year, subjects trained under supervision only periodically $(\approx$ once per month). Furthermore, during the whole intervention period, subjects were encouraged to participate in leisure time activity on individual basis at least once a week. Training diaries were handed out to all subjects, into which they were asked to record all training activities. Training duration and intensity were progressively increased over the first 6 months. The half-yearly incremental bicycle tests formed the basis for readjustment of the individual training programs. Table 3.1 gives an indication of the training actually performed in the course of the study. It contains data of the subjects who completed the 2 year training program.

In each column, data is presented for the respective 6 month-training periods, calculated from three training diaries per period per subject. For each person,

\begin{tabular}{|lcccc|}
\hline & 6 mo & 12 mo & 18 mo & 24 mo \\
Minutes per week & $71 \pm 32$ & $125 \pm 122$ & $116 \pm 93$ & $106 \pm 94$ \\
$\begin{array}{l}\text { Sessions per week } \\
85 \%<\text { HR }<95 \% \text { HRmax } \\
(\% \text { of training time })\end{array}$ & $1.9 \pm 0.4$ & $2.1 \pm 0.5$ & $1.9 \pm 0.5$ & $1.8 \pm 0.7$ \\
$\begin{array}{l}\text { HR }>95 \% \text { HRmax } \\
(\% \text { of training time })\end{array}$ & $2.6 \pm 3.8$ & $4.6 \pm 9$ & $4.9 \pm 7$ & $5.1 \pm 7$ \\
\hline
\end{tabular}

Table 3.1: Training data 


\section{Chapter 3}

heart rate data from 10 randomly selected training sessions were analysed per half year. We arbitrarily chose to calculate the percentage of time per training session spend above $85 \%$ and $95 \%$ of maximum heart rate (HRmax), to be able to give an indication of training intensity. $85 \%$ and $95 \%$ of HRmax correspond to approximately $76 \%$ Wmax and $94 \%$ Wmax, respectively (1). 


\section{References}

1. Arts, F. J., and H. Kuipers. The relation between power output, oxygen uptake and heart rate in male athletes. Int-J-Sports-Med 15: 22831, 1994.

2. DeFronzo, R. A., R. Gunnarsson, O. Bjorkman, M. Olsson, and J. Wahren. Effects of insulin on peripheral and splanchnic glucose metabolism in noninsulin-dependent (type 2) diabetes mellitus. J Clin Invest 76: 149-55, 1985.

3. Doberne, L., M. S. Greenfield, B. Schulz, and G. M. Reaven. Enhanced glucose utilization during prolonged glucose clamp studies. Diabetes 30: 829-35, 1981.

4. Durnin, J. V., and J. Womersley. Body fat assessed from total body density and its estimation from skinfold thickness: measurements on 481 men and women aged from 16 to 72 years. Br J Nutr 32: 77-97, 1974.

5. Evans, W. J., S. D. Phinney, and V. R. Young. Suction applied to a muscle biopsy maximizes sample size. Med Sci Sports Exerc 14: $101-$ 2, 1982.

6. Gutmann, I., and A. W. Wahlefeld. L-(+)-Lactate, determination with lactate dehydrogenase and NAD. In: Methods in enzymatic analysis (2nd ed. ed.), edited by H. U. Bergmeyer. New York: Academic Press, 1974, p. $1464-1468$.

7. Schneider, S. H., L. F. Amorosa, A. K. Khachadurian, and N. B. Ruderman. Studies on the mechanism of improved glucose control during regular exercise in type 2 (non-insulin-dependent) diabetes. Diabetologia 26: 355-60, 1984.

8. Trovati, M., Q. Carta, F. Cavalot, S. Vitali, C. Banaudi, P. G. Lucchina, F. Fiocchi, G. Emanuelli, and G. Lenti. Influence of physical training on blood glucose control, glucose tolerance, insulin secretion, and insulin action in non-insulindependent diabetic patients. Diabetes Care 7: 416-20, 1984.

9. Yamanouchi, K., T. Shinozaki, K. Chikada, T. Nishikawa, K. Ito, S. Shimizu, N. Ozawa, Y. Suzuki, H. Maeno, K. Kato, and et al. Daily walking combined with diet therapy is a useful means for obese NIDDM patients not only to reduce body weight but also to improve insulin sensitivity. Diabetes Care 18:775. 8,1995 . 


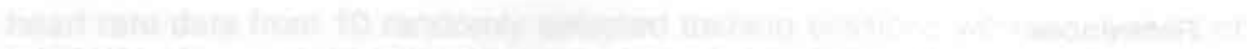

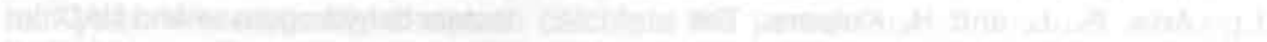

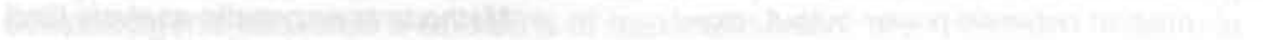

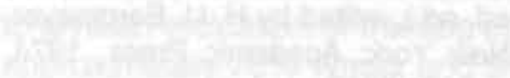

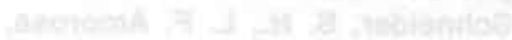

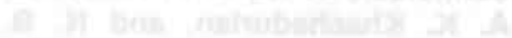

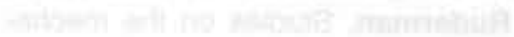

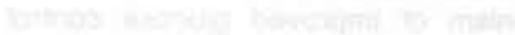

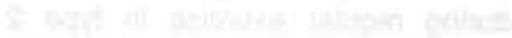

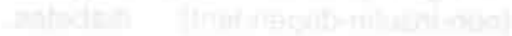

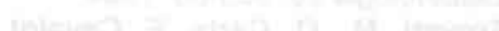

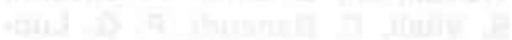

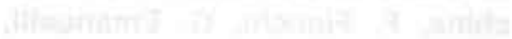

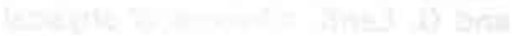




\title{
Substrate Utilisation in Type 2 Diabetes at Rest and during Exercise
}

\section{Chapter}

L.B. Borghouts, A.J.M. Wagenmakers, P.L.L. Goyens, H.A. Keizer

\begin{abstract}
Summary
Substrate utilisation was studied at rest and during moderate intensity exercise in well-controlled type 2 diabetes patients and healthy controls.

Stable isotope tracers of palmitate and glucose were infused for $2 \mathrm{~h}$ at rest and $1 \mathrm{~h}$ of bicycle exercise at $40 \% \mathrm{VO}_{2}$ max in volunteers with type 2 diabetes and a healthy control group. A separate test was performed in each subject to measure the acetate recovery factor, to account for label loss in the tricarboxylic acid cycle. At rest, substrate oxidation was similar between groups, but plasma glucose rate of disappearance was higher than rate of appearance in type 2 diabetes patients, and not in controls. During exercise, type 2 diabetes patients had similar rates of total fat and glucose oxidation, but muscle glycogen oxidation was lower than in controls, and plasma glucose contributed more to energy expenditure in type 2 diabetes. Plasma free fatty acid oxidation was not significantly different in type 2 diabetic patients from non-diabetic subjects.

We conclude that during moderate intensity exercise, type 2 diabetes patients have a decreased muscle glycogen oxidation and an increased plasma glucose oxidation. In the present study, type 2 diabetes patients did not exhibit significant aberrations in fat metabolism.
\end{abstract}


Type 2 diabetic patients are encouraged to be physically active, since physical activity is recognised as an effective treatment for type 2 diabetes (6). Patients are advised to participate in moderate intensity endurance exercise, preferably on a regular basis (6). However, substrate utilisation during this type of exercise has been reported to be abnormal in type 2 diabetic patients $(2,8,13)$. Unlike in non-diabetic persons, plasma glucose often declines during exercise in type 2 diabetes $(13,19)$. This has been attributed to either an impaired splanchnic glucose output $(14)$ or increased plasma glucose uptake $(2,13)$ by exercising muscle. Whole body substrate utilisation, calculated from respiratory exchange ratio's (RER), is usually found to be normal in type 2 diabetes during exercise $(2,9)$, but others (13) have observed increased rates of carbohydrate oxidation. In studies applying tracer methodology, the rate of plasma glucose uptake during exercise is generally assumed to be equal to the rate of plasma glucose oxidation $(2,7,14)$. However, this assumption can not be made for plasma free fatty acid (FFA) uptake and oxidation (23). Consequently, to quantify plasma FFA oxidation, carbon labelled fatty acid tracers should be infused, with concurrent measurement of carbon labelled $\mathrm{CO}_{2}$ production. Such measurements have not yet been reported for type 2 diabetes patients during exercise, and therefore it is unknown whether plasma FFA oxidation is disturbed under these conditions. Under resting conditions, it has been demonstrated that skeletal muscle of type 2 diabetes patients shows an impaired utilisation of plasma FFA, while whole body lipid oxidation is normal (11). Since skeletal muscle is responsible for the major part of plasma FFA oxidation during exercise, an impaired utilisation of FFA by skeletal muscle could result in decreased rates of FFA oxidation during exercise in type 2 diabetes. The main aim of the present study was therefore to study whether plasma FFA oxidation during moderate intensity exercise is decreased in type 2 diabetic patients. To investigate this, ${ }^{13} \mathrm{C}$ palmitate was infused. However, Sidossis et al. (22) have observed that a significant amount of infused ${ }^{13} \mathrm{C}$-label accumulates in the tricarboxylic acid (TCA) cycle, and that this can cause a significant underestimation of fatty acid oxidation (22). It has been shown in several studies (20-22) that this underestimation can be corrected for by measuring the recovery of ${ }^{13} \mathrm{CO}_{2}$ in breath during a ${ }^{13} \mathrm{C}$-acetate infusion (the acetate correction factor (ACF)). This is because acetate, in contrast to FFA, directly enters the TCA cycle $(21,22)$. The ACF should be determined individually for every subject, under conditions identical to those in which fatty acid oxidation was measured (20).

This study was designed to investigate substrate utilisation at rest and during moderate intensity exercise in type 2 diabetes patients and a healthy control group. During $2 \mathrm{~h}$ of postabsorptive rest and $1 \mathrm{~h}$ of cycling exercise at $40 \%$ $\mathrm{VO}_{2}$ max, stable isotopes of glucose and palmitate were infused simultaneously to determine the rates of appearance $(\mathrm{Ra})$ and disappearance (Rd) of these metabolites, and the rate of oxidation of plasma FFA. An acetate recovery test 
was applied on a separate occasion in every volunteer to account for ${ }^{13} \mathrm{C}$-label loss in the TCA-cycle, and RER measurements were made to quantify whole body substrate metabolism.

\section{Methods}

Subjects The protocol of the study was approved by the Medical Ethics Committee of Maastricht University. Eight male, moderately obese type 2 diabetes patients were recruited in collaboration with the department of Internal Medicine of the St. Anna Hospital Geldrop, the Netherlands. The subjects volunteered for the study after giving their written informed consent. Exclusion criteria were: impaired renal or liver function, usage of corticosteroids, history of cardiac disease, hypertension, diabetic complications and insulin therapy. All type 2 diabetic subjects were taking oral blood glucose lowering medication. Mean $( \pm$ standard deviation) glycosylated haemoglobin was $7.7 \pm 2.0$. The healthy control group $(n=8)$ was matched for weight and body composition, and underwent a standard medical examination. Control subjects with a family history of diabetes were excluded. All volunteers were sedentary. The type 2 diabetes group and control group will subsequently be referred to as D and C, respectively. Subject characteristics are presented in table 4.1.

Body composition Subjects were weighed and their body fat percentage and fat free mass (FFM) were determined using a skinfold calliper. Skinfolds measured were located subscapular, suprailiac, and over the biceps and triceps of the upper arm. From the sum of skinfolds, the body fat percentage was calculated according to the method of Durnin and Womersley (4).

$\mathrm{VO}_{2}$ max testing A maximal bicycle test was performed in all volunteers. Subjects cycled on an electromagnetically braked bicycle ergometer (Lode, Groningen, The Netherlands) at a self-determined rate, but above $60 \mathrm{rpm}$, at a workload of $0.75 \mathrm{~W} \cdot \mathrm{kg} \mathrm{FFM}^{-1}$ for $3 \mathrm{~min}$. After $3 \mathrm{~min}$, the workload was adjusted to 1.5 $\mathrm{W} \cdot \mathrm{kg} \mathrm{FFM}^{-1}$ and increased every $3 \mathrm{~min}$ by $0.5 \mathrm{~W} \cdot \mathrm{kg} \mathrm{FFM}^{-1}$ until subjects were no longer able to maintain a pedalling frequency above $60 \mathrm{rpm}$. Open-circuit spirometry was performed with an Oxycon $\beta$ (Mijnhardt Jaeger, Mannheim, Germany), $\mathrm{VO}_{2}$ and $\mathrm{VCO}_{2}$ were measured in the breath-by-breath mode and averaged over 15 seconds. $\mathrm{VO}_{2}$ max was achieved in all tests as judged from the levelling off of the oxygen uptake at the end of the test.

Experimental protocol Subjects were asked to consume a carbohydrate-rich diet

Table 4.1: Subject characteristics.

\begin{tabular}{|c|c|c|}
\hline & D & C \\
\hline Age (yr.) & $58 \pm 5$ & $47 \pm 5^{a}$ \\
\hline Body mass (kg) & $86.4 \pm 14.1$ & $86.3 \pm 9.5$ \\
\hline $\mathrm{BMI}\left(\mathrm{kg} \cdot \mathrm{m}^{-2}\right)$ & $28.7 \pm 4.2$ & $27.8 \pm 2.8$ \\
\hline Body fat (\%) & $26.5 \pm 8.4$ & $29.2 \pm 5.3$ \\
\hline LBM (kg) & $59.9 \pm 6.7$ & $60.7 \pm 3.9$ \\
\hline $\mathrm{VO}_{2} \max \left(\mathrm{ml} \cdot \mathrm{kg}^{-1} \cdot \mathrm{min}^{-1}\right)$ & $25.8 \pm 3.3$ & $36.2+2.0^{\mathrm{a}}$ \\
\hline \multicolumn{3}{|c|}{$\begin{array}{l}\text { Values are mean } \pm S D \text {. }{ }^{a} \text { denotes significant } \\
\text { difference from } D \text { with } p<0.05 \text {. }\end{array}$} \\
\hline
\end{tabular}


( $>200 \mathrm{~g} \mathrm{CHO} /$ day) and to refrain from physical exercise 3 days prior to the test day. They were asked to abstain from food high in naturally enriched carbon one week before and during the test period, to which goal they were provided with a list of such products. In addition, type 2 diabetes patients discontinued medication known to affect glucose uptake during this period.

On the test day, subjects reported to the laboratory at 8.30 A.M. after an overnight fasting period of 12 hours. Subjects were recumbent with one hand in a heated air box $\left(60^{\circ} \mathrm{C}\right)$. This hand was cannulated in a dorsal hand vein in order to obtain arterialised blood samples.

A second catheter was inserted in an antecubital vein of the contralateral arm for infusion of the tracers of glucose and palmitate. Basal blood samples $(20 \mathrm{ml})$ were drawn into EDTA containing tubes for determination of the concentrations of glucose, FFA, insulin and lactate, for measurement of plasma FFA profiles, and enrichment of glucose and palmitate. Blood was immediately centrifuged at $4^{\circ} \mathrm{C}$ for 8 minutes and subsequently plasma was frozen in liquid nitrogen and stored at $-80^{\circ} \mathrm{C}$ until analysis. Blood sampling was repeated at $90,105,120$, 160,170 and 180 minutes. Simultaneously, breath samples were taken from a mixing chamber into vacuum tubes for measurement of $\mathrm{CO}_{2}$ enrichment.

After basal sampling, a priming dose of sodiumbicarbonate $(0.085 \mathrm{mg} / \mathrm{kg}$ $\mathrm{NaH}^{13} \mathrm{CO}_{3}$ ) was administered, followed by a priming dose of $\left[6,6-{ }^{2} \mathrm{H}_{2}\right]$-glucose (equal to the accumulated dose of 1 hour of continuous infusion). This marked the start of two hours of rest, during which a continuous intravenous infusion of $\left[6,6-{ }^{2} \mathrm{H}_{2}\right]$-glucose $\left(0.300 \mu \mathrm{mol} \cdot \mathrm{kg}^{-1} \cdot \mathrm{min}^{-1}\right)$ and $\left[\mathrm{U}^{-13} \mathrm{C}\right]$-palmitate $\left(0.0064 \mu \mathrm{mol} \cdot \mathrm{kg}^{-}\right.$ ${ }^{1} \cdot \mathrm{min}^{-1}$ ) was given. Isotopes were obtained from Cambridge Isotope Laboratories, Andover, USA. Subjects were placed under a ventilated hood, with an air flow of $35 \mathrm{~L} / \mathrm{min}$, for indirect calorimetry. At $120 \mathrm{~min}$ the subjects were placed on a magnetically braked cycle ergometer and commenced cycling at a load calculated to correspond to $40 \% \mathrm{VO}_{2 \max }$. Isotope infusion was rates were increased to $0,460 \mu \mathrm{mol} \cdot \mathrm{kg}^{-1} \cdot \mathrm{min}^{-1}$ and $0.0127 \mu \mathrm{mol} \cdot \mathrm{kg}^{-1} \cdot \mathrm{min}^{-1}$ for glucose and palmitate, respectively. The true concentrations of palmitate, glucose and acetate in the infusate were determined for each experiment, so that the exact rate of infusion could be calculated. During the first $10 \mathrm{~min}$ of exercise, indirect calorimetry was performed and the load was adjusted such, that the desired value of $40 \% \mathrm{VO}_{2} \max$ was approximated. Five min prior to each blood and breath sampling indirect calorimetry was repeated. Exercise was discontinued after $60 \mathrm{~min}$.

Acetate recovery protocol One week before the experimental trial, a similar test was performed in each subject, in order to calculate the ACF. The acetate correction factor accounts for ${ }^{13} \mathrm{C}$-label lost in exchange reactions in the TCAcycle (20-22). In brief, the same protocol as during experimental test was followed, with the omission of blood sampling. In stead of the palmitate and glucose infusions, a sodiumbicarbonate primed $\left(0.085 \mathrm{mg} / \mathrm{kg} \mathrm{NaH}^{13} \mathrm{CO}_{3}\right)$ continuous infusion of $\left[1,2-{ }^{13} \mathrm{C}\right]$-acetate (Cambridge Isotope Laboratories) was given, in which the amount of ${ }^{13} \mathrm{C}$-label given equalled that of the palmitate infusion during the experimental test.

Sample analysis

Blood plasma was analysed for glucose using the hexokinase method (Roche, Basel, Switzerland), for lactate (5) and for FFA (Wako Chemicals, Neuss, 
Germany) on a COBAS FARA analyser. Insulin was measured with AutoDELFIA fluoroimmunoassay (1) (EG\&G, Breda, The Netherlands ; coefficient of variation $4.4 \%$ ). Breath samples ${ }^{13} \mathrm{C} /{ }^{12} \mathrm{C}$ ratio's were analysed using a gas chromatograph-isotope ratio mass spectrometer system (GC-IRMS; Finnigan MAT 252, Bremen, Germany). For determination of plasma palmitate, FFA were extracted from plasma, isolated by thin-layer chromatography, and derivatised to their methyl esters. Palmitate concentration was determined on a gas chromatograph with flame ionisation detection using heptadecanoic acid as an internal standard. Palmitate concentration was on average $31 \pm 4 \%$ of total FFA. Isotope tracer/tracee ratio (TTR) of palmitate was determined using GC combustion-IRMS (Finnigan MAT 252, Bremen, Germany) and corrected for the extra methyl group in the derivative. For determination of glucose enrichment in plasma, aliquots of EDTA plasma were extracted first with methanol:chloroform and then with chloroform:water. The clear water layer was dried and a butylboronic acid-acetyl-derivative was made. Subsequently, the enrichment of the glucose derivative was determined by electron ionisation/gas chromatographymass spectrometry (Finnigan INCOS XL, San Jose, CA, USA).

Calculations Breath and plasma enrichment is expressed as the tracer-tracee ratio (TTR) of the sample, corrected for background. TTR is defined as:

$$
\left({ }^{13} \mathrm{C} /{ }^{12} \mathrm{C}\right)_{\mathrm{sa}}-\left({ }^{13} \mathrm{C} /{ }^{12} \mathrm{C}\right)_{b k}
$$

In which sa is sample and bk is background.

Total fat and carbohydrate ( $\mathrm{CHO})$ oxidation was calculated from indirect calorimetry using the following equations (15):

$$
\begin{aligned}
& \text { Total fat oxidation }=1.695 \mathrm{VO}_{2}-1.701 \mathrm{VCO}_{2} \\
& \text { Total } \mathrm{CHO} \text { oxidation }=4.585 \mathrm{VCO}_{2}-3.226 \mathrm{VO}_{2}
\end{aligned}
$$

with $\mathrm{VO}_{2}$ and $\mathrm{VCO}_{2}$ in litres per minute and total fat and $\mathrm{CHO}$ oxidation in grams per minute.

The rate of total fatty acid oxidation was calculated by converting total fat oxidation in grams to its molar equivalent, assuming that 1 mole of triglycerides equals 860 grams, and multiplying the molar rate of triglyceride oxidation by three, since one molecule of triglycerides contains three fatty acids.

${ }^{13} \mathrm{C}$ recovery in breath from $\left[\mathrm{U}-{ }^{-3} \mathrm{C}\right]$-palmitate $\left(\mu \mathrm{mol} \cdot \mathrm{min}^{-1}\right)$ was calculated as:

$$
\left(\left(\mathrm{TTR}_{\mathrm{CO} 2} \cdot \mathrm{VCO}_{2}\right) / 22.2966\right) \cdot 1000
$$

where $T \mathrm{TR}_{\mathrm{CO} 2}$ is the ${ }^{13} \mathrm{C} /{ }^{12} \mathrm{C}$ ratio in breath $\mathrm{CO}_{2}, \mathrm{VCO}_{2}$ the carbon dioxide production in $\mathrm{ml} \cdot \mathrm{min}^{-1}$ and 22.2966 the volume of 1 mole of carbon dioxide.

The ACF was calculated from the acetate infusion experiment as:

$$
\left.\left(\mathrm{TTR}_{\mathrm{CO} 2} \cdot \mathrm{VCO}_{2}\right) / 22.2966\right) / \mathrm{F} \cdot 2
$$

in which $\mathrm{F}$ is the rate of $\left[1,2 \cdot{ }^{13} \mathrm{C}\right]$-acetate infusion $\left(\mathrm{mmol} \cdot \mathrm{min}^{-1}\right)$. 
The rate of plasma palmitate oxidation $\left(\mu \mathrm{mol} \cdot \mathrm{min}^{-1}\right)$ can subsequently be calculated as:

$$
\left(\left({ }^{13} \mathrm{C} \text { recovery in breath from palmitate/ACF }\right) / 16\right) / T T R_{p}
$$

in which 16 is the number of ${ }^{13} \mathrm{C}$ carbon atoms in $\left[\mathrm{U}-{ }^{13} \mathrm{C}\right]$-palmitate and $T T R_{p}$ is the TTR of palmitate in plasma. Total plasma fatty acid oxidation was subsequently calculated by dividing the palmitate oxidation rate by the fraction that palmitate makes up to total plasma FFA. When indirect calorimetry derived total fatty acid oxidation was higher than the total plasma fatty acid oxidation, the difference between these values was assumed to be accounted for by oxidation of fatty acids derived from inter- or intramuscular triglycerides and circulating triglycerides (mainly very-low density lipoprotein (VLDL)) (25). These sources will collectively referred to as triglyceride (TG) derived fatty acids (FA).

TG derived FA oxidation = Total fatty acid oxidation-Plasma FFA oxidation

Rate of appearance $(\mathrm{Ra})$ of palmitate was calculated from steady state equations, since at the time of sampling under both basal and exercise conditions, a tracer and tracee steady state was present (that is, both palmitate $T T R_{p}$ and plasma palmitate concentration were stable). Therefore, Ra was assumed to be equal to the rate of disappearance (Rd) and calculated as:

$$
\mathrm{Ra}=\mathrm{F}(\mathrm{TTR} / \mathrm{TTR})
$$

where $T T R_{i}$ stands for the TTR of palmitate carbon in the infusate.

For glucose, non-steady state equations were applied (24), since glucose has a slower turnover than FFA, and because in the diabetic subjects plasma glucose decreased during the course of the experiment, and thus Rd must have been higher than $\mathrm{Ra}$.

These equations have been described elsewhere (26) as:

$$
R a=\frac{\left.\left.F-V\left[C_{2}+C_{1}\right) / 2\right]\left(T T R_{2}-T T R_{1}\right) /\left(t_{2}-t_{1}\right)\right]}{\left(T T R_{2}-T T R_{1}\right) / 2}
$$

in which $\mathrm{F}$ is the rate of $\left[6,6-{ }^{2} \mathrm{H}_{2}\right]$-glucose infusion $\left(\mu \mathrm{mol} \cdot \mathrm{kg}^{-1} \cdot \mathrm{min}^{-1}\right)$, and

$$
\mathrm{Rd}=\mathrm{Ra}-\mathrm{V}\left(\mathrm{C}_{2}-\mathrm{C}_{1}\right)\left(\mathrm{t}_{2}-\mathrm{t}_{1}\right)
$$

in which $V$ is the assumed volume of distribution for glucose, which was assumed to be $160 \mathrm{ml} \cdot \mathrm{kg}^{-1}, \mathrm{C}_{2}$ and $\mathrm{C}_{1}$ are the concentrations at time points $\mathrm{t}_{2}$ and $t_{1}$, respectively.

When indirect calorimetry derived values of glucose oxidation were higher than glucose Rd, muscle glycogen oxidation was calculated as:

Muscle glycogen oxidation $=$ Total glucose oxidation-Rd glucose 
For this calculation to be valid, it has to be assumed that all glucose disappearing from the plasma is oxidised. A previous study has shown that this condition is met during exercise (7). However, at rest this is not the case and, therefore, this calculation has only been made for the exercise period.

Statistics Differences between groups were tested with two tailed Student's $t$ test for unpaired data, within groups with two-tailed Student's $t$-test for paired data.

\section{Results}

Basal conditions Basal glucose was higher in D than in C, and insulin was similar (table 4.2). After $120 \mathrm{~min}$, plasma glucose was decreased $1.4 \pm 0.5 \mathrm{mM}$ in D $(p<0.05)$ and was unchanged in C. Insulin levels did not change in either group during the course of the experiment. Plasma FFA levels were similar in D and C. Mean resting energy expenditure was $320 \pm 67$ in D and $307 \pm 95 \mathrm{KJ} / \mathrm{h}$ in C (NS). Total glucose oxidation and total fatty acid oxidation were not significantly different between D and $C$ (table4.3). Blood plasma TTRs for $\left[6,6-{ }^{2} \mathrm{H}_{2}\right]$ glucose and $\left[\mathrm{U}-{ }^{13} \mathrm{C}\right]$-palmitate are depicted in figure 4.1. Plasma glucose $\mathrm{Ra}$ was similar in D and C (table 4.3). Plasma glucose Rd was significantly greater than Ra $(p<0.05)$ in $D$, but not in $C$, as already indicated by the significant decline in plasma glucose in $\mathrm{D}$ only. There was no difference in plasma FFA Ra between groups. Plasma FFA oxidation as measured from ${ }^{13} \mathrm{CO}_{2}$ production with correction for the ACF was not significantly different between groups. The ACF was similar in D and C, $22.1 \pm 0.02$ and $22.4 \pm 0.02 \%$, respectively.

Exercise Subjects cycled at a relative exercise intensity of $44 \pm 3 \%$ and $41 \pm 6 \%$ (D and $\mathrm{C}$, respectively, NS). Since $\mathrm{VO}_{2}$ max was higher in $\mathrm{C}$ than in $\mathrm{D}$, the absolute power output during exercise was higher in C (69 \pm 23 vs. $52 \pm 11$ Watt in D). During the $60 \mathrm{~min}$ of exercise glucose declined $1.5 \pm 1 \mathrm{mM}$ in $D$ only $(p<0.05)$. Insulin levels did not change significantly from basal values. Lactate levels rose slightly in the course of exercise, but this change was not significant compared to basal. Plasma FFA levels increased significantly, with no difference between groups. Respiratory exchange ratio's (RER) were similar, $0.87 \pm 0.04$ in $D$ and $0.86 \pm 0.04$ in C. Total glucose oxidation was increased $\sim 9$ fold compared to basal and total fatty acid oxidation increased $\sim 3$-fold, differ-

\begin{tabular}{lcccc|}
\hline & \multicolumn{2}{c}{ Basal } & \multicolumn{2}{c|}{ Exercise } \\
& D & C & D & C \\
\hline Glucose $(\mathrm{mmol} / \mathrm{l})$ & $7.7 \pm 1.5$ & $4.9 \pm 0.3^{\mathrm{b}}$ & $6.3 \pm 1.1^{\mathrm{a}}$ & $4.9 \pm 0.5$ \\
Insulin $(\mu \mathrm{U} / \mathrm{l})$ & $11 \pm 3$ & $9 \pm 2$ & $10 \pm 2$ & $8 \pm 1$ \\
NEFA $(\mu \mathrm{mol} / \mathrm{l})$ & $476 \pm 92$ & $447 \pm 120$ & $605 \pm 130^{\mathrm{a}}$ & $639 \pm 237^{\mathrm{a}}$ \\
Lactate $(\mathrm{mmol} / \mathrm{l})$ & $0.8 \pm 0.1$ & $0.8 \pm 0.2$ & $1.3 \pm 0.5$ & $1.2 \pm 0.5$ \\
& & & \\
Values are mean \pm SD. & & & \\
a denotes significant difference from basal with $p<0.05$; & \\
b denotes significant difference from $\mathrm{D}$ with $p<0.05$ & \\
\end{tabular}

Table 4.2: Blood plasma measurements. 


\begin{tabular}{|c|c|c|c|c|}
\hline \multirow{2}{*}{ 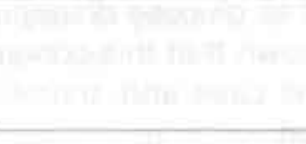 } & \multicolumn{2}{|c|}{$\begin{array}{c}\text { Basal } \\
\left(\mu \mathrm{mol} \cdot \mathrm{kg}^{-1} \cdot \mathrm{min}^{-1}\right)\end{array}$} & \multicolumn{2}{|c|}{$\begin{array}{c}\text { Exercise } \\
\left(\mu \mathrm{mol} \cdot \mathrm{kg}^{-1} \cdot \mathrm{min}^{-1}\right)\end{array}$} \\
\hline & D & C & D & C \\
\hline Glucose $\mathrm{Ra}$ & $9.20 \pm 1.71$ & $9.79 \pm 1.43$ & $14.92+4.76^{a}$ & $16.14 \pm 3.70^{3}$ \\
\hline Glucose Rd & $10.60 \pm 0.98^{b}$ & $10.06 \pm 1.63$ & $19.12 \pm 4.92^{\mathrm{ab}}$ & $15.33 \pm 4.34^{\mathrm{a}}$ \\
\hline Palmitate Ra (=Rd) & $6.34 \pm 1.83$ & $5.12+0.94$ & $11.78 \pm 4.82^{\mathrm{a}}$ & $10.84 \pm 3.39^{\mathrm{a}}$ \\
\hline $\begin{array}{l}\text { Plasma NEFA } \\
\text { oxidation }\end{array}$ & $2.13 \pm 0.51$ & $1.93 \pm 0.54$ & $8.10 \pm 1.44^{\mathrm{a}}$ & $8.00 \pm 3.12^{\mathrm{a}}$ \\
\hline $\begin{array}{l}\text { TG derived FA } \\
\text { oxidation }\end{array}$ & $1.97 \pm 0.54$ & $1.47 \pm 0.81$ & $1.52+1.41$ & $4.07 \pm 4.47$ \\
\hline $\begin{array}{l}\text { Total fatty acid } \\
\text { oxidation }\end{array}$ & $4.10 \pm 0.74$ & $3.40 \pm 0.90$ & $9.62 \pm 1.84^{\mathrm{a}}$ & $12.08 \pm 4.59^{a}$ \\
\hline Glycogen oxidation & - & - & $25.16 \pm 13.82$ & $42.04 \pm 10.58$ \\
\hline $\begin{array}{l}\text { Total CHO oxida- } \\
\text { tion }\end{array}$ & $5.37 \pm 2.44$ & $6.51 \pm 3.12$ & $44.28 \pm 10.36$ & $57.37 \pm 14.54$ \\
\hline \multicolumn{5}{|c|}{$\begin{array}{l}\text { Values are in } \mu \mathrm{mol} \cdot \mathrm{kg}^{-1} \cdot \mathrm{min}^{-1} \text { and expressed as mean } \pm \mathrm{SD} \text {. }{ }^{a} \text { denotes significant } \\
\text { difference from basal with } p<0.01 ; \text { b denotes significant difference from Ra with } \\
p<0.05 \text {; c denotes significant difference from } \mathrm{D} \text { with } p<0.05 \text {. }\end{array}$} \\
\hline
\end{tabular}

Table 4.3: Glucose and lipid turnover and oxidation.

ences were not significant between groups (table 4.3). Blood plasma TTRs for $\left[6,6-{ }^{2} \mathrm{H}_{2}\right]$-glucose and $\left[\mathrm{U}-{ }^{13} \mathrm{C}\right]$-palmitate during exercise are depicted in figure 4.1. Glucose $R a$ and Rd increased during exercise, with no significant difference between $\mathrm{D}$ and $\mathrm{C}$. As under basal conditions, glucose Rd was significantly higher than $\mathrm{Ra}$ in $\mathrm{D}$ only $(p<0.01)$. Muscle glycogen oxidation was significantly lower in D than in C (table 4.3). Plasma FFA levels were stable during the last $20 \mathrm{~min}$ of exercise, and elevated compared to basal. FFA Ra was similar in D and C. Plasma FFA oxidation corrected for ACF was not significantly different between $D$ and $C$ (table 4.3). Calculated TG derived FA oxidation was more than 2.5-fold lower in $D$ than $C$, but this difference did not attain significance. The ACF was $54.5 \pm 0.06 \%$ in $D$ and $70.7 \pm 0.07 \%$ in C $(p<0.05)$. Figure 4.2 depicts the contribution of the different substrates to energy provision during exercise.

Converting absolute amounts of substrate oxidised to their relative contribution to energy delivery (figure 4.2 ) revealed that plasma glucose oxidation accounted for $26 \pm 3$ and $15 \pm 2 \%(p<0.01)$, and muscle glycogen oxidation for $29 \pm 5$ and $42 \pm 4 \%(p<0.05)$ of total energy expenditure in D and C, respectively. $38 \pm 5$ and $30 \pm 12 \%$ (NS) of total energy was derived from plasma FFA and $7 \pm 7$ and $14 \pm 14 \%$ (NS) from TG derived FA in D and C, respectively.

\section{Discussion}

Although type 2 diabetes is a disorder characterised by a derangement in postprandial glucose metabolism, the overall pattern of substrate utilisation under fasting conditions is not altered. This has been repeatedly demonstrated 
Figure 4.1: Plasma tracer/tracee ratio's of glucose and palmitate at rest (90-120 $\mathrm{min})$ and during exercise (160-180 $\mathrm{min}$ ) in type 2 diabetes $(\bullet)$ and control $(\square)$ groups.

\section{Plasma glucose enrichment}

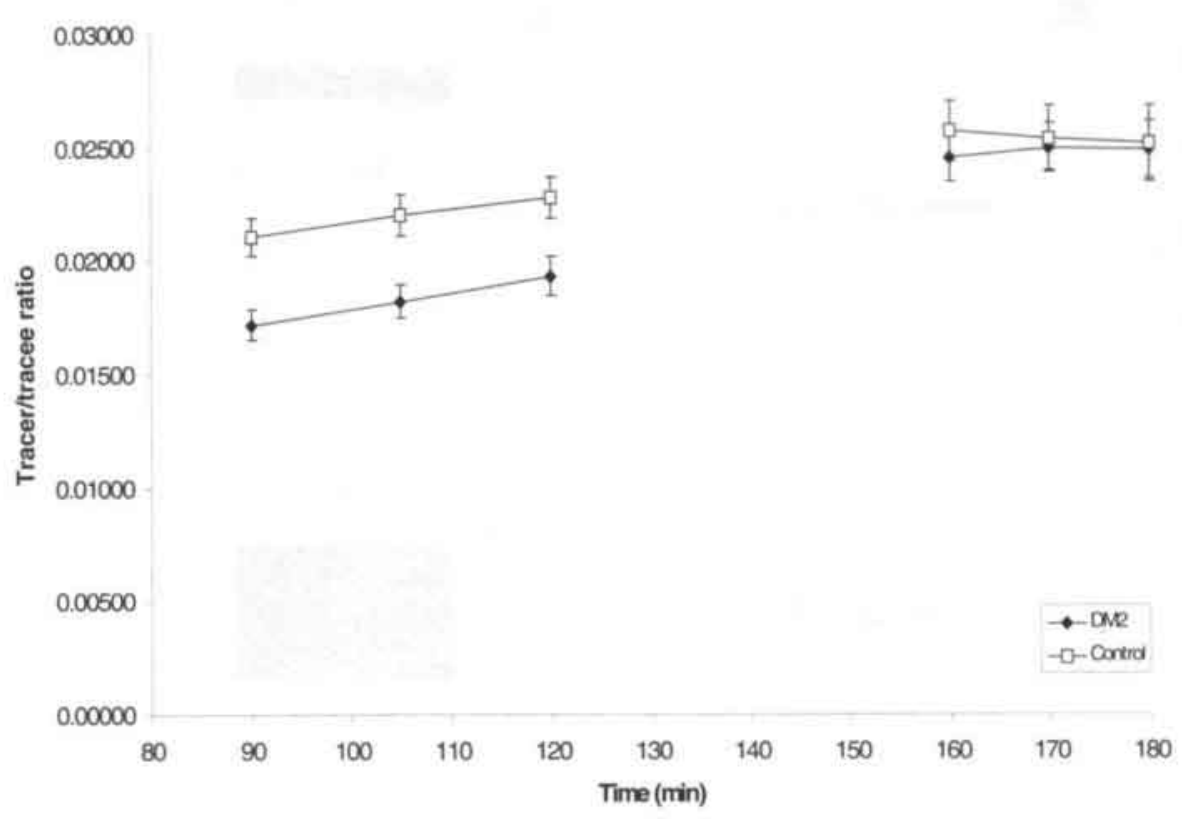

\section{Plasma palmitate enrichment}

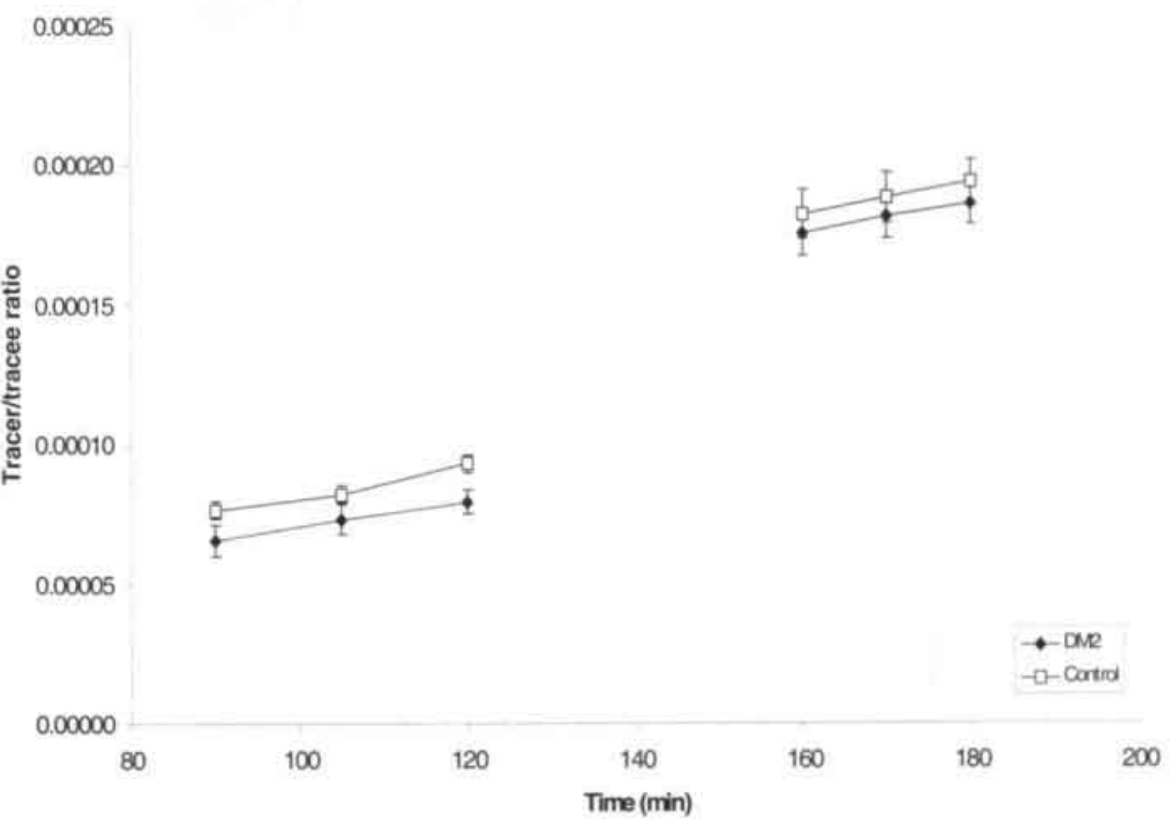


Chapter 4

80

70

60

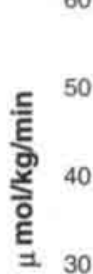

20

10

0

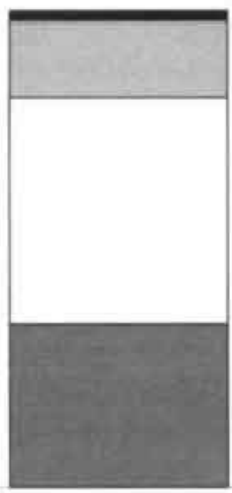

Type-2 diabetes

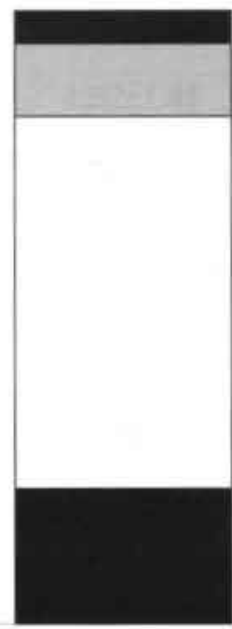

Control

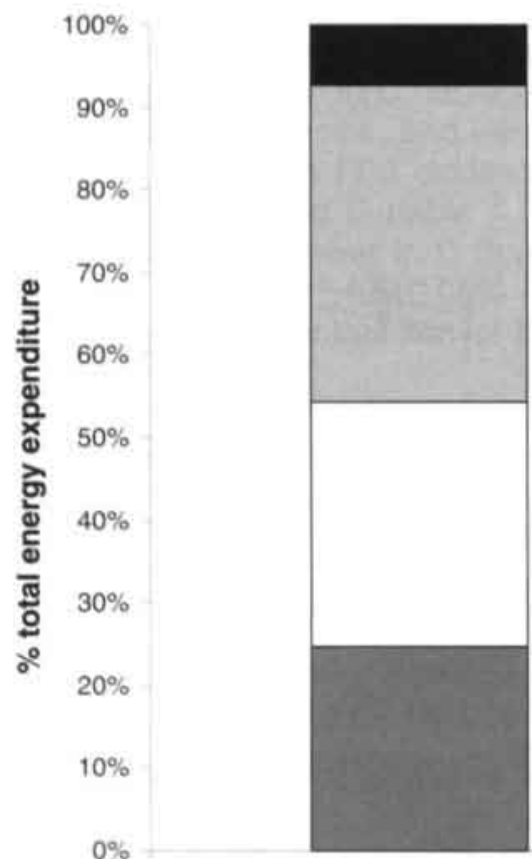

Type-2 diabetes

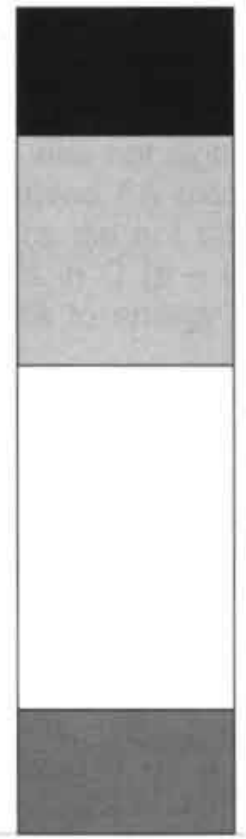

Control 
Previous page

Figure 4.2: Substrate utilization during exercise in type 2 diabetes and control groups. Upper graph shows the absolute amounts oxidized, lower graph the relative contribution to energy expenditure. From base to top: $\square$ Glucose Rd; $\square$ Glycogen oxidation; $\mathbb{}$ Plasma FFA oxidation; $\square$ TG derived FA oxidation.

in studies applying indirect calorimetry to asses the contribution of carbohydrates and fat to total energy expenditure $(2,8,9,14)$. The present study confirms these findings, the sole difference at rest from $C$ in the $D$ group being a higher glucose Rd in comparison to Ra. However, it has also been demonstrated that in hyperglycaemic type 2 diabetic patients, skeletal muscle metabolism is altered (11). Under postabsorptive resting conditions, leg uptake of FFA and oxidation of lipids is diminished (11). During exercise, skeletal muscle metabolism will account for the larger part of total energy expenditure, and therefore substrate utilisation in type 2 diabetes during exercise may be altered. Accordingly, it has repeatedly been shown that in type 2 diabetes, in contrast to the healthy population, plasma glucose declines during exercise $(13,14)$. Minuk et al. (14) attributed this decline in plasma glucose to impaired glucose production with glucose uptake rates similar to controls, but this conclusion directly opposes that of others $(2,13)$ who suggested that during exercise peripheral glucose utilisation is enhanced in type 2 diabetes, with normal splanchnic glucose output. The present study supports the notion that in type 2 diabetes, plasma glucose uptake is elevated relative to splanchnic glucose production, causing plasma glucose levels to decline. However, this appears to have been caused by the combined effects of a modestly increased plasma glucose uptake, and a modestly decreased splanchnic glucose production. Both these parameters were not significantly different from those in non-diabetics, but plasma glucose Rd was significantly higher than Ra in type 2 diabetic patients only. Additionally, our study shows that during moderate intensity exercise, muscle glycogen utilisation is decreased in type 2 diabetes, and that the contribution of plasma glucose oxidation to energy expenditure is increased. This illustrates that, although muscle insulin stimulated glucose uptake is diminished, there is no impairment in contraction stimulated plasma glucose uptake in type 2 diabetes. Glucose transport, by the insulin and contraction regulatable glucose transport protein GLUT-4, is the rate limiting step for glucose disposal (17). It has been shown that in muscle of type 2 diabetes patients, contraction induced translocation of the glucose transporter GLUT-4 is not disturbed (12). Combined with the mass-effect of hyperglycaemia, this probably contributes to the decline in plasma glucose during exercise seen in type 2 diabetes.

Plasma FFA levels were similar in D and C, as has been reported in some (2, 13 ) but not all studies $(10,11)$, and FFA Rd increased during exercise to the same level in both groups. As has been outlined earlier, it is impossible to quantify plasma FFA oxidation based on plasma FFA Rd, since it cannot be assumed that all FFA taken up on whole body level are oxidised during exercise, as is done for plasma glucose (7). This is illustrated by the data of the present study, in which the ratio of plasma FFA Rd to plasma FFA oxidation 
was $71 \pm 15$ and $75 \pm 13 \%$ in $D$ and C, respectively (difference NS). Therefore, we have calculated the oxidation of plasma FFA measuring the ${ }^{13} \mathrm{CO}_{2}$ production from $\left[\mathrm{U}-{ }^{13} \mathrm{C}\right]$-palmitate. By subtracting plasma FFA oxidation from total fat oxidation as measured by indirect calorimetry, TG derived FA oxidation was estimated. Plasma FFA oxidation and TG derived FA oxidation were not significantly different between D and C, despite TG derived FA oxidation being twice as high in $\mathrm{C}$ as in D. Thus, if there is an impairment in skeletal muscle FFA oxidation in type 2 diabetes patients, as has been suggested by others under resting conditions (11), than this is not reflected by decreased FFA oxidation during exercise.

We would like to emphasise the considerable influence the ACF can have on the obtained value for FFA oxidation. If no account would have been taken of the ACF, the relative contribution of plasma FFA to energy turnover would have been substantially underestimated: $22 \pm 4$ and $22 \pm 8 \%$ in D and C, respectively. With application of the ACF these values were $38 \pm 5$ and $30 \pm 12 \%$, respectively. There was a rather large and significant difference in ACF between the two groups during exercise: $54.5 \pm 0.06 \%$ in D and $70.7 \pm 0.07 \%$ in C. Part of this difference may have been caused by a somewhat higher absolute $\mathrm{VO}_{2}$ in the control group, but analysis of variance for repeated measurements of the ACF, with $\mathrm{VO}_{2}$ as a covariant, showed that this explains only a part of the difference in ACF between groups. We can only speculate on what might cause this difference (e.g. increased gluconeogenesis in type 2 diabetes (3), or increased production rates of glutamine from TCA cycle intermediates (13)). Irrespective of its cause, this study shows that differences in ACF can exist between research populations, and that in comparing groups such as patients vs. controls or trained vs. untrained subjects, failure to correct for label-loss could lead to not only quantitative, but also qualitative misinterpretations of research data.

In the present study, all subjects were sedentary, and the D and C group had a similar lean body mass, but $\mathrm{VO}_{2}$ max was significantly higher in $\mathrm{C}$. This is in agreement with previously reported reduced rates of maximal $\mathrm{VO}_{2}$ in type 2 diabetic subjects (16). Therefore, the observed difference in $\mathrm{VO}_{2}$ max may reflect the difference found between the type 2 diabetic and non-diabetic populations. Nonetheless, the difference in $\mathrm{VO}_{2}$ max resulted in a higher absolute workload during exercise in $\mathrm{C}$, despite the closely matched relative exercise intensity between groups. It should be noted that, had the D-group exercised at the same absolute intensity as $\mathrm{C}$, then the contribution of $\mathrm{CHO}$ (both blood glucose and muscle glycogen,) to energy expenditure would probably have increased at the expense of fat. This is because $\mathrm{CHO}$ utilisation, both relatively and absolutely, increases with exercise intensity (18).

In summary, total $\mathrm{CHO}$ and fat oxidation at rest and during moderate-intensity exercise are unaltered in moderately obese type 2 diabetes patients. During exercise, muscle glycogen oxidation is decreased in type 2 diabetes, and the contribution of plasma glucose oxidation to energy expenditure is increased. No significant aberrations are present in plasma FFA Rd and oxidation rates; triglyceride derived FA oxidation was twofold lower in type 2 diabetes patients than controls, but this difference was not significant. These findings indicate that type 2 diabetes patients exhibit no impairment in uptake and oxidation of plasma glucose and FFA during moderate intensity exercise. 


\section{References}

1. Andersen, L., B. Dinesen, P. N. Jorgensen, F. Poulsen, and M. E. Roder. Enzyme immunoassay for intact human insulin in serum or plasma. Clin Chem 39: 578-82, 1993.

2. Colberg, S. R., J. M. Hagberg, S. D. McCole, J. M. Zmuda, P. D. Thompson, and D. E. Kelley. Utilisation of glycogen but not plasma glucose is reduced in individuals with NIDDM during mild-intensity exercise. J-Appl-Physiol 81: 2027 33, 1996.

3. Consoli, A. Role of liver in pathophysiology of NIDDM. Diabetes Care 15: 430-41, 1992.

4. Durnin, J. V., and J. Womersley. Body fat assessed from total body density and its estimation from skinfold thickness: measurements on 481 men and women aged from 16 to 72 years. Br J Nutr 32: 77-97, 1974.

5. Gutmann, I., and A. W. Wahlefeld. $\mathrm{L}-(+)$-Lactate, determination with lactate dehydrogenase and NAD. In: Methods in enzymatic analysis (2nd ed. ed.), edited by H. U. Bergmeyer. New York: Academic Press, 1974, p. 1464-1468.

6. IDF. A desktop guide to type-2 diabetes mellitus. Diabetic Medicine 16: 716-730, 1999.

7. Jeukendrup, A. E., A. Raben, A. Gijsen, J. H. Stegen, F. Brouns, W. H. Saris, and A. J. Wagenmakers. Glucose kinetics during prolonged exercise in highly trained human subjects: effect of glucose ingestion. J-Physiol-Lond 515: 579 89, 1999.

8. Kang, J., D. E. Kelley, R. J. Robertson, F. L. Goss, R. R. Suminski, A. C. Utter, and S. G. Dasilva. Substrate utilisation and glucose turnover during exercise of varying intensities in individuals with NIDDM. Med-Sci-Sports-Exercise 31: 82-89, 1999.

9. Kang, J., R. J. Robertson, J. M. Hagberg, D. E. Kelley, F. L. Goss, S. G. DaSilva, R. R. Suminski, and
A. C. Utter. Effect of exercise intensity on glucose and insulin metabolism in obese individuals and obese NIDDM patients. Diabetes-Care 19: 341-9, 1996.

10. Kelley, D., M. Mokan, and T. Veneman. Impaired postprandial glucose utilisation in non-insulindependent diabetes mellitus. Metabolism 43: 1549-57, 1994.

11. Kelley, D. E., and J. A. Simoneau. Impaired free fatty acid utilisation by skeletal muscle in non-insulindependent diabetes mellitus. J-ClinInvest 94: 2349-56, 1994.

12. Kennedy, J. W., M. F. Hirshman, E. V. Gervino, J. V. Ocel, R. A. Forse, S. J. Hoenig, D. Aronson, L. J. Goodyear, and E. S. Horton. Acute exercise induces GLUT4 translocation in skeletal muscle of normal human subjects and subjects with type 2 diabetes. Diabetes 48: 1192-7, 1999.

13. Martin, I. K., A. Katz, and J. Wahren. Splanchnic and muscle metabolism during exercise in NIDDM patients. Am-J-Physiol 269: E583-90, 1995.

14. Minuk, H. L., M. Vranic, E. B. Marliss, A. K. Hanna, A. M. Albisser, and B. Zinman. Glucoregulatory and metabolic response to exercise in obese noninsulindependent diabetes. Am J Physiol 240: E458-64, 1981.

15. Peronnet, F., and D. Massicotte. Table of nonprotein respiratory quotient: an update. Can-J-Sport-Sci 16: 23-9, 1991.

16. Regensteiner, J. G., J. Sippel, E. T. McFarling, E. E. Wolfel, and W. R. Hiatt. Effects of non-insulindependent diabetes on oxygen consumption during treadmill exercise. Med-Sci-Sports-Exerc 27: 875-81, 1995.

17. Ren, J. M., B. A. Marshall, E. A. Gulve, J. Gao, D. W. Johnson, J. O. Holloszy, and M. Mueckler. Evidence from transgenic mice that glucose transport is rate-limiting for glycogen deposition and glycolysis 
in skeletal muscle. $J$ Biol Chem 268: 16113-5, 1993.

18. Romijn, J. A., E. F. Coyle, L. S. Sidossis, A. Gastaldelli, J. F. Horowitz, E. Endert, and R. R. Wolfe. Regulation of endogenous fat and carbohydrate metabolism in relation to exercise intensity and duration. Am-J-Physiol 265: E380-91, 1993.

19. Schneider, S. H., A. K. Khachadurian, L. F. Amorosa, H. Gavras, S. E. Fineberg, and N. B. Ruderman. Abnormal glucoregulation during exercise in type 2 (non-insulindependent) diabetes. Metabolism 36: 1161-6, 1987.

20. Schrauwen, P., D. P. van Aggel Leijssen, W. D. van Marken Lichtenbelt, M. A. van Baak, A. P. Gijsen, and A. J. Wagenmakers. Validation of the $[1,2-13 \mathrm{C}]$ acetate recovery factor for correction of [U$13 \mathrm{C}$ ]palmitate oxidation rates in humans. J-Physiol-Lond 513: 21523, 1998.

21. Sidossis, L. S., A. R. Coggan, A. Gastaldelli, and R. R. Wolfe. A new correction factor for use in tracer estimations of plasma fatty acid oxidation. Am-J-Physiol 269: E649-56, 1995.

22. Sidossis, L. S., A. R. Coggan, A. Gastaldelli, and R. R. Wolfe. Pathway of free fatty acid oxidation in human subjects. Implications for tracer studies. J-Clin-Invest 95: 27884, 1995.

23. Sidossis, L. S., A. Gastaldelli, S. Klein, and R. R. Wolfe. Regulation of plasma fatty acid oxidation during low- and high- intensity exercise. Am J Physiol 272: E1065-70, 1997.

24. Steele, R. Influences of glucose loading and of injected insulin on hepatic glucose output. Ann-NYAcad-Sci 82: 420-430, 1959.

25. Van der Vusse, G. J., and R. S. Reneman. Lipid metabolism in muscle. In: Exercise: regulation and integration of multiple systems, edited by L. B. Rowell and J. T. Sheperd. Oxford: Oxford University Press, 1996, p. 953-994.

26. Wolfe, R. R. Radioactive and stable isotope tracers in biomedicine: principles and practice of kinetic analysis. New York: Wiley-Liss, Inc., 1992. 


\section{Effect of Training Intensity on Insulin Sensitivity}

\section{Evaluated by Insulin Tolerance Test}

\section{Chapter}

L.B. Borghouts, K. Backx, M.F. Mensink, H.A. Keizer

European Journal of Applied Physiology 80 (5) 1999

\section{Summary}

The purpose of this study was to evaluate the role of exercise intensity in the effect of physical training on insulin sensitivity. The insulin tolerance test (ITT) was applied to quantify insulin sensitivity. 18 healthy, young, untrained men and women participated in a 4 week, 5 times a week, one hour per session bicycle ergometer training program. Training consisted of 3 minute bouts interspersed with 2 minutes at a lower intensity. Intensities were 80$40 \%$ of pretraining maximal power output (Wmax) in the high intensity $(\mathrm{HI})$ and $40-20 \%$ Wmax in the low intensity (LI) group. Insulin sensitivity index ( $\left.\mathrm{IS}_{\text {index }}\right)$ was similar in the $\mathrm{HI}$ and $\mathrm{LI}$ group before the training intervention ($0.1898 \pm 0.058$ and $-0.1892 \pm 0.045$ respectively). After training, IS index $_{\text {Was - }}$ $0.2358 \pm 0.051$ ( $p=0.005$ vs. pretraining) in $\mathrm{HI}$ group and $-0.2050 \pm 0.035$ ( $p=0.099$ against pretraining) in LI group. We conclude that improvements in insulin sensitivity are more pronounced with high intensity training, when exercise frequency and duration are kept similar. We further conclude that ITT seems suitable for use in intervention studies. 
Skeletal muscle is responsible for a major portion of insulin dependent glucose uptake in man $(6,7)$. In accordance, there have been numerous studies showing that physical activity enhances insulin sensitivity $(9,11,20,21,29)$. Helmrich et al. (16) have shown that the risk for developing type 2 diabetes, a metabolic disorder characterised by peripheral insulin resistance, decreases with increasing physical activity levels. Although metabolic adaptations to physical training are generafly considered to be more pronounced in response to high intensity exercise than to moderate to low intensity exercise (26), type 2 diabetes patients are often advised to participate in less vigorous exercise $(28,30)$. This is in part due to the fact that type 2 diabetes patients are at higher risk of developing complications, such as ischaemic heart disease or angiopathy, but probably also because it has never been conclusively found that high intensity training is more beneficial to insulin sensitivity than moderate or low intensity training.

Surprisingly few studies have addressed this question, often investigating the acute effect of exercise $(5,29)$ rather than effects of training not due to recent exercise $(19,25)$. The latter studies have kept the total amount of work performed similar between high and low intensity training programs, consequently also introducing a difference in duration. The primary aim of this study was therefore to investigate whether an exercise program of high intensity is more beneficial to insulin sensitivity than a program of moderate intensity, when keeping exercise duration similar. This approach also serves a practical goal: for people participating in an exercise program, the amount of time they wish to spend can be a consideration, and they would probably be interested to know whether it would matter if the exercise of a given duration be vigorous or mild.

An additional goal of this study was to evaluate the applicability of the short Insulin Tolerance test (ITT) to an intervention study. Studies quantifying insulin sensitivity or glucose tolerance usually make use of glucose clamp techniques, steady state plasma glucose (SSPG) techniques, and intravenous or oral glucose tolerance tests (IVGTT or OGTT). Although these techniques all have their specific advantages, they also have their drawbacks. Apart from being laborious (clamp, SSPG), or poorly reproducible (OGTT), a major disadvantage of all techniques is that they are time-consuming ( $>2$ hours).

The ITT, as described by Bonora (4), has been applied to quantify in vivo insulin action in relatively few studies $(2,13,27)$. Using the ITT, it is possible to measure the insulin sensitivity of two subjects within the hour, which theoretically makes it suitable for large scale epidemiological or intervention studies. The ITT correlates well with the euglycaemic clamp $(1,4)$ and with Bergman's Minimal Model (23), and has been shown to be reproducible (17). Sympatho-adrenal responses to possible hypoglycaemia have been shown not to occur within the 
time span of the ITT (4). To our knowledge, the present study is the first to use the ITT to evaluate an intervention study.

\section{Methods}

Subjects and exercise testing This study was approved by the Medical Ethics Committee at Maastricht University. 18 healthy, young, untrained subjects participated in the intervention study after giving their written informed consent. Untrained was defined as not regularly participating in any vigorous activity, or exercising for less than 1,5 hour a week. Subjects known to have diabetes or diabetes present in first degree relatives were excluded. Subject characteristics are shown in table 5.1. Percentage body fat was measured using the skinfold method, taking the mean of 4 skinfolds, measured in duplicate and applying the formula of Durnin and Womersley (12). After admission to the study, all subjects underwent an incremental bicycle ergometer test (Lode ergometer, Groningen, the Netherlands) with open circuit indirect calorimetry (Oxycon $\beta$, Mijnhardt, Bunnik, the Netherlands) and heart rate monitoring (Polar, Kempele, Finiand). After an initial warm up of $5 \mathrm{~min}$ at $100 \mathrm{~W}$, the load was increased every 2,5 minutes by $50 \mathrm{~W}$. When heart rate reached $160 \mathrm{bpm}$, the load was increased 25 W every 2,5 min until exhaustion. Maximal power output (Wmax) was determined from the formula:

$$
W \max =W_{\text {last complete step }}+(t / 150) \cdot 25 \text {, }
$$

in which $\mathrm{W}$ is workload and $\mathrm{t}$ is the time completed of the final step.

Whether $\mathrm{VO}_{2}$ max was reached was established using the levelling off criterion. This test was repeated at the end of the training program.

Training program Subjects for the training study were divided into two groups matched on re-training insulin sensitivity (see below). They participated in a 4 week training program, to a total of 19 sessions. Exercise consisted of bicycle ergometer interval sessions of one hour each in our laboratory. Intervals were 3 minute bouts interspersed with 2 minutes at a lower intensity. The exercise intensity for these bouts were 80 and $40 \%$ of pre-training Wmax in the high intensity $(\mathrm{HI})$ and 40 and $20 \%$

Wmax in the low intensity (LI) group. Included in the one hour exercise were 5 min warm up and cool down at $80 \mathrm{~W}$. The subjects that participated in the HI program build up the high intensity bouts towards $80 \%$ Wmax in the following way:

day $1: 60 \%$, day $2: 65 \%$, day 3 : $70 \%$, day 4-19: $80 \%$.

On two occasions during the training program between exercise day 4-19, subjects in the $\mathrm{HI}$ group were allowed to exercise at $70 \%$ Wmax instead of $80 \%$ Wmax, since some subjects perceived the program to be very strenuous.

Insulin tolerance test The ITT was performed before and after the training program.

Subjects were instructed to refrain from exercise and keep a diet of at least $200 \mathrm{~g}$ of carbohydrates daily, for 48 hours preceding both ITT's. Compliance to 
this instruction was checked on the morning of the test. Subjects reported to the laboratory after an overnight fast ( 12 hours at least). They were placed in a supine position, with one hand warmed in a heated air box set at $60^{\circ} \mathrm{C}$ to obtain arterialised blood samples. One Teflon catheter was inserted retrogradely in a dorsal hand vein of the heated hand for blood sampling, and another catheter was placed in an antecubital vein of the contralateral arm for injection of insulin. Blood samples were drawn at -5 , and 0 minutes, and every two minutes thereafter until 16 minutes, for immediate measurement of blood glucose (Analox GM7, Meyvis, the Netherlands). At 0 minutes, subjects were administered an intravenous bolus of Human Actrapid Insulin (Novo Nordisk A/S, Denmark) of $0,1 \mathrm{U} \cdot \mathrm{kg}^{-1}$ body weight. The test was terminated at 16 minutes and a $25 \mathrm{ml}$ bolus of $20 \%$ dextrose was injected, to prevent symptoms of hypoglycaemia, and subjects were given breakfast. Blood glucose was checked again at 22 minutes after insulin injection and if necessary (blood glucose $<2.5 \mathrm{mmol} / \mathrm{L}$ ) another intravenous bolus of $10 \mathrm{ml}$ of glucose was given. No subjects reported symptoms of hypoglycaemia during the ITT, but on 5 occasions such symptoms occurred 20-30 minutes after the insulin injection.

Calculation of the insulin sensitivity index (IS $\left.S_{\text {index }}\right)$ The decline in blood glucose between 4 and 16 minutes was used to determine insulin sensitivity, since no changes in blood glucose were noted within 4 minutes after insulin injection. A linear regression line was fitted through these blood glucose values, and the slope of this line was taken as the Insulin Sensitivity Index ( $I_{\text {index, }}$ in $\mathrm{mM} / \mathrm{min}$ ). Regression lines were fitted using Microsoft Excel on an Apple Macintosh computer.

Statistics Unpaired two tailed t-tests were applied to re-training measurements between groups. Re-training against post-training values were tested within groups with a one tailed paired t-test. Comparisons among groups before and after training were made with two way analysis of variance for repeated measurements on blood glucose in time with the factors $\mathrm{HI}$ or $\mathrm{LI}$ group and before or after training. Statistical analysis were performed using Statview 4.02 on an Apple Macintosh Computer.

\section{Results}

The training program resulted in a significant increase in Wmax and maximal oxygen uptake $\left(\mathrm{VO}_{2} \max \right)$ in both the $\mathrm{HI}$ and $\mathrm{LI}$ group $(\mathrm{p}<0.05)$ (difference not significant between groups,) while body mass and fat percentage were unchanged in both groups (table 5.2). Total external work performed with exercise

\begin{tabular}{|c|c|c|c|c|}
\hline & $\mathrm{HI}$ before & $\mathrm{HI}$ after & LI before & $\mathrm{LI}$ after \\
\hline Body mass $(\mathrm{kg})$ & $72.2 \pm 10$ & $73.3 \pm 10$ & $68.8 \pm 11$ & $69.3 \pm 11$ \\
\hline Body fat $\%$ & $25.1 \pm 6.0$ & $25.3 \pm 5.3$ & $27.4 \pm 5.7$ & $27.9 \pm 5.9$ \\
\hline$W \max (W)$ & $261 \pm 41$ & $288 \pm 42^{*}$ & $230 \pm 40$ & $248 \pm 39^{*}$ \\
\hline $\mathrm{VO}_{2} \max$ & $43.1 \pm 5$ & $46.1 \pm 4^{*}$ & $40.9 \pm 6$ & $42.9 \pm 6^{*}$ \\
\hline $\mathrm{IS}_{\text {index }}\left(\mathrm{mM} \cdot \mathrm{min}^{-1}\right)$ & $\begin{array}{l}-0.1898 \\
\pm 0.058\end{array}$ & $\begin{array}{l}-0.2358 \\
\pm 0.051^{\star}\end{array}$ & $\begin{array}{l}-0.1892 \\
\pm 0.045\end{array}$ & $\begin{array}{l}-0.2050 \\
\pm 0.035\end{array}$ \\
\hline
\end{tabular}

Table 5.2: Pretraining and posttraining data for $\mathrm{HI}$ and $\mathrm{LI}$ group (mean $\pm \mathrm{SD}$ ). 
during the whole training program was approximately $3643 \mathrm{MJ}$ in the $\mathrm{LI}$ and $9216 \mathrm{MJ}$ in the $\mathrm{HI}$ group.

The linear regression lines that were fit to represent the blood glucose data had a mean $R^{2}$ of $0.975 \pm 0.024$, indicating an adequate representation of the decline in blood glucose by the slope of the regression line. The mean $I S_{\text {index }}$ was similar in the $\mathrm{HI}$ and $\mathrm{LI}$ group before the training intervention, $-0.1898 \pm 0.058$ and $-0.1892 \pm 0.045$ respectively, which was the objective of the matching procedure. After training, insulin sensitivity was significantly improved in the $\mathrm{HI}$ group only, averaging $-0.2358 \pm 0.051(p=0.005)$. In the $\mathrm{LI}$ group, the $\mathrm{IS}_{\text {index }}$ after training was $-0.2050 \pm 0.035(p=0.099$ against re-training). The pooled $I S_{\text {index }}$ for both groups before and after training were $-0.1894 \pm 0.051$ and 0.2203 $\pm 0.041(\mathrm{p}=0.002)$.

Two way analysis of variance for repeated measurements showed a significant effect of training $(\mathrm{HI}$ and $\mathrm{LI}$ pooled) on blood glucose decline $(p=0.006)$ during the ITT. The change in blood glucose decline after training compared to before training was not different between $\mathrm{HI}$ and $\mathrm{LI}$ groups $(\mathrm{p}=0.251)$. However, after training the blood glucose declined more in the $\mathrm{HI}$ than in $\mathrm{LI}$ group $(\mathrm{p}=0.043$; Figure 5.1).

\section{Discussion}

Although numerous studies have shown the beneficial effects of acute exercise and training on insulin sensitivity in both healthy and glucose intolerant subjects $(9,11)$, there is still no consensus on the mode of exercise that is most appropriate. The majority of training studies have focused on endurance training, often being of moderate intensity in type 2 diabetes or obese groups. Relatively little research on the role of exercise intensity has been conducted, probably because sedentary subjects are usually unable to perform prolonged high intensity training. In addition, the risk of complications is greater with high intensity exercise in patient groups. We have applied a training protocol designed to enable sedentary subjects to do substantial amounts of high intensity training, by having them do 3 minute blocks at $80 \%$ of Wmax interspersed with 2 minutes of recuperation at $40 \%$ Wmax. All our subjects were able to complete this protocol. We have to point out however, that although our subjects were sedentary, they were young and healthy. The feasibility of the present program in a patient group remains to be determined.

The intervention was successful in improving insulin sensitivity, as indicated by a significant improvement in $\mathrm{IS}_{\text {index }}$ after training for the group as a whole. However, when split by exercise intensity, IS $_{\text {index }}$ was significantly altered in the $\mathrm{HI}$ group only. The observation that $\mathrm{HI}$ training was more effective in improving

Next page:

Figure 5.1: Blood glucose (mM) during ITT before and after training. HI group (closed circles) significantly different from LI group (open circles) after training $(P=0.043)$. Change from before to after training not significantly different between $\mathrm{HI}$ and $\mathrm{LI}(\mathrm{P}=0.251)$. 
6

Before training
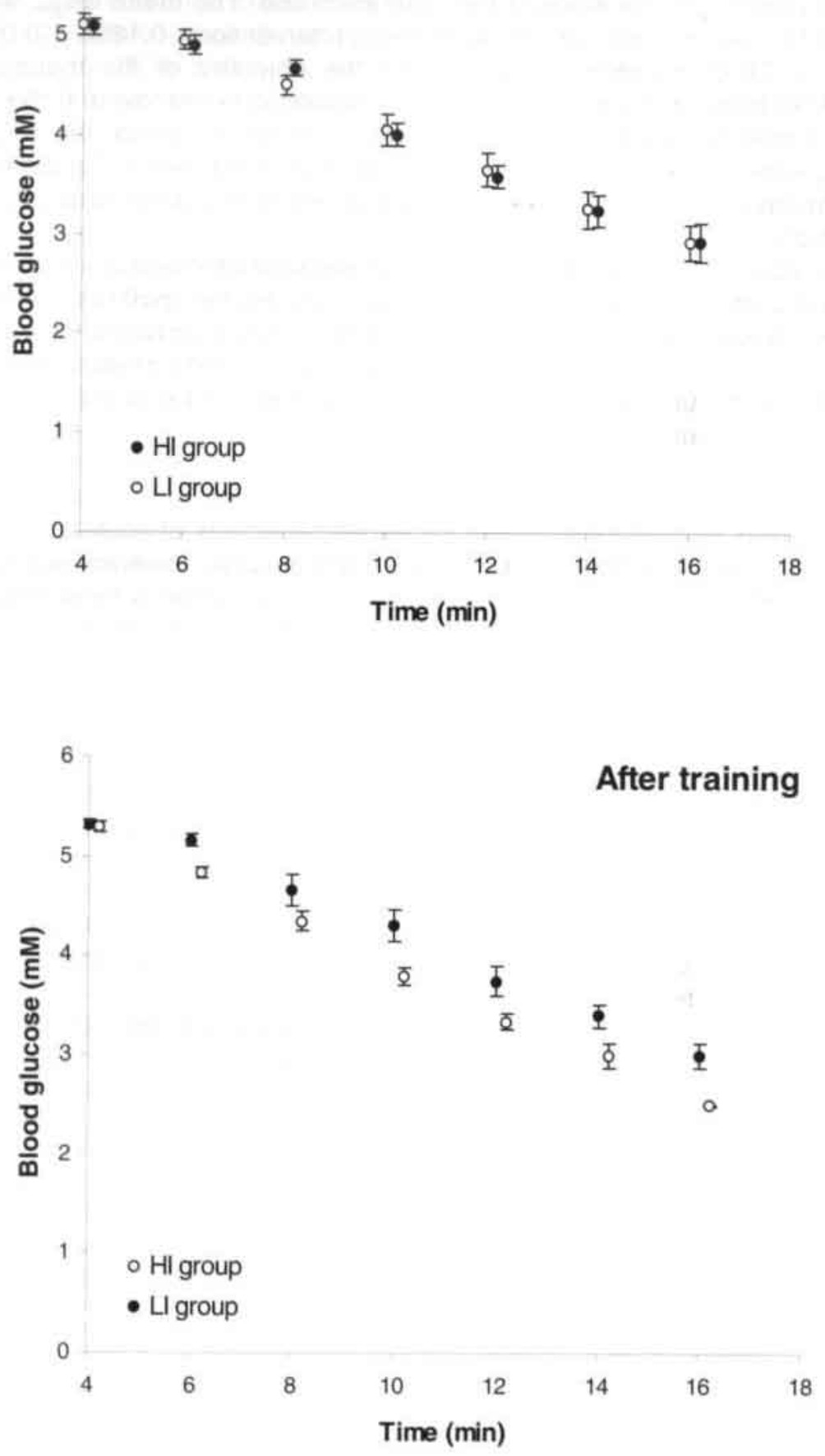
insulin sensitivity than $\mathrm{LI}$ training is confirmed by the fact that blood glucose values during the ITT (ANOVA repeated measurements) were significantly lower after $\mathrm{HI}$ than after $\mathrm{LI}$ training. This conclusion seemingly opposes that of others, investigating either a single bout of exercise (29) or several days of training (25). These studies found a decreased insulin response during OGTT after exercise, but no effect of exercise intensity. The reason for this discrepancy may be that our results probably represent an effect of training not due to the last exercise bout (which was at least 48 hours before the ITT), instead of an acute effect of the last session, and that the method applied to quantify insulin sensitivity may have been more sensitive in the present study.

Braun et al. (5) have used the SSPG to evaluate the effect of two days of high versus low intensity exercise in women with type 2 diabetes. Again, subjects were studied on the morning after the last exercise bout, and no effect of exercise intensity was found. However, in this study, the total amount of energy expended was kept similar in both training groups. As a result, next to exercise intensity, exercise duration had to be different between the two groups. In fact, the duration of exercise in the low intensity group was $63 \%$ longer compared to the high intensity group. Using the same approach of keeping total energy expenditure similar, applying an OGTT, Kang et al. (19) found an effect of exercise intensity ( $50 \%$ vs. $70 \% \mathrm{VO}_{2} \max$ ) in obese individuals, but surprisingly not in obese type 2 diabetes patients.

In practice training consists of three components: frequency, duration and intensity. These three together determine the total amount of energy expended over a given training period. type 2 diabetes patients as well as healthy individuals are often advised to perform physical exercise on a daily basis, which is obviously too time-consuming for most people. In other words, frequency and duration of training will often be determined by the amount of time an individual is willing or able to spend, leaving intensity as the variable to advise people on. It is therefore that we have varied exercise intensity without varying duration or frequency of training. Consequently, total energy expenditure during the training program was higher in the $\mathrm{HI}$ group than in the $\mathrm{LI}$ group. This approach led to an increase in absolute maximal oxygen uptake that was somewhat greater in the $\mathrm{HI}$ group than in the $\mathrm{LI}$ group $(8.4 \%$ vs. $6.4 \%)$, Unfortunately, none of the aforementioned investigators reported on the effects of training on maximal oxygen uptake. Seals et al. (24) did determine maximal oxygen uptake before and after training. In eleven healthy older individuals, a six month $\mathrm{LI}$ program was followed by a six month $\mathrm{HI}$ program. After $\mathrm{HI}$ training, maximal oxygen uptake as well as insulin sensitivity were increased above the level achieved after LI. Unfortunately, a carry over effect of the initial 6 month LI training on the $\mathrm{HI}$ program is inevitable with this design. Furthermore, all insulin sensitivity measurements were carried out 14 hours after the last exercise session, and consequently the effect of the last exercise bout could not be ruled out (11).

Taken together, we conclude from our study that an exercise program of high intensity is more effective in increasing insulin sensitivity than a program of low to moderate intensity, when training duration and frequency are similar. Whether this effect is due to the difference in exercise intensity per sé, or (also) to the increase in total energy expenditure remains to be determined. In this respect, it would be interesting to perform a study introducing a similar differ- 
ence in energy expenditure by varying exercise duration or frequency, instead of intensity.

Adaptations of skeletal muscle may be responsible for the increased glucose uptake after training. It has been shown that insulin sensitivity after exercise is inversely correlated with muscle glycogen levels (18). However, it is very unlikely that a substantial difference in glycogen levels was present between our two groups, since they were studied 48 hours after the last exercise bout and had been instructed to maintain an adequate carbohydrate intake. Glucose transport is thought to be the rate limiting step for non-oxidative glucose disposal in skeletal muscle, rather than non-oxidative enzyme capacity (22). Therefore, an effect at the expression or intrinsic activity of the insulin and contraction regulatable glucose transporter GLUT-4 could be responsible for the observed difference. Indeed, training has been shown to increase GLUT-4 in human skeletal muscle (10). Alternatively (or in addition), changes in splanchnic insulin sensitivity could bring about the changes in IS $_{\text {index }}$ observed in this study. In obese persons, 6 weeks of endurance training is effective in enhancing suppression of hepatic glucose output by insulin (8). Similar findings have been reported in NIDDM patients in whom 12 weeks of training induced significant reductions in basal glucose production (17\%) and hepatic glucose output during insulin stimulation (25\%) (3). In healthy subjects, this effect has not conclusively been shown.

However, since it is impossible with the ITT to discriminate between peripheral and splanchnic contribution to the decline in blood glucose, our study cannot provide evidence as to what mechanisms are responsible for the greater insulin sensitivity after $\mathrm{HI}$ exercise.

A secondary goal of this study was to test the usefulness of the ITT in an intervention study. Although the ITT has been favourably evaluated $(1,4,14,17$, $23)$, its further use has been limited. Different approaches have been taken to express the results of the ITT into a single measure of insulin sensitivity. Most investigators have used the $\mathrm{K}_{\mathrm{itt}}$ as an index, which involves fitting a natural logarithmic function through blood glucose values and calculating the half life of the decline in glucose concentration (4) or applied the same procedure to the logarithm of blood glucose $(1,17)$, making absolute differences in the blood glucose level of influence on comparisons between groups. Others have used the absolute decline in blood glucose, $\Delta \mathrm{G}$, divided by the initial blood glucose, $\mathrm{GO}$, to the same goal (15). The rationale behind these procedures is not easily understood. We have simply used the slope of the decline in blood glucose to

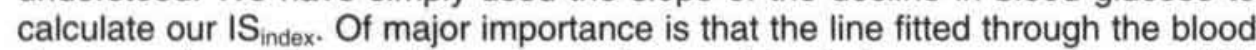
glucose values adequately represents the true blood glucose concentration. We have shown that this is very well possible using a linear regression line through time points 4-16 minutes. In fact, with our data, the fit of the line was slightly better with linear regression than when a logarithmic function was applied ( $R$ values $0.975 \pm 0.024$ vs. $0.924 \pm 0.061$ ). However, when we calculate the $K_{i t t}$ in analogy to others $(1,17)$, we come to the same general conclusion regarding our training intervention: $\mathrm{HI}$ training was more effective in improving $\mathrm{K}_{\text {itt }}$ than was $\mathrm{LI}$ training (table 5.3). The difference in training effect however, seems more pronounced when the $\mathrm{K}_{\text {itt }}$ is calculated instead of the $\mathrm{IS}_{\text {index. }}$. This may be explained by the use of the logarithm of blood glucose instead of the absolute blood glucose values, since this increases differences between low values 


\begin{tabular}{|lcccc|}
\hline & $\begin{array}{c}\mathrm{HI} \\
\text { before }\end{array}$ & $\begin{array}{c}\mathrm{HI} \\
\text { after }\end{array}$ & $\begin{array}{c}\mathrm{LI} \\
\text { before }\end{array}$ & $\begin{array}{c}\mathrm{LI} \\
\text { after }\end{array}$ \\
\hline $\mathrm{K}_{\text {itt }}$ & 0.0421 & 0.0560 & 0.0396 & 0.0438 \\
$\left(\log \mathrm{mM} \cdot \mathrm{min}^{-1}\right)$ & \pm 0.017 & $\pm 0.016^{*}$ & \pm 0.008 & \pm 0.012 \\
& \\
* denotes significant difference from pretraining value, $\mathrm{P}<0.01$.
\end{tabular}

Table 5.3: $\mathrm{K}_{\text {itt }}$ values (mean $\pm \mathrm{SD}$ )

relative to differences between higher values. Consequently, differences between the slopes of the regression lines will be more pronounced after logarithmic transformation. It should be noted that this effect is an artificial one, since it does not represent training induced changes, but is the result of a mathematical transformation.

Of the eighteen subjects tested before and after training, sixteen actually had an $\mathrm{IS}_{\text {index }}$ lower (indicating a higher insulin sensitivity) after training. Two subjects with a higher ${ } \mathrm{S}_{\text {index }}$ after training were both in the $\mathrm{LI}$ group. In our opinion, this indicates that the ITT is very well suited to measure differences in insulin sensitivity of the magnitude brought about by interventions such as that of the present study.

In conclusion, we have shown that insulin sensitivity can be improved by a four week training program in normal subjects, and that this improvement is exercise intensity specific, when exercise duration and frequency are kept equal. Furthermore, we have shown that the relatively easy to perform insulin tolerance test is sensitive enough for use in an intervention study. 


\section{References}

1. Akinmokun, A., P. L. Selby, K. Ramaiya, and K. G. Alberti. The short insulin tolerance test for determination of insulin sensitivity: a comparison with the euglycaemic clamp. Diabet-Med 9: 432-7, 1992.

2. Anderson, P. J., J. C. Chan, Y. L. Chan, B. Tomlinson, R. P. Young, Z. S. Lee, K. K. Lee, C. Metreweli, C. S. Cockram, and J. A. Critchley. Visceral fat and cardiovascular risk factors in Chinese NIDDM patients. Diabetes Care 20: 1854-8, 1997.

3. Bogardus, C., E. Ravussin, D. C. Robbins, R. R. Wolfe, E. S. Horton, and E. A. Sims. Effects of physical training and diet therapy on carbohydrate metabolism in patients with glucose intolerance and non-insulin-dependent diabetes mellitus. Diabetes 33: 311-8, 1984.

4. Bonora, E., P. Moghetti, C. Zancanaro, M. Cigolini, M. Querena, V. Cacciatori, A. Corgnati, and M. Muggeo. Estimates of in vivo insulin action in man: comparison of insulin tolerance tests with euglycaemic and hyperglycemic glucose clamp studies. J-ClinEndocrinol-Metab 68: 374-8, 1989.

5. Braun, B., M. B. Zimmermann, and $\mathrm{N}$. Kretchmer. Effects of exercise intensity on insulin sensitivity in women with non-insulindependent

diabetes mellitus. J Appl Physiol 78: 300-6, 1995.

6. DeFronzo, R. A. Lilly lecture 1987. The triumvirate: beta-cell, muscle, liver. A collusion responsible for NIDDM. Diabetes 37: 667-87, 1988.

7. DeFronzo, R. A., E. Jacot, E. Jequier, E. Maeder, J. Wahren, and J. P. Felber. The effect of insulin on the disposal of intravenous glucose. Results from indirect calorimetry and hepatic and femoral venous catheterization. Diabetes 30: 1000-7, 1981.
8. DeFronzo, R. A., R. S. Sherwin, and N. Kraemer. Effect of physical training on insulin action in obesity. Diabetes 36: 1379-85, 1987.

9. Dela, F., K. J. Mikines, M. von Linstow, N. H. Secher, and $\mathbf{H}$. Galbo. Effect of training on insulinmediated glucose uptake in human muscle. Am-J-Physiol 263: E113443, 1992.

10. Dela, F., T. Ploug, A. Handberg, L. N. Petersen, J. J. Larsen, K. J. Mikines, and $\mathbf{H}$. Galbo. Physical training increases muscle GLUT4 protein and mRNA in patients with NIDDM. Diabetes 43: 862-5, 1994.

11. Devlin, J. T., M. Hirshman, E. D. Horton, and E. S. Horton. Enhanced peripheral and splanchnic insulin sensitivity in NIDDM men after single bout of exercise. Diabetes 36: 434-9, 1987.

12. Durnin, J. V., and J. Womersley. Body fat assessed from total body density and its estimation from skinfold thickness: measurements on 481 men and women aged from 16 to 72 years. Br J Nutr 32: 77-97, 1974.

13. Gautier, J. F., A. Mourier, E. de Kerviler, A. Tarentola, A. X. Bigard, J. M. Villette, C. Y. Guezennec, and G. Cathelineau. Evaluation of abdominal fat distribution in noninsulin-dependent diabetes mellitus: relationship to insulin resistance. J Clin Endocrinol Metab 83: 1306-11, 1998.

14. Gelding, S. V., S. Robinson, S. Lowe, R. Niththyananthan, and D. G. Johnston. Validation of the low dose insulin tolerance test for evaluation of insulin sensitivity. Clin End 40: 611-615, 1994.

15. Grulet, H., V. Durlach, A. C. Hecart, A. Gross, and M. Leutenegger. Study of the rate of early glucose disappearance following insulin injection: insulin sensitivity index. Diabetes-Res-Clin-Pract 20: 201-7, 1993.

16. Helmrich, S. P., D. R. Ragland, R. W. Leung, and R. S. Paffenbar- 
ger, Jr. Physical activity and reduced occurrence of non-insulindependent diabetes mellitus. $N$ Engl-J-Med 325: 147-52, 1991.

17. Hirst, S., D. I. W. Phillips, S. K. Vines, P. M. Clark, and C. N. Hales. Reproducibility of the short insulin tolerance test. Diab Med 10: 839-842, 1993.

18. Ivy, J. L., B. A. Frishberg, S. W. Farrell, W. J. Miller, and W. M. Sherman. Effects of elevated and exercise-reduced muscle glycogen levels on insulin sensitivity. $J$ Appl Physiol 59: 154-9, 1985.

19. Kang, J., R. J. Robertson, J. M. Hagberg, D. E. Kelley, F. L. Goss, S. G. DaSilva, R. R. Suminski, and A. C. Utter. Effect of exercise intensity on glucose and insulin metabolism in obese individuals and obese NIDDM patients. Diabetes-Care 19: 341-9, 1996.

20. King, D. S., G. P. Dalsky, M. A. Staten, W. E. Clutter, D. R. Van Houten, and J. O. Holloszy. Insulin action and secretion in endurance-trained and untrained humans. J-Appl-Physiol 63: 2247-52, 1987.

21. Mikines, K. J., B. Sonne, P. A. Farrell, B. Tronier, and H. Galbo. Effect of physical exercise on sensitivity and responsiveness to insulin in humans. Am-J-Physiol 254: E248-59, 1988.

22. Price, T. B., G. Perseghin, A. Duleba, W. Chen, J. Chase, D. L. Rothman, R. G. Shulman, and G. I. Shulman. NMR studies of muscle glycogen synthesis in insulinresistant offspring of parents with non-insulin-dependent diabetes mellitus immediately after glycogen-depleting exercise. Proc Natl Acad Sci U S A 93: 5329-34, 1996.

23. Rey, R. H., L. D. Masnatta, D. Pirola, L. A. Cuniberti, C. Maceira, and J. P. Werba. [Re- peatability of insulin sensitivity estimation using the Minimal Model and comparison with a modified short low-dose insulin tolerance test]. Medicina B Aires 56: 650-6, 1996.

24. Seals, D. R., J. M. Hagberg, B. F. Hurley, A. A. Ehsani, and J. O. Holloszy. Endurance training in older men and women. I. Cardiovascular responses to exercise. $J$ Appl-Physiol 57: 1024-9, 1984.

25. Shriver, T. C., D. L. Schaulis, S. R. Thompson, R. L. Sharp, and D.

S. King. Effect of exercise intensity on glucose tolerance and insulin sensitivity. Med. Sci. Sports Exerc. 25: S76, 1993.

26. Tremblay, A., J. A. Simoneau, and C. Bouchard. Impact of exercise intensity on body fatness and skeletal muscle metabolism. Metabolism 43: 814-8, 1994.

27. Vettor, R., G. De Pergola, C. Pagano, P. Englaro, E. Laudadio, F. Giorgino, W. F. Blum, R. Giorgino, and G. Federspil. Gender differences in serum leptin in obese people: relationships with testosterone, body fat distribution and insulin sensitivity. Eur $J$ Clin Invest 27: 1016-24, 1997.

28. Wallberg Henriksson, H., J. Rincon, and J. R. Zierath. Exercise in the management of noninsulin-dependent diabetes mellitus. Sports Med 25: 25-35, 1998.

29. Young, J. C., J. Enslin, and B. Kuca. Exercise intensity and glucose tolerance in trained and nontrained subjects. J-Appl-Physiol 67: 39-43, 1989.

30. Zierath, J. R., and H. Wallberg Henriksson. Exercise training in obese diabetic patients. Special considerations. Sports-Med 14: 171-89, 1992. 


\section{No Effect of Training on Glucose Homeostasis}

\section{during Acute Exercise to Exhaustion}

in Type 2 Diabetes

L.B. Borghouts, H. Pijl, H. Kuipers, H.A. Keizer

\section{Summary}

We tested the hypothesis that in type 2 diabetes, exercise training results in augmentation of the presumed increase in plasma glucose during acute exhaustive exercise. Sedentary type 2 diabetes patients followed an exercise training program for one year, and were compared with a healthy control group and a sedentary type 2 diabetic control group. Neither the response of glucose, nor any of the associated hormones, was different between diabetes patients and control subjects at baseline. Training increased $\mathrm{VO}_{2} \max (47.6 \pm 8$ to $52.8 \pm 8 \mathrm{ml} / \mathrm{kgFFM} ; \mathrm{p}<0.05)$, but did not result in significant changes in glucose levels during exercise. Accordingly, responses of catecholamines, insulin and glucagon were unchanged after training. Glycosylated haemoglobin ( $\mathrm{HbA} 1 \mathrm{c}$ ) did not change in either type 2 diabetic group, fasting glucose decreased from $7.8 \pm 2$ to $6.0 \pm 2(p=0.054)$ in the training group. We conclude that 1 ) there is no difference in the glucoregulatory response to acute exercise to exhaustion between type 2 diabetic and healthy control subjects, and 2) physical training does not alter this response in type 2 diabetes patients. 
Substrate metabolism during exercise is dependent upon exercise duration, the individual's nutritional and training status, and most importantly upon exercise intensity. Despite increased glucose utilisation during exercise, blood glucose levels are usually tightly regulated during exercise in healthy individuals. Plasma glucose utilisation increases with exercise intensity, and accordingly the rate of appearance $(\mathrm{Ra})$ of glucose in blood increases (18) to match the increased rate of disappearance (Rd). In type 2 diabetes however, blood glucose declines during prolonged moderate intensity exercise $(16,17)$. This decline is probably caused by an increased glucose uptake from the blood by exercising skeletal muscle, due to the mass effect of hyperglycaemia, that is not balanced by liver glucose output $(5,10,16)$. Alternatively, it has been suggested that splanchnic glucose output is impaired, while glucose uptake in muscle is normal in type 2 diabetes (17). It has been suggested that during high intensity exercise (as opposed to low or moderate intensity exercise), plasma glucose levels increase in type 2 diabetes (13). This increase has been attributed to a disproportional increase of hepatic glucose production over peripheral uptake (13). Declining plasma insulin levels and an increase in adrenaline are probably the most important factors stimulating glucose production by the liver during intense exercise (11). Both these hormones have been reported to be increased during exhaustive exercise in type 2 diabetes (13), which would have opposite effects on blood glucose.

Type 2 diabetes patients are routinely advised to engage in low- to moderateintensity physical activity, since this has been shown to alleviate insulin resistance (9). It has recently been shown that in young, healthy individuals, high intensity exercise is more beneficial to insulin sensitivity than low intensity exercise (2). Given the possibility that blood glucose levels are transiently increased by high intensity exercise in type 2 diabetes, it is questionable whether these patients should be advised to participate in exercise training of such high intensity. This notion is further supported by the observation that endurance trained athletes have an increased glucose $\mathrm{Ra}$ and decreased glucose rate of disappearance (Rd) during exhaustive exercise, leading to elevated plasma glucose levels after cessation of exercise (12). This implies that in type 2 diabetes, exercise training may strengthen the blood glucose increasing effect of acute exhaustive exercise, through its effect on glucose production and clearance. We therefore investigated glucoregulation during exhaustive incremental exercise in a group of type 2 diabetes patients participating in a training intervention study of one year. We chose a prolonged period of training to be able to gradually build up training intensity and duration, and monitor possible long-term changes. 


\section{Materials and methods}

A group of type 2 diabetes patients followed a physical training program for 12 months (DT group). At the start and at 6 and 12 months thereafter, they performed an incremental bicycle ergometer test. The response to exhaustive exercise was compared with that of a healthy control group at baseline (C group), and with a non-training group of type 2 diabetes patients (DC group) before and after the intervention period.

Subjects Characteristics of the volunteers are given in table 6.1. Eleven type 2 diabetes patients were recruited at the Departments of Movement Sciences, Maastricht University, and Internal Medicine, University Hospital Maastricht, through an advertisement in a local newspaper. An age and body composition matched type 2 diabetes control group $(n=7)$ was recruited according to the same in- and exclusion criteria at the Dept. of Internal Medicine of the University Hospital Leiden. These patients were to serve as a non-training control group. In addition, 6 body composition matched, healthy male subjects were recruited as a pre-training control group. These groups underwent tests exactly similar to the type 2 diabetes group who were to follow the training program, at the start and end of the intervention period. Further details of subject recruitment can be found in chapter 3 .

Incremental bicycle ergometer test Please refer to chapter 3 for details.

Blood sampling Please refer to chapter 3 for details.

Sample analysis Please refer to chapter 3 for details.

Training intervention Please refer to chapter 3 for details.

Statistical analysis All data was tested for Normal distribution. Basal measurements between two groups were compared with Student's t-test for unpaired data or in the case of non-Normally distributed data with Wilcoxons signed ranks test. When multiple t-tests were applied within one measurement, a Bonferroni correction for the level of significance was made. Measurements between all three groups were compared with two-way analysis of variance (ANOVA) or Friedman's ANOVA for non-Normally distributed data. The effect of training on the responses to exercise was evaluated with ANOVA for repeated measurements.

\begin{tabular}{|lccc|}
\hline & DT & DC & C \\
\hline Age (yr.) & $54 \pm 7$ & $47 \pm 7$ & $47 \pm 5^{\mathrm{a}}$ \\
Body mass (kg) & $85.7 \pm 10$ & $81.7 \pm 17$ & $77.6 \pm 12$ \\
Body fat (\%) & $31 \pm 5^{\mathrm{a}}$ & $25 \pm 9$ & $19 \pm 4$ \\
VO2max (ml/kgFFM) & $47 \pm 8$ & $41 \pm 8$ & $48 \pm 12$ \\
Fasting glucose (mM) & $7.3 \pm 1^{\mathrm{a}}$ & $10.5 \pm 2^{\mathrm{a}}$ & $4.8 \pm 0.2$ \\
Fasting insulin ( $\mu \mathrm{U} / \mathrm{ml})$ & $6 \pm 2$ & $11 \pm 7$ & $3.6 \pm 1^{\mathrm{b}}$ \\
Hba1c (\%) & $6.8 \pm 0.9$ & $7.1 \pm 0.4$ & - \\
Data are mean \pm SD; ${ }^{\text {a }}$ significantly different from C; & \\
bignificantly different from DC; FFM = fat free mass & \\
& & \\
\hline
\end{tabular}

Table 6.1: Subject characteristics. 


\section{Results}

Before training, body weight was similar in all groups, but body fat was lower in $C$ than in DT (table 6.1). The C group was slightly younger than DT, the difference with DC was borderline non-significant. Glucose levels were significantly elevated in D and DC groups compared to C. Insulin in DT and DC was elevated compared to $C$, but this difference reached significance between $D C$ and $\mathrm{C}$ only. There was no significant difference in C-peptide levels between groups. Initial exercise testing There were no significant differences in $\mathrm{VO}_{2} \max$ between groups (table 6.1). Maximum lactate values were $8.6 \pm 1.8,8.4 \pm 1.6$ and $6.5 \pm$ $2.2 \mathrm{mM}$ in DT, DC and C groups, respectively (NS between groups). Blood glucose did not change significantly in any of the three groups during exercise. Catecholamine levels increased during exercise. There were no significant differences in catecholamine levels between groups, except for maximal noradrenaline levels being higher in DT than DC (5414 \pm 1121 vs. $2608 \pm 1114$ $\mathrm{pg} / \mathrm{ml} ; \mathrm{p}<0.05$ ). Insulin decreased significantly during exercise in DT (from 6.34 \pm 2.3 to $2.54 \pm 1.9 \mu \mathrm{U} / \mathrm{ml} ; \mathrm{p}<0.05)$, and decreased but not significantly in DC (from $13.06 \pm 8.2$ to $10.99 \pm 5.3 \mu \mathrm{U} / \mathrm{ml}, \mathrm{p}=0.38$ ). The insulin response to exercise in C was highly variable (an increase in 3 subjects, no change in one, a decrease in 2 subjects). Mean insulin did not change in $\mathrm{C}$ during exercise. Cpeptide did not change during exercise in any group. Basal glucagon was increased in both diabetic groups compared to C $(23 \pm 4$ in DT, $24 \pm 11$ in DC vs. $15 \pm 3$ in C). In none of the groups did glucagon change significantly during exercise.

Training adaptations Mean training duration increased from $71 \pm 32$ to $125 \pm$ 112 minutes per week from 6 to 12 months $(p<0.05)$. Corresponding training frequency was $1.9 \pm 0.4$ and $2.1 \pm 0.5$ sessions per week (NS). The large standard deviations in training duration were largely caused by one person riding up to $7 \mathrm{~h}$ per week on a road racing bicycle. Training (DT group) did not change body weight, but body fat percentage declined significantly from $30.0 \pm$ $5 \%$ to $27.9 \pm 4 \%(\mathrm{p}<0.01)$ and accordingly fat free mass increased significantly (from $59.7 \pm 5 \mathrm{~kg}$ to $61.1 \pm 5 \mathrm{~kg}$ ). $\mathrm{VO}_{2}$ max per $\mathrm{kg}$ fat free mass was increased significantly after training (table 6.2). Glycosylated haemoglobin ( $\mathrm{HbA1c}$ ) was

\begin{tabular}{|lccc|}
\hline & Basal & 6 months & 12 months \\
\hline $\mathrm{VO}_{2}$ max $(\mathrm{ml} / \mathrm{kgFFM})$ & $47.6 \pm 8$ & $50.9 \pm 9$ & $52.8 \pm 8^{\mathrm{a}}$ \\
Wmax $(\mathrm{W})$ & $219 \pm 31$ & $231 \pm 36^{\mathrm{a}}$ & $230 \pm 45^{\mathrm{a}}$ \\
Fasting glucose $(\mathrm{mM})$ & $7.8 \pm 2$ & $7.7 \pm 3$ & $6.0 \pm 2^{\mathrm{b}}$ \\
Fasting insulin $(\mu \mathrm{U} / \mathrm{ml})$ & $6 \pm 2$ & $7 \pm 4$ & $6 \pm 3$ \\
Fasting glucagon $(\mathrm{pg} / \mathrm{ml})$ & $24 \pm 4$ & $26 \pm 6$ & $23 \pm 7$ \\
$\mathrm{HbA1c}(\%)$ & $6.8 \pm 0.9$ & $7.1 \pm 1.0$ & $7.1 \pm 0.9$ \\
\hline
\end{tabular}

Table 6.2: Training associated values of exercise performance and glucoregulation in DT. 


\section{Glucose}

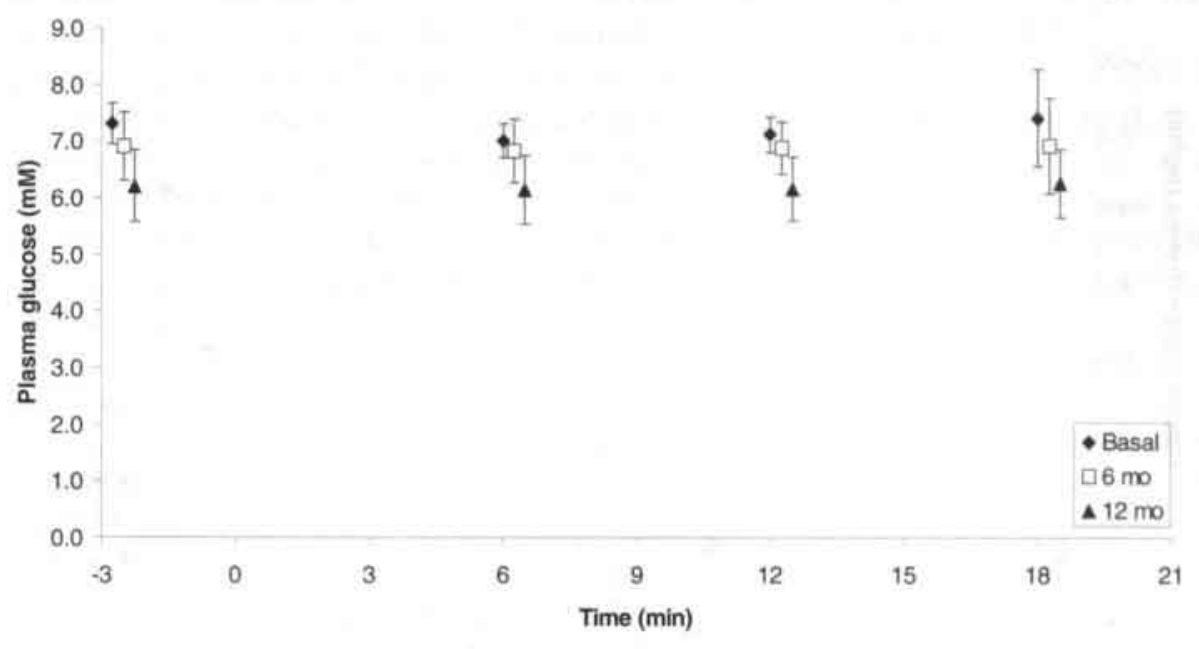

Insulin

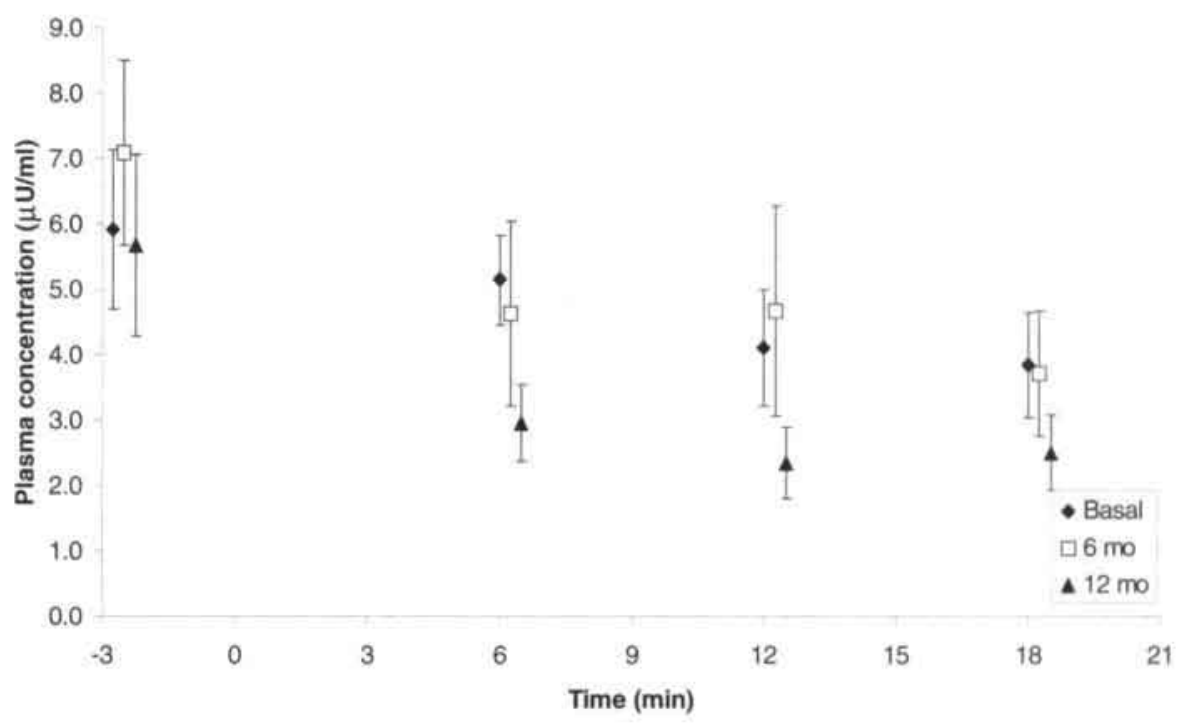

Figure 6.1: Plasma glucose and insulin during exercise (mean \pm SEM) before, after 6 months, and after 12 months of training in DT-group. 


\section{Adrenaline}

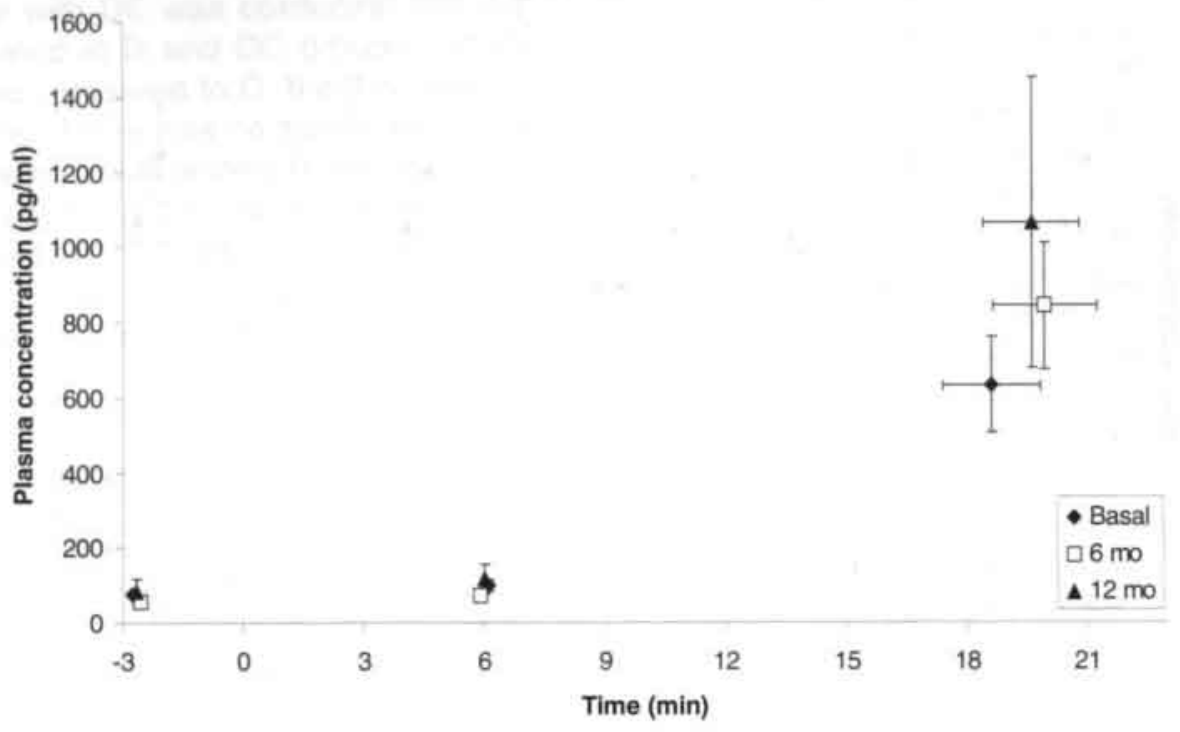

Noradrenaline

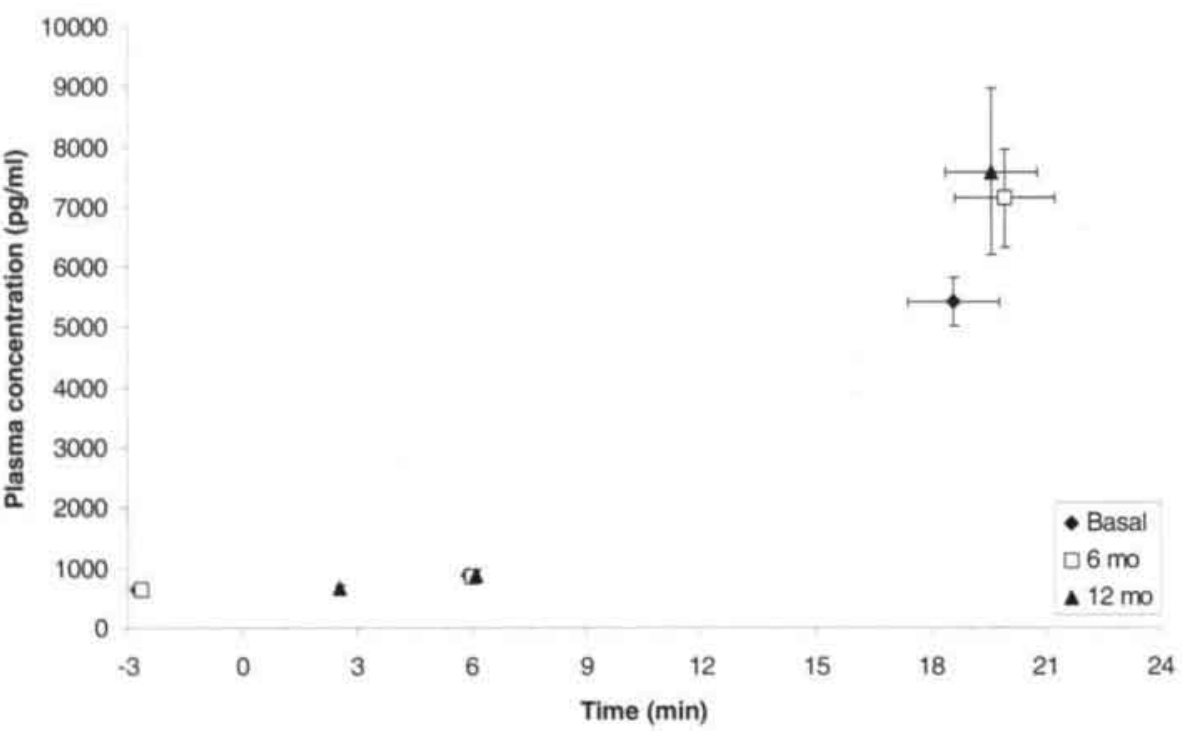

Figure 6.2: Plasma adrenaline and noradrenaline responses (mean \pm SEM) during exercise before, after 6 months, and after 12 months of training in DTgroup. 
not changed after training (table 6.2). Training did not change basal or exercise associated levels of glucose, insulin, glucagon (table 6.2; figure 6.1), C-peptide, adrenaline and noradrenaline (figure 6.2), albeit that the decrease in fasting glucose was on the borderline of significance. Plasma lactate response to exercise was altered by training, this change was attributable to a significant increase $(\mathrm{P}<0.01)$ in maximal lactate values after one year of training.

Control group re-test $\mathrm{VO}_{2}$ max per $\mathrm{kg}$ fat free mass was unaltered in DC $(41 \pm 2$ and $41 \pm 0 \mathrm{ml} / \mathrm{kg}$ respectively). Body weight increased from $81.7 \pm 16$ to $85.8 \pm$ $16 \mathrm{~kg}(\mathrm{p}=0.044)$. This increase was attributable to an increase in fat mass. Fat free mass did not change in DC. Basal and exercise associated values of glucose, insulin, C-peptide, glucagon, and catecholamines did not change in DC over the intervention period. Hba1c did not change significantly either $(7.1 \pm 1.4$ to $6.8 \pm 0.6 \%$ ).

\section{Discussion}

In the present study, we found no difference in the glucoregulatory response to exhaustive exercise between type 2 diabetic patients and healthy control subjects. Physical training did not alter this response in the type 2 diabetic patients. Plasma glucose concentration during high intensity exercise has been reported to increase in normal subjects, (12) and even more so in type 2 diabetes patients (13), although this has not been extensively studied in either group. This increase has been attributed to an increased rate of glucose appearance ( $\mathrm{Ra}$ ) relative to the rate of disappearance $(R d)$. However, it is uncertain whether the tracer methodology required to establish glucose kinetics can be applied during exhaustive exercise, given its extreme non-steady state nature (22). Furthermore, it has been demonstrated that trained athletes have an exaggerated rise of plasma glucose $(4,12)$ during intensive exercise which has been ascribed to a lower glucose $\mathrm{Rd}(4)$ or a higher glucose $\mathrm{Ra}$ (12). We hypothesised that if plasma glucose rises more strongly during high-intensity exercise in type 2 diabetic patients than in the healthy population, then physical training could strengthen this response. If this would be the case, plasma glucose during exercise in trained type 2 diabetes patients would rise disproportionally and cause a temporary aggravation of hyperglycaemia. Consequently, frequent exhaustive exercise would be inadvisable in this group.

However, in the present study, acute exhaustive bicycle exercise did not change plasma glucose in healthy nor in type 2 diabetes subjects, as opposed to findings of some earlier studies $(12,13)$, but in agreement with the results of Coggan in healthy, untrained subjects (4). Apparently, utilisation and production of plasma glucose during exercise were effectively balanced. A recent study by Larsen et al. (14) also suggested that plasma glucose levels are not increased by intense exercise in type 2 diabetes, but this finding was attributed to the fact that subjects were studied under postprandial conditions. In the present study, subjects were fasted, but still there was no increase in plasma glucose during exercise in neither type 2 diabetic patients, nor healthy controls.

Catecholamines, glucagon and insulin all influence plasma glucose Ra and Rd, of which insulin and adrenaline are probably the most potent blood glucose regulators during exercise. Growth hormone, ACTH, and cortisol are not considered to be important for acute regulation of plasma glucose levels (3). Splanchnic glucose production is stimulated by catecholamines, and as ex- 
pected, adrenaline and noradrenaline rose during exercise in all groups. Insulin was unaffected by acute exercise in the healthy control group, but declined in DT. In our view, the latter should not be taken to represent a unique feature of type 2 diabetes during exhaustive exercise, since in DC, insulin did not change significantly during exercise, even though basal insulin was even higher in DC than DT. Plasma glucagon levels were not affected by acute exercise in any of the groups.

Plasma glucagon and insulin concentrations in response to acute exercise did not change after training. This is in accordance with previous studies comparing athletes with sedentary subjects $(4,12,21)$. In addition, there was no evidence of increased responsiveness of the adrenal medulla after training: the catecholamine responses were similar before and after training. This finding is in apparent contrast to the results of studies demonstrating that trained subjects and untrained subjects differ in their response to exercise $(1,6,15)$. However, Deuster (6) demonstrated that trained subjects have noradrenaline and adrenaline levels lower than those of untrained subjects at the same absolute exercise intensity, but similar levels when tested at the same relative exercise intensity $\left(\% \mathrm{VO}_{2} \max \right)$. Our subjects were tested according to a protocol with the same initial power output and stepwise increase at every occasion. Therefore, the absolute exercise intensity was identical at submaximal stages before and after training. Submaximal adrenaline and noradrenaline levels were measured after the second exercise step, which averaged $100 \pm 7 \mathrm{~W}$. If we express this relative to the maximal power output before $(219 \pm 31 \mathrm{~W})$ and after one year of training $(230 \pm 45 \mathrm{~W})$, the relative submaximal intensities were 46 and $44 \%$, respectively, which is obviously a negligible difference. Thus, although the maximal power output was significantly improved as a result of training, this did not result in the same submaximal workload being of a significantly lower relative exercise intensity. Given the observation that hormonal responses during exercise are not affected by training, when relative exercise intensities are equal (6), this makes a large shift in hormonal responses unlikely. Effects of training are often studied in cross-sectional studies between highly trained and untrained subjects. Consequently, the differences in $\mathrm{VO}_{2} \max$ between groups are rather large. Such differences are unattainable in training intervention studies, even if they are as long-term as the present study.

The training intervention did not bring about changes in blood glucose control as assessed by $\mathrm{HbA1c}$ levels. Since the exercise training performed was quite strenuous, this indirectly underscores our conclusion that training of high intensity in type 2 diabetes patients does not adversely affect glucose homeostasis over a prolonged period. On the other hand, $\mathrm{HbA1c}$ levels were not improved either by the training program. However, given that the subjects were in good glycaemic control at the start of the study ( $\mathrm{HbA1c}$ of $6.8 \%$ ), this is not surprising. Studies that have demonstrated a beneficial effect of training on $\mathrm{HbA1c}$ have done so in subjects that were considerably less well-controlled $(19,20)$.

In conclusion, in the present study, we find no evidence for the hypothesis that strenuous exercise could have a deleterious effect on blood glucose control in patients with type 2 diabetes, nor that this effect could be invoked or strengthened by endurance training. The hormonal responses to exercise are no different in type 2 diabetes patients than in the healthy population, and long-term endurance training does not change these responses. 
References

1. Bloom, S. R., R. H. Johnson, D. M. Park, M. J. Rennie, and W. R. Sulaiman. Differences in the metabolic and hormonal response to exercise between racing cyclists and untrained individuals. J-Physiol-Lond 258: 1-18, 1976.

2. Borghouts, L. B., K. Backx, M. F. Mensink, and H. A. Keizer. Effect of exercise intensity on insulin sensitivity as evaluated by insulin tolerance test. Eur J Appl Physiol 80: 461-66, 1999.

3. Clutter, W. E., R. A. Rizza, J. E. Gerich, and P. E. Cryer. Regulation of glucose metabolism by sympathochromaffin catecholamines. Diabetes Metab Rev 4: 1-15, 1988.

4. Coggan, A. R., C. A. Raguso, B. D. Williams, L. S. Sidossis, and A. Gastaldelli. Glucose kinetics during high-intensity exercise in endurance-trained and untrained humans. J-Appl-Physiol 78: 1203-7, 1995.

5. Colberg, S. R., J. M. Hagberg, S. D. McCole, J. M. Zmuda, P. D. Thompson, and D. E. Kelley. Utilization of glycogen but not plasma glucose is reduced in individuals with NIDDM during mild-intensity exercise. J-Appl-Physiol 81: 2027 33, 1996.

6. Deuster, P. A., G. P. Chrousos, A. Luger, J. E. DeBolt, L. L. Bernier, U. H. Trostmann, S. B. Kyle, L. C. Montgomery, and D. L. Loriaux. Hormonal and metabolic responses of untrained, moderately trained, and highly trained men to three exercise intensities. Metabolism 38: 141-8, 1989.

7. Durnin, J. V., and J. Womersley. Body fat assessed from total body density and its estimation from skinfold thickness: measurements on 481 men and women aged from 16 to 72 years. $B r J$ Nutr 32: 77-97, 1974.

8. Gutmann, I., and A. W. Wahlefeld. L-(+)-Lactate, determination with lactate dehydrogenase and NAD. In: Methods in enzymatic analysis (2nd ed. ed.), edited by H. U. Bergmeyer.
New York: Academic Press, 1974, p. 1464-1468.

9. Ivy, J. L. Role of exercise training in the prevention and treatment of insulin resistance and non-insulindependent diabetes mellitus. Sports Med 24: 321-36, 1997.

10. Kang, J., D. E. Kelley, R. J. Robertson, F. L. Goss, R. R. Suminski, A. C. Utter, and S. G. Dasilva. Substrate utilization and glucose turnover during exercise of varying intensities in individuals with NIDDM. Med-Sci-Sports-Exercise 31: 82-89, 1999.

11. Kjaer, M. Hepatic glucose production during exercise. In: Skeletal muscle metabolism in exercise and diabetes, edited by E. A. e. a. Richter. New York: Plenum Press, 1998, p. 117-127.

12. Kjaer, M., P. A. Farrell, N. J. Christensen, and H. Galbo. Increased epinephrine response and inaccurate glucoregulation in exercising athletes. J-Appl-Physiol 61 : 1693-1700, 1986.

13. Kjaer, M., C. B. Hollenbeck, B. Frey Hewitt, H. Galbo, W. Haskell, and G. M. Reaven. Glucoregulation and hormonal responses to maximal exercise in non-insulin-dependent diabetes. J-Appl-Physiol 68: 2067 74, 1990.

14. Larsen, J. J. S., F. Dela, S. Madsbad, and H. Galbo. The effects of intense exercise on postprandial glucose homeostasis in type II diabetic patients. Diabetologia 42: 1282-1292, 1999.

15. Lehmann, M., J. Keul, G. Huber, and M. Da Prada. Plasma catecholamines in trained and untrained volunteers during graduated exercise. Int-J-Sports-Med 2: 143-7, 1981.

16. Martin, I. K., A. Katz, and J. Wahren. Splanchnic and muscle metabolism during exercise in NIDDM patients. Am-J-Physiol 269: E583-90, 1995.

17. Minuk, H. L., M. Vranic, E. B. Marliss, A. K. Hanna, A. M. Albisser, and B. Zinman. Glucoregula- 
tory and metabolic response to exercise in obese noninsulindependent diabetes. Am J Physiol 240: E458-64, 1981.

18. Romijn, J. A., E. F. Coyle, L. S. Sidossis, A. Gastaldelli, J. F. Horowitz, E. Endert, and R. R. Wolfe. Regulation of endogenous fat and carbohydrate metabolism in relation to exercise intensity and duration. Am-J-Physiol 265: E380-91, 1993.

19. Schneider, S. H., L. F. Amorosa, A. K. Khachadurian, and N. B. Ruderman. Studies on the mechanism of improved glucose control during regular exercise in type 2 (non-insulin-dependent) diabetes. Diabetologia 26: 355-60, 1984.
20. Trovati, M., Q. Carta, F. Cavalot, S. Vitali, C. Banaudi, P. G. Lucchina, F. Fiocchi, G. Emanuelli, and G. Lenti. Influence of physical training on blood glucose control, glucose tolerance, insulin secretion, and insulin action in non-insulindependent diabetic patients. Diabetes Care 7: 416-20, 1984.

21. Wirth, A., C. Diehm, H. Mayer, H. Morl, I. Vogel, P. Bjorntorp, and G. Schlierf. Plasma C-peptide and insulin in trained and untrained subjects. J-Appl-Physiol 50: 71-7, 1981.

22. Wolfe, R. R. Radioactive and stable isotope tracers in biomedicine: principles and practice of $\mathrm{ki}$ netic analysis. New York: WileyLiss, Inc., 1992. 


\section{Effects of Long-Term Physical Training}

\section{on Type 2 Diabetes}

\section{Chapter}

L.B. Borghouts, G.P.J. van Kranenburg, H. Pij,

G. Schaart, H. Kuipers, H.A. Keizer.

\section{Summary}

To study the effects of long-term training on insulin responsiveness and muscle metabolism in type 2 diabetes, 12 patients started a two-year endurance training program. Nine patients completed the entire program. To investigate the feasibility of inducing a more active life-style in this group, training supervision was minimised during the second year. This caused the mean training duration per week to decrease to $~ 50 \%$ of its amount after the first year. Insulin responsiveness was increased $27 \%$ after one year of training, but had returned to pre-training levels after the second year. The expression of GLUT-4 protein in vastus lateralis muscle paralleled this biphasic pattern, as did muscle citrate synthase activity, cytoplasmic fatty acid binding protein, and the plasma total cholesterol/HDL-cholesterol ratio. Muscle 3-hydroxyacyl-CoA dehydrogenase, fasting insulin, and glycosylated haemoglobin were not altered by training. We conclude that long-term training has profound effects on insulin responsiveness and muscle metabolism, but that a certain minimal amount of training is required to sustain these effects. In the present study, this amount was not maintained without training supervision. 
From the literature overviewed in chapter 2, it can be concluded that physical exercise is an important cornerstone in the treatment and prevention of insulin resistance. Large-scale epidemiological studies have shown that the level of physical activity is associated with the incidence of type 2 diabetes $(11,17,32)$. Indeed, the risk for developing type 2 diabetes in women who engage in exercise at least once a week has been estimated to be $33 \%$ lower than for their sedentary counterparts (32). Cross-sectional studies have shown that trained subjects are more insulin sensitive than untrained subjects $(16,26,29,45)$ and that, although ageing is associated with declining insulin sensitivity (IS), endurance trained elderly subjects are more insulin sensitive than young, sedentary subjects (40). Training intervention studies directed toward populations with impaired insulin sensitivity have generally found beneficial effects of physical training on insulin sensitivity (measured with glucose clamp studies) $(2,8,46)$, oral glucose tolerance $(19,28,35)$ and metabolic control (as indicated by $\mathrm{HbA} 1 \mathrm{c}$ levels) $(38,42)$. However, none of these parameters have been found to change to levels found in healthy, non-diabetic subjects. This indicates that the applied exercise programs have not been able to fully overcome or compensate insulin resistance.

Skeletal muscle is responsible for the major part of insulin stimulated glucose uptake (5), and it is the most important site of insulin resistance in type 2 diabetes (4). Training-induced adaptations of skeletal muscle include increases in GLUT-4 protein content (9), insulin stimulated GLUT-4 translocation (13), muscle blood flow $(1,12)$, and enzyme capacities of glucose metabolism (1, 18). In addition, endurance exercise training can increase the muscle's ability to take up and metabolise fatty acids $(3,36)$. Muscle free fatty acid uptake and oxidation have been shown to be impaired in type 2 diabetes under resting conditions (23).

Although the above-mentioned effects of physical training warrant the conclusion that type 2 diabetic patients should be encouraged to participate in regular exercise training, not all reports hereof are favourable. Adherence to long-term (>3 month) exercise programs has been suggested to be poor (39), and the feasibility of such programs in type 2 diabetes patients has been questioned (41). Indeed, studies into the mechanisms underlying physical exercise-induced improvements in insulin sensitivity have almost exclusively applied short-term training interventions, or cross-sectional designs. Therefore, data about training of long duration in type 2 diabetic patients is scarce.

In the present study, type 2 diabetes patients followed a physical training program for two years. This enabled us to study long-term effects of training on insulin responsiveness, as measured by hyperinsulinaemic glucose clamp. The effects of the prolonged exercise training on several indicators of skeletal muscle metabolism was monitored by taking half-yearly muscle biopsies. Since the long-term compliance of these patients to a training program has been sug- 
gested to be poor, the participants in the study were coached intensively during the first year of the intervention. However, in the second year supervision was strongly reduced, to examine whether the more active life-style could be maintained.

\section{Materials and Methods}

Subjects 12 sedentary male, moderately obese type 2 diabetes patients (WHO criteria), aged 45-65 yr., were recruited after they had responded to an advertisement in a local newspaper. All gave their written consent to participate in this study, which was approved by the Medical Ethics Committee of Maastricht University and Maastricht University Hospital. Mean ( \pm SD) time since diagnosis of type 2 diabetes was $2.5 \pm 1.5 \mathrm{yr}$. Further procedures regarding subject recruitment have been described in chapter 3 . Of the 12 men included at the start of the project, 9 completed the full 2 year training intervention. Three men dropped-out during the first six months of the intervention, because of reported lack of time. This paper will further report the data of the 9 persons who complied to the 2 year program.

Incremental bicycle test At the start of the study and every half year thereafter, a maximal bicycle test was performed by all subjects. Procedures of this test have been described in Chapter 3.

Muscle sample analysis Muscle was analysed for citrate synthase (CS), 3hydroxyacyl-CoA dehydrogenase (HAD), cytosolic fatty acid-binding protein (FABPc) and GLUT-4 protein content. Procedures of these analyses have been described in Chapter 3.

The hyperinsulinaemic euglycaemic clamp A hyperinsulinaemic euglycaemic clamp was performed at the start of the project, and repeated after one and two years of physical training. The procedures of the hyperinsulinaemic euglycaemic clamp have been described in Chapter 3.

Blood sample analysis Blood was analysed for $\mathrm{HbA1c}$, glucose, insulin. Procedures of blood sample analyses have been described in Chapter 3.

Training program: Subjects included in the training intervention followed an endurance training program based on individual maximal heart rate as determined in the incremental bicycle ergometer tests. The training program has been described in Chapter 3. Table 7.1 gives an indication of the training actu-

\begin{tabular}{|lcccc|}
\hline & $0-6 \mathrm{mo}$ & $6-12 \mathrm{mo}$ & $12-18 \mathrm{mo}$ & $18-24 \mathrm{mo}$ \\
\hline Minutes per week & $74 \pm 35$ & $149 \pm 133$ & $120 \pm 80$ & $118 \pm 111$ \\
Sessions per week & $1.9 \pm 0.4$ & $2.2 \pm 0.6$ & $2.0 \pm 0.5$ & $1.8 \pm 0.4$ \\
HR>85\% HRmax & $44.2 \pm 16$ & $41.3 \pm 11$ & $46.5 \pm 16$ & $48.0 \pm 18$ \\
$\begin{array}{l}\text { (\% of training time) } \\
\text { HR }>95 \% \text { HRmax } \\
(\% \text { of training time })\end{array}$ & $2.5 \pm 3$ & $4.8 \pm 9$ & $4.9 \pm 6$ & $5.1 \pm 9$ \\
\hline
\end{tabular}

Table 7.1: Training data. 
ally performed by the subjects in the course of the present study. In each column, data is presented for the respective 6 month-training periods, calculated from three training diaries per period per subject.

Statistical analysis: Measurements taken half-yearly were analysed with analysis of variance for repeated measurements. Data for citrate synthase, HAD and FABPc had a non-normal distribution, and therefore Friedman's two way analysis of variance was applied. When significant changes over time were detected, where indicated, data of the one- and two-year measurements were compared with baseline measurements using paired t-tests (or Wilcoxon matched pairs signed rank sum test for non-normally distributed data). When within one variable repeated paired comparisons were made, a Bonferroni correction for the level of significance was applied. The level of significance was set at $p<0.05$.

\section{Results}

Given the outline of our training intervention, we analysed the training diaries (covering 2 months) prior to the clamps at 12 and 24 months. This showed that during the second year, when training supervision was decreased, training duration progressively declined. In other words, mean training duration per week was significantly higher $(\mathrm{p}<0.01)$ in the 2 months preceding the glucose clamp at 12 months $(161 \pm 118 \mathrm{~min})$ than in the 2 months preceding the glucose clamp at 24 months (104 $\pm 103 \mathrm{~min}$ ). The large standard deviations with these data are mainly caused by one subject who rode large distances on a road racing bike (up to $400 \mathrm{~min} /$ week). When this subject was excluded, mean training duration was $117 \pm 48$ and $63 \pm 22 \mathrm{~min}$, respectively. During the second year, contrary to training duration, training intensity and frequency did not change significantly from the first year.

Body weight of the subjects did not change significantly over time (table 7.2). Body fat decreased $(p<0.05)$, while the increase in lean body mass was not significant $(p=0.08)$. Mean maximal power output changed significantly by training and remained fairly stable after an initial increase at 6 months (table 7.3). This pattern was identical for maximal oxygen uptake, which increased approximately $15 \%$ during the training program $(\mathrm{p}<0.05)$.

Basal insulin was $9.4 \pm 8.5 \mu \mathrm{U} / \mathrm{ml}$ (normal range $5-15 \mu \mathrm{U} / \mathrm{ml}$ ) and did not change significantly during the training intervention. Mean insulin during the hyperinsulinaemic clamp was $1190 \pm 540 \mu \mathrm{U} / \mathrm{ml}$, mean plasma glucose was 5.1 $\pm 0.2 \mathrm{mmol} / \mathrm{l}$, with no significant differences between clamps at baseline, 12 and 24 months. Insulin stimulated glucose uptake (ISGU) as measured during the

\begin{tabular}{|c|c|c|c|c|}
\hline & Baseline & 12 months & 24 months & Change \\
\hline Weight (kg) & $81.9 \pm 13$ & $83.1 \pm 11$ & $83.1 \pm 13$ & $=$ \\
\hline Fat $\%$ & $28.7 \pm 7$ & $27.7 \pm 4$ & $26.4 \pm 4$ & - \\
\hline LBM (kg) & $57.9 \pm 6$ & $60.2 \pm 6$ & $61.1 \pm 6$ & $=$ \\
\hline
\end{tabular}

Table 7.2: Body composition. 
clamp was increased $27 \%$ after 12 months $(p \leq 0.01)$ but had returned to levels similar to baseline after 24 months. Glycosylated haemoglobin (Hba1c) levels were within well-controlled ranges at the outset of the study and did not change significantly over time, and neither did fasting glucose values. However, medication was decreased in several subjects, and was unchanged in the remaining subjects. Further information regarding use of medication is presented in the next chapter. There was a notable similarity in the pattern of GLUT-4 expression in vastus lateralis muscle and ISGU. In all subjects GLUT-4 and M were increased after one year, and during the second year GLUT-4 protein levels paralleled the fluctuation in ISGU (figure 7.1). Table 7.5 shows data for muscle enzyme capacity and FABPc levels. FABPc increased during the first year $(p<0.01)$. After 24 months, FABPc levels were still increased compared to basal, however again the trend was a decline during the second year. CS was significantly increased after 12 and 18 months, but not after 24 months. HAD levels were unchanged in the course of training. Data of plasma lipids are presented in table 7.6. Total plasma cholesterol, low-density lipoprotein cholesterol (LDL-C), and total plasma triglycerides were not significantly altered during the training program. However, high-density lipoprotein cholesterol (HDL-C) was increased $(p<0.05)$ after 24 months.

\begin{tabular}{|lcccccc|}
\hline & Baseline & $6 \mathrm{mo}$ & $12 \mathrm{mo}$ & $18 \mathrm{mo}$ & $24 \mathrm{mo}$ & Change \\
\hline $\mathrm{Wmax}(\mathrm{W})$ & $213 \pm 41$ & $232 \pm 37$ & $230 \pm 46$ & $246 \pm 55$ & $234 \pm 48$ & + \\
$\mathrm{VO}_{2} \max$ & $2.7 \pm 0.6$ & $3.2 \pm 0.5$ & $3.1 \pm 0.6$ & $3.1 \pm 0.6$ & $3.0 \pm 0.7$ & + \\
$(\mathrm{l} / \mathrm{min})$ & & & & & \\
$\mathrm{VO}_{2} \mathrm{max}$ & $33.7 \pm 7$ & $38.9 \pm 7$ & $37.8 \pm 8$ & $37.5 \pm 7$ & $36.9 \pm 8$ & + \\
$\left(\mathrm{ml} \cdot \mathrm{kg} \cdot \mathrm{min}^{-1}\right)$ & & & & & \\
\end{tabular}

Table 7.3: Maximal power output and maximal oxygen uptake.

\begin{tabular}{|lcccccc|}
\hline & Baseline & 6 mo & 12 mo & 18 mo & 24 mo & Change \\
\hline Fasting insulin & 9.4 & 7.0 & 6.9 & 6.7 & 7.3 & $=$ \\
$(\mu \mathrm{U} / \mathrm{ml}$ & \pm 8 & \pm 4 & \pm 3 & \pm 5 & \pm 5 & \\
$\mathrm{M}$ & 7.42 & & 9.44 & & 6.91 & $\mathrm{n} . \mathrm{a}$. \\
$\left(\mathrm{mg} \cdot \mathrm{kg} \cdot \mathrm{min}^{-1}\right)$ & \pm 1.6 & & $\pm 0.9^{*}$ & & $\pm 1.9^{\text {ns }}$ & \\
$\mathrm{Hba1c}(\%)$ & 6.6 & 6.9 & 6.9 & 7.3 & 7.0 & $=$ \\
\multicolumn{7}{c}{ denotes a significant difference from baseline ( $\mathrm{p}<0.01)$; n.s. denotes no signifi- } \\
cant difference from baseline; = denotes no significant change in time from base- \\
line; n.a. not applicable. M: whole-body glucose uptake. \\
\hline
\end{tabular}

Table 7.4: Fasting insulin, whole body glucose uptake and meta- 
Chapter 7

\begin{tabular}{|c|c|c|c|c|c|c|}
\hline & Baseline & $6 \mathrm{mo}$ & $12 \mathrm{mo}$ & $18 \mathrm{mo}$ & $24 \mathrm{mo}$ & Change \\
\hline \multirow[t]{2}{*}{ CS } & 0.40 & 0.51 & 0.53 & 0.55 & 0.44 & + \\
\hline & \pm 0.12 & \pm 0.22 & $\pm 0.23^{\circ}$ & \pm 0.30 & $\pm 0.18^{n s}$ & \\
\hline \multirow[t]{2}{*}{ HAD } & 0.35 & 0.38 & 0.38 & 0.39 & 0.32 & $=$ \\
\hline & \pm 0.06 & \pm 0.12 & \pm 0.09 & \pm 0.16 & \pm 0.13 & \\
\hline \multirow[t]{2}{*}{ FABPC } & 6.1 & 7.7 & 10.6 & 11.0 & 9.9 & + \\
\hline & \pm 1.8 & \pm 3.1 & $\pm 3.7^{*}$ & \pm 4.8 & $\pm 3.2^{*}$ & \\
\hline \multicolumn{7}{|c|}{$\begin{array}{l}\text { All parameters expressed as } \mu \mathrm{g} / \mathrm{mg} \text { protein; "denotes a significant difference from } \\
\text { baseline }(p<0.01) ; n . s \text {. denotes no significant difference from baseline; }+ \text { denotes } \\
\text { significant increase in time from baseline; = denotes no significant change in time } \\
\text { from baseline. }\end{array}$} \\
\hline
\end{tabular}

Table 7.5: Muscle enzymes and FABPc.

\begin{tabular}{|lcll|}
\hline & Baseline & $12 \mathrm{mo}$ & $24 \mathrm{mo}$ \\
\hline Total Cholesterol & $5.55 \pm 1.38$ & $5.63 \pm 0.99$ & $6.08 \pm 1.32$ \\
HDL-C (mmo//) & $0.78 \pm 0.20$ & $0.85 \pm 0.26$ & $1.04 \pm 0.31^{*}$ \\
LDL-C (mmol//) & $3.80 \pm 1.27$ & $3.64 \pm 1.10$ & $3.86 \pm 1.30$ \\
Triglycerides (mmol/l) & $2.16 \pm 1.24$ & $2.89 \pm 1.94$ & $2.60 \pm 0.61$ \\
\multicolumn{4}{|l}{} \\
significantly different from baseline $(\mathrm{p}<0.05)$. Other differences not \\
significant. TotChol: Plasma total cholesterol.
\end{tabular}

Table 7.6: Plasma lipoprotein-lipid profile

\section{Discussion}

In the present study, type 2 diabetes patients followed a long-term physical training program. During the first year, when most training was supervised, training induced a large increase in insulin responsiveness $(27 \%)$, that coincided with favourable changes in selected parameters of skeletal muscle metabolism, and an improved plasma lipoprotein-lipid profile. However, during the second year, when training supervision was minimised, the mean training duration decreased and training adaptations waned.

Three out of twelve patients in the training program dropped out early in the intervention period. These subjects reported that they lacked time to keep up the training regimen. All remaining subjects completed the full two-year training program, but reduced their training volume during the second year. This indicates that a more physically active life-style can be achieved in type 2 diabetes patients, but that training supervision is required to assure an adequate training stimulus. It should be noted however, that the patients that participated in our study were well-controlled, non-morbidly obese volunteers, that were unhampered by diabetic complications. Obviously, this facilitates physical activity.

The training program followed by the subjects in this study was prolonged and quite intense in comparison to other studies in type 2 diabetes patients $(2,8$, 46). During the first year, this caused a large increase in insulin responsiveness 

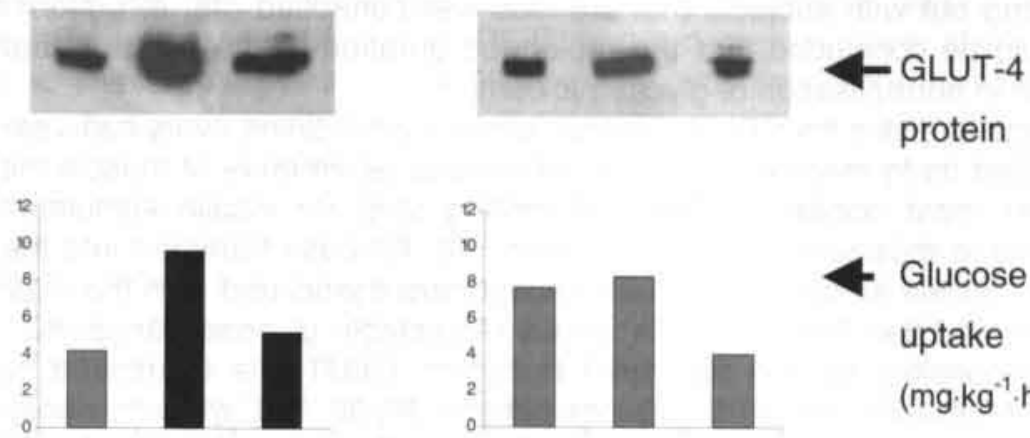

\& Glucose uptake (mg.kg ${ }^{-1} \cdot h^{-1}$ )
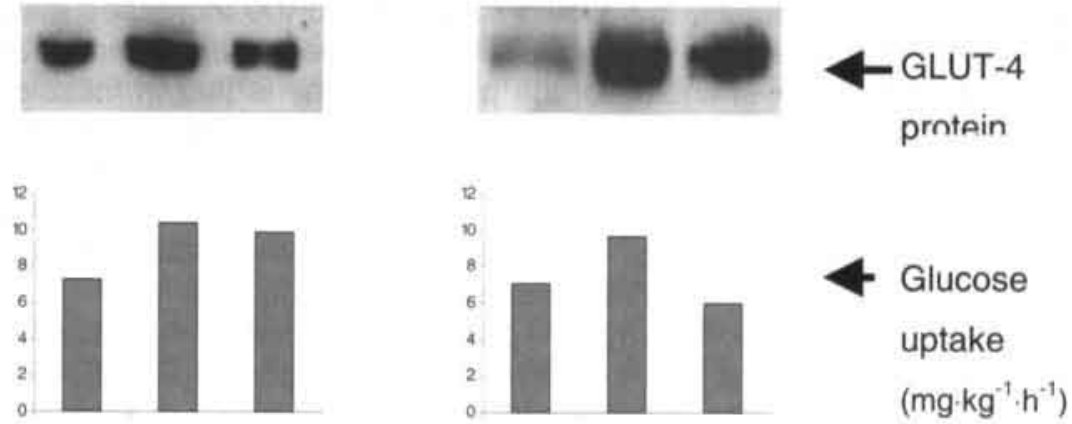

Figure 7.1: Insulin responsiveness and Western blotting of muscle GLUT-4 protein for four representative type 2 diabetic subjects. 
measured during the hyperinsulinaemic euglycaemic clamp, but glycaemic control did not change to normal levels (HbA1c 4.2-6.2 \%).

Indeed, subjects were in good glycaemic control at the outset of the study, and $\mathrm{HbA1c}$ levels were unchanged throughout the entire study. Although this finding may have been confounded by changes in oral anti-diabetic medication (see chapter 8), it is in agreement with the observations of other (shorter-term) training studies; improvements in $\mathrm{HbA1c}$ levels have been found only in studies starting out with subjects that are less well-controlled $(38,42)$. Nonetheless, it should be concluded that the prolonged duration of the present study did not result in normalisation of glycaemic control.

Muscle biopsies from the $\mathrm{m}$. vastus lateralis were taken every half year, and this enabled us to measure the levels of several parameters of muscle metabolism. Under most conditions, the rate limiting step for insulin stimulated glucose uptake in muscle is glucose transport (34). Glucose transport into the myocyte relies on the amount of glucose transporters associated with the plasma membrane and the T-tubules. The insulin regulatable glucose transporter, GLUT-4, is responsible for this facilitated transport. GLUT-4 is expressed normally in skeletal muscle of type 2 diabetes patients $(9,30,37)$, while its translocation to the sarcolemma, crucial to its operation, is attenuated $(14,22)$. Nonetheless, a correlation between total muscle GLUT-4 content and insulin responsiveness has repeatedly been demonstrated in rats $(21,25)$ and healthy human volunteers (27). Exercise training increases skeletal muscle GLUT-4 content (15, 20, 33). If this leads to an increased number of GLUT-4 translocating to the plasma membrane and T-tubules, this would contribute to the increased insulin stimulated glucose uptake after training. This has indeed been demonstrated in the obese rat (13). A novel finding of the present study is that in muscle of type 2 diabetes patients, a similar association between total GLUT-4 content, physical training and insulin responsiveness exists. GLUT-4 protein content in vastus lateralis muscle did not only increase in concert with insulin responsiveness during the first year of training, it also paralleled the decrease in responsiveness during the second year that was observed in most subjects.

The effect of physical training on glucose metabolism has been attributed largely to an increased non-oxidative glucose disposal $(8,16)$. Our findings indicate that training also increases the oxidative capacity of skeletal muscle in type 2 diabetic subjects, since levels of citrate synthase, a key-enzyme of the tricarboxylic acid cycle, changed in concert with muscle GLUT-4 protein content during the training program.

Cytoplasmic FABP is a small $(15 \mathrm{kDa})$ protein that is thought to transport fatty acids from the sarcolemma to the intracellular sites of utilisation, such as the mitochondria. To our knowledge, the present study is the first to report traininginduced effects on cytoplasmic FABP in human (albeit diabetic) skeletal muscle. Rat studies have been equivocal in this regard, some studies finding FABPc to be unchanged in skeletal muscle after training $(43,47)$ while another found an $\sim 80 \%$ increase (7). In the present study, FABPc in human vastus lateralis muscle was increased $\sim 74 \%$ in response to training, without a concurrent rise in HAD. The finding that the capacity to transport FA's through the cytosol without an increase in HAD could either indicate that training increases transfer of FA's to sites of non-oxidative FA disposal, such as the formation of intramuscular triglycerides, or that the capacity of HAD in the vastus lateralis muscle is not 
limiting for the oxidation of the increased amount of FA's delivered by FABPc. Interestingly, an increase in FABPc with unchanged levels of $\mathrm{HAD}$ has also been reported after weight loss in obese females (24). As Van der Vusse and Reneman have indicated (44), circumstantial evidence suggests that the delivery rather than the oxidative metabolism of FA's is the rate-limiting factor for FA oxidation. Although FABP levels did decline toward the end of the two year training intervention, they were still elevated compared to basal.

The most frequently reported changes in plasma lipoprotein-lipids due to physical training are an increased plasma HDL-C, and a decreased level of plasma triglycerides. These changes in plasma lipoprotein-lipids can occur irrespective of changes in body composition (10). In the present study, training caused the plasma HDL-C to change favourably, accompanied by a decreased percentage of body fat. Therefore, it cannot be discerned whether this change in HDL-C can be attributed solely to a reduction in fat mass, to the effect of physical training, or both. Regardless of the exact mechanisms, this finding is important given the increased risk for micro- and macrovascular pathology in type 2 diabetes, since $\mathrm{HDL}-\mathrm{C}$ is known to have a protective effect against atherogenesis. The effect of training on HDL-C seems to have developed gradually over the prolonged training period, since it was increased slightly but not significantly after 12 months, but increased further to a level significantly different from baseline after 24 months. The biphasic pattern observed in other variables seems not to apply to the change in HDL-C, as was also the case with FABPc.

We conclude that long-term physical training in type 2 diabetes patients results in a significant improvement in insulin responsiveness, and that this improvement coincides with increases in muscle GLUT-4 protein expression. Skeletal muscle $\mathrm{FABPC}$ also increases after endurance training, and this increase is not paralleled by a change in HAD levels. However, plasma lipoprotein-lipid profiles and percentage body fat change favourably. Despite these effects, glycaemic control does not change from "well-controlled" to normal levels. In the present study, when training supervision was minimised, training quantity decreased and training adaptations largely waned. This indicates that in type 2 diabetic patients without major diabetic complications, prolonged adherence to a physical training program can be achieved, but that training should be supervised. 


\section{References}

1. Allenberg, K., K. Johansen, and

B. Saltin. Skeletal muscle adaptations to physical training in type II (non-insulin-dependent) diabetes mellitus. Acta Med Scand 223: 36573, 1988.

2. Bogardus, C., E. Ravussin, D. C. Robbins, R. R. Wolfe, E. S. Horton, and E. A. Sims. Effects of physical training and diet therapy on carbohydrate metabolism in patients with glucose intolerance and noninsulin-dependent diabetes mellitus. Diabetes 33: 311-8, 1984.

3. Calles Escandon, J., M. I. Goran, M. O'Connell, K. S. Nair, and E. Danforth, Jr. Exercise increases fat oxidation at rest unrelated to changes in energy balance or lipolysis. Am-J-Physiol 270: E100914, 1996.

4. DeFronzo, R. A., R. Gunnarsson, O. Bjorkman, M. Olsson, and J. Wahren. Effects of insulin on peripheral and splanchnic glucose metabolism in noninsulin-dependent (type II) diabetes mellitus. J Clin Invest 76: 149-55, 1985.

5. DeFronzo, R. A., E. Jacot, E. Jequier, E. Maeder, J. Wahren, and J. P. Felber. The effect of insulin on the disposal of intravenous glucose. Results from indirect calorimetry and hepatic and femoral venous catheterization. Diabetes 30 : 1000-7, 1981.

6. DeFronzo, R. A., R. S. Sherwin, and N. Kraemer. Effect of physical training on insulin action in obesity. Diabetes 36: 1379-85, 1987.

7. Degens, H., J. H. Veerkamp, H. T. van Moerkerk, Z. Turek, L. J. Hoofd, and R. A. Binkhorst. Metabolic capacity, fibre type area and capillarization of rat plantaris muscle. Effects of age, overload and training and relationship with fatigue resistance. Int J Biochem 25: 1141 8, 1993.

8. Dela, F., J. J. Larsen, K. J. Mikines, T. Ploug, L. N. Petersen, and $\mathbf{H}$. Galbo. Insulin-stimulated muscle glucose clearance in pa- tients with NIDDM. Effects of onelegged physical training. Diabetes 44: 1010-20, 1995.

9. Dela, F., T. Ploug, A. Handberg, L. N. Petersen, J. J. Larsen, K. J. Mikines, and H. Galbo. Physical training increases muscle GLUT4 protein and mRNA in patients with NIDDM. Diabetes 43: 862-5, 1994.

10. Durstine, J. L., and W. L. Haskell. Effects of exercise training on plasma lipids and lipoproteins. Exerc Sport Sci Rev 22: 477-521, 1994.

11. Eriksson, K. F., and F. Lindgarde. Prevention of type 2 (non-insulindependent) diabetes mellitus by diet and physical exercise. The 6-year Malmo feasibility study. Diabetologia 34: 891-8, 1991.

12. Eriksson, K. F., B. Saltin, and F. Lindgarde. Increased skeletal muscle capillary density precedes diabetes development in men with impaired glucose tolerance. A 15-year follow-up. Diabetes 43: 805-8, 1994.

13. Etgen, G. J., Jr., J. Jensen, C. M. Wilson, D. G. Hunt, S. W. Cushman, and J. L. Ivy. Exercise training reverses insulin resistance in muscle by enhanced recruitment of GLUT-4 to the cell surface. Am-JPhysiol 272: E864-9, 1997.

14. Garvey, W. T., L. Maianu, J. H. Zhu, G. Brechtel Hook, P. Wallace, and A. D. Baron. Evidence for defects in the trafficking and translocation of GLUT4 glucose transporters in skeletal muscle as a cause of human insulin resistance. J-Clin-Invest 101: 2377-86, 1998.

15. Gulve, E. A., and R. J. Spina. Effect of 7-10 days of cycle ergometer exercise on skeletal muscle GLUT-4 protein content. J Appl Physiol 79: 1562-6, 1995.

16. Hardin, D. S., B. Azzarelli, J. Edwards, J. Wigglesworth, L. Maianu, G. Brechtel, A. Johnson, A. Baron, and W. T. Garvey. Mechanisms of enhanced insulin sensitivity in endurance-trained athletes: effects on blood flow and 
differential expression of GLUT 4 in skeletal muscles. J Clin Endocrinol Metab 80: 2437-46, 1995.

17. Helmrich, S. P., D. R. Ragland, R. W. Leung, and R. S. Paffenbarger, Jr. Physical activity and reduced occurrence of non-insulindependent diabetes mellitus [see comments]. N-Engl-J-Med 325: 147 52, 1991.

18. Holloszy, J. O., and E. F. Coyle. Adaptations of skeletal muscle to endurance exercise and their metabolic consequences. J-Appl-Physiol 56: 831-8, 1984.

19. Holloszy, J. O., J. Schultz, J. Kusnierkiewicz, J. M. Hagberg, and A. A. Ehsani. Effects of exercise on glucose tolerance and insulin resistance. Brief review and some preliminary results. Acta Med Scand Suppl 711: 55-65, 1986.

20. Hughes, V. A., M. A. Fiatarone, R. A. Fielding, B. B. Kahn, C. M. Ferrara, P. Shepherd, E. C. Fisher, R. R. Wolfe, D. Elahi, and W. J. Evans. Exercise increases muscle GLUT-4 levels and insulin action in subjects with impaired glucose tolerance. Am J Physiol 264: E855-62, 1993.

21. Kawanaka, K., I. Tabata, S. Katsuta, and M. Higuchi. Changes in insulin-stimulated glucose transport and GLUT-4 protein in rat skeletal muscle after training. J Appl Physiol 83: 2043-7, 1997.

22. Kelley, D. E., M. A. Mintun, S. C. Watkins, J. A. Simoneau, F. Jadali, A. Fredrickson, J. Beattie, and $\mathbf{R}$. Theriault. The effect of noninsulin-dependent diabetes mellitus and obesity on glucose transport and phosphorylation in skeletal muscle. J Clin Invest 97: 2705-13, 1996.

23. Kelley, D. E., and J. A. Simoneau. Impaired free fatty acid utilization by skeletal muscle in non-insulindependent diabetes mellitus. J-ClinInvest 94: 2349-56, 1994.

24. Kempen, K. P., W. H. Saris, H. Kuipers, J. F. Glatz, and G. J. Van Der Vusse. Skeletal muscle meta- bolic characteristics before and after energy restriction in human obesity: fibre type, enzymatic beta-oxidative capacity and fatty acid-binding protein content. Eur J Clin Invest 28: 1030-7, 1998.

25. Kern, M., J. A. Wells, J. M. Stephens, C. W. Elton, J. E. Friedman, E. B. Tapscott, P. H. Pekala, and G. L. Dohm. Insulin responsiveness in skeletal muscle is determined by glucose transporter (Glut4) protein level. Biochem-J 270: 397-400, 1990.

26. King, D. S., G. P. Dalsky, M. A. Staten, W. E. Clutter, D. R. Van Houten, and J. O. Holloszy. Insulin action and secretion in endurancetrained and untrained humans. JAppl-Physiol 63: 2247-52, 1987.

27. Koranyi, L. I., R. E. Bourey, H. Vuorinen-Markkola, V. A. Koivisto, M. Mueckler, M. A. Permutt, and $\mathbf{H}$. Yki-Jarvinen. Level of skeletal muscle glucose transporter protein correlates with insulinstimulated whole body glucose disposal in man. Diabetologia 34: 763 5, 1991.

28. Krotkiewski, M., P. Lonnroth, K. Mandroukas, Z. Wroblewski, M. Rebuffe Scrive, G. Holm, U. Smith, and P. Bjorntorp. The effects of physical training on insulin secretion and effectiveness and on glucose metabolism in obesity and type 2 (non-insulin-dependent) diabetes mellitus. Diabetologia 28: $881-90,1985$.

29. Lohmann, D., F. Liebold, W. Heilmann, H. Senger, and A. Pohl. Diminished insulin response in highly trained athletes. Metabolism 27: $521-4,1978$.

30. Lund, S., H. Vestergaard, P. H. Andersen, O. Schmitz, L. B. Gotzsche, and 0 . Pedersen. GLUT-4 content in plasma membrane of muscle from patients with non-insulin-dependent diabetes mellitus. Am-J-Physiol 265: E88997, 1993.

31. Malaspina, J. P., H. Bussiere, and G. Le Calve. The total choles- 
terol/HDL cholesterol ratio: a suitable atherogenesis index [letter]. Atherosclerosis 40: 373-5, 1981.

32. Manson, J. E., E. B. Rimm, M. J. Stampfer, G. A. Colditz, W. C. Willett, A. S. Krolewski, B. Rosner, C. H. Hennekens, and F. E. Speizer. Physical activity and incidence of non-insulin-dependent diabetes mellitus in women. Lancet 338: 774-8, 1991.

33. Ploug, T., B. M. Stallknecht, $\mathbf{O}$. Pedersen, B. B. Kahn, T. Ohkuwa, J. Vinten, and $\mathbf{H}$. Galbo. Effect of endurance training on glucose transport capacity and glucose transporter expression in rat skeletal muscle. Am-J-Physiol 259: E77886, 1990.

34. Ren, J. M., B. A. Marshall, E. A. Gulve, J. Gao, D. W. Johnson, J. O. Holloszy, and M. Mueckler. Evidence from transgenic mice that glucose transport is rate-limiting for glycogen deposition and glycolysis in skeletal muscle. J Biol Chem 268: 16113-5, 1993.

35. Ruderman, N. B., O. P. Ganda, and $\mathrm{K}$. Johansen. The effect of physical training on glucose tolerance and plasma lipids in maturityonset diabetes. Diabetes 28 Suppl 1: 89-92, 1979.

36. Saltin, B., and P. O. Astrand. Free fatty acids and exercise. Am-J-ClinNutr 57: 752S-757S; discussion 757S-758S, 1993.

37. Scheck, S. H., R. J. Barnard, L. O. Lawani, J. F. Youngren, D. A. Martin, and R. Singh. Effects of NIDDM on the glucose transport system in human skeletal muscle. Diabetes Res 16: 111-9, 1991.

38. Schneider, S. H., L. F. Amorosa, A. K. Khachadurian, and N. B. Ruderman. Studies on the mechanism of improved glucose control during regular exercise in type 2 (non-insulin-dependent) diabetes. Diabetologia 26: 355-60, 1984.

39. Schneider, S. H., A. K. Khachadurian, L. F. Amorosa, L. Clemow, and N. B. Ruderman. Ten-year experience with an exercise-based outpatient life-style modification program in the treatment of diabetes mellitus. Diabetes-Care 15: 180010, 1992.

40. Seals, D. R., J. M. Hagberg, W. K. Allen, B. F. Hurley, G. P. Dalsky, A. A. Ehsani, and J. O. Holloszy. Glucose tolerance in young and older athletes and sedentary men. $J$ Appl Physiol 56: 1521-5, 1984.

41. Skarfors, E. T., T. A. Wegener, H. Lithell, and I. Selinus. Physical training as treatment for type 2 (non-insulin-dependent) diabetes in elderly men. A feasibility study over 2 years. Diabetologia 30: 930-3, 1987.

42. Trovati, M., Q. Carta, F. Cavalot, S. Vitali, C. Banaudi, P. G. Lucchina, F. Fiocchi, G. Emanuelli, and G. Lenti. Influence of physical training on blood glucose control, glucose tolerance, insulin secretion, and insulin action in non-insulindependent diabetic patients. Diabetes Care 7: 416-20, 1984.

43. van Breda, E., H. A. Keizer, M. M. Vork, D. A. Surtel, Y. F. de Jong, G. J. van der Vusse, and J. F. Glatz. Modulation of fatty-acidbinding protein content of rat heart and skeletal muscle by endurance training and testosterone treatment. Pflugers Arch 421: 274-9, 1992.

44. Van der Vusse, G. J., and R. S. Reneman. Lipid metabolism in muscle. In: Exercise: regulation and integration of multiple systems, edited by L. B. Rowell and J. T. Sheperd. Oxford: Oxford University Press, 1996, p. 953-994.

45. Vestergaard, H., P. H. Andersen, S. Lund, O. Schmitz, S. Junker, and $O$. Pedersen. Pre- and posttranslational upregulation of musclespecific glycogen synthase in athletes. Am J Physiol 266: E92-101, 1994.

46. Yamanouchi, K., T. Shinozaki, K. Chikada, T. Nishikawa, K. Ito, S. Shimizu, N. Ozawa, Y. Suzuki, H. Maeno, K. Kato, and et al. Daily walking combined with diet therapy is a useful means for obese NIDDM 
patients not only to reduce body weight but also to improve insulin sensitivity. Diabetes Care 18: 775-8, 1995.

47. Zonderland, M. L., P. R. Bar, J. C. Reijneveld, B. M. Spruijt, H. A.
Keizer, and J. F. Glatz. Different metabolic adaptation of heart and skeletal muscles to moderateintensity treadmill training in the rat. Eur-J-Appl-Physiol 79: 391-6, 1999. 


\title{
Physical Training Reduces
}

\section{Oral Anti-Hyperglycaemic Drug Requirements} in Type 2 Diabetes

\section{Chapter}

\author{
L.B. Borghouts, H. Pijl, B.H. Wolffenbuttel, \\ J.P.J. Sels, H.A. Keizer.
}

\section{Summary}

Type 2 diabetes patients that followed the training program described in chapter 6, were evaluated with regard to their use of oral antihyperglycaemic medication. This data was compared with the antihyperglycaemic drug requirements of a sedentary diabetic control group. In general, in type 2 diabetes patients participating in physical training, medication was unchanged or decreased after one year. In contrast, sedentary patients tended to increase their use of medication. These changes were significantly different between groups $(p<0.05)$. Their were no alterations in $\mathrm{HbA1c}$ levels in either group over the intervention period. Our findings indicate that training-induced improvements in insulin sensitivity are capable of reducing or stabilising medication requirements. Further studies are needed to confirm these observations on a larger scale. 
Physical exercise is considered to be one of the cornerstones in the treatment of type 2 diabetes, together with dietary management and drug therapies (6). The effect of drug treatment or diet on glucose metabolism in type 2 diabetes patients has been shown to be potentiated by exercise training (8). Patients on insulin therapy, but also those taking sulfonylureas, have an increased risk for developing hypoglycaemia during or after exercise (5). Therefore, these patients are often advised to adjust their drug dose prior to exercise. Little is known about the long-term effects that chronic physical exercise training might have on the use of medication, although it is well-documented that exercise training is beneficial to insulin sensitivity (3). This is surprising, since the health care costs of type 2 diabetes are reported to be substantial, especially in the light of its increasing prevalence (2), while the costs of physical exercise are negligible. Thus, physical training could potentially play a role in decreasing the usage, and hence costs, of anti-hyperglycaemic medication, while attaining better metabolic control. One of the obvious reasons this topic has received little attention, is that most training intervention studies are of a relatively short duration. To be able to measure an effect on the use of medication, a prolonged physical training program would be required. We have therefore designed a study, to evaluate the effects of a one year endurance training program on glucoregulation, and the associated use of anti-hyperglycaemic drugs.

\section{Subjects and Methods}

Subjects 12 sedentary male, moderately obese type 2 diabetes patients (WHO criteria), aged 45-65 yr., were recruited after they had responded to an advertisement in a local newspaper. All gave their written consent to participate in this study, which was approved by the Medical Ethics Committee of Maastricht University and Maastricht University Hospital. Mean ( \pm SD) time since diagnosis of type 2 diabetes was $2.5 \pm 1.5 \mathrm{yr}$. Further procedures regarding subject recruitment have been described in chapter 3 . Of the 12 men included at the start of the project, 9 completed the full 2 year training intervention. Three men dropped-out during the first six months of the intervention, because of reported lack of time. This paper will report the data of the 9 persons who complied to the 2 year program (further referred to as T). At admittance to the study, 5 of these men were taking sulphonylureas, 4 were not using blood glucose lowering medication. A control group matched for age and body composition $(n=9)$ was recruited according to the same in- and exclusion criteria. These patients were to serve as a non-training control group (further referred to as C). Two patients in this group reported they lacked time to return for the post-intervention measurements. Furthermore, several of the remaining patients in the control group were unwilling to undergo the repeated glucose clamp test, allegedly because it was too time-consuming. Therefore, the glucose clamp was not repeated in the C group, since statistical power would have been inadequate. Of the control 
group, 5 were taking oral sulphonylureas only, one was taking an oral sulfonylurea in combination with metformine, and one was not using blood glucose lowering medication. Medication in both groups was prescribed by each subject's habitual physician, who was unaware of the study objectives with regard to drug treatment. Medication was scored during the period the glucose clamp studies were performed. After completion of the study, changes in medication were evaluated independently by two skilled internists, blinded for the training condition.

Incremental bicycle ergometer test Subjects were asked to refrain from oral blood glucose lowering medication for 48 hours preceding the test, and reported to the laboratory after an overnight fast. Further procedures have been described in detail in chapter 3.

Hyperinsulinaemic euglycaemic clamp At least one week after the bicycle ergometer test, the subjects reported to the laboratory at $9.00 \mathrm{~h}$ in the morning after an overnight fast. They were asked to refrain from oral blood glucose lowering medication and exercise for 48 hours preceding the test. For detailed procedures, please refer to chapter 3 .

Training intervention. Subjects were given endurance interval training protocols to perform on bicycle ergometers, and were also instructed to increase leisuretime activity. Heart rate monitors (Polar Sporttester, Polar Electro, Kempele, Finland) with storage capacity were handed out to all subjects, and training was carried out based on each individual's maximal heart rate (HRmax), as measured during the incremental bicycle test. All subjects kept a training diary in which they recorded all physical activity. Training duration and intensity was built up gradually, and during the last two months of the intervention training duration averaged $161 \pm 118$ min per week. Training was fairly intense, $\sim 50 \%$ of training time was performed above $85 \%$ HRmax. Further details have been given in chapter 3 .

Analytical procedures. Blood plasma was analysed for glucose (Analox GM7, Meyvis, The Netherlands), and insulin with fluoroimmunoassay (EG\&G, Breda, The Netherlands). HbA1c was measured with HPLC (Bio-Rad Diamat, Munich, Germany, normal values $4.2-6.2 \%$ )

Statistical analysis. Differences between $\mathrm{T}$ and $\mathrm{C}$ were tested with Student's ttest for unpaired data. Training effects were analysed with Student's t-test for paired data, except for changes in medication, which was tested with MannWhitney's U-test. The level of significance was set at $p<0.05$.

\section{Results}

Before training there were no significant differences between $T$ and $C$ in fasting glucose $(7.3 \pm 2.4$ and $10.5 \pm 2.3 \mathrm{mmol} / \mathrm{l}$, respectively) and insulin $(55 \pm 50$ and $70 \pm 45 \mathrm{pmol} / \mathrm{l}$ respectively). $\mathrm{HbA1c}$ was $6.6 \pm 0.7$ in $\mathrm{T}$ and $7.1 \pm 1.4 \%$ in $\mathrm{C}$ (NS). Body mass ( $T: 85.7 \pm 10$ and C: $81.7 \pm 17$ ) and body fat percentage ( $T: 31$ \pm 5 and $C: 25 \pm 9$ ) were not significantly different.

After training, body mass and fat percentage were not significantly changed in $T$ (table 8.1), but in $\mathrm{C}$, body mass increased from $81.7 \pm 16$ to $85.8 \pm 16 \mathrm{~kg}$ $(p=0.044)$. This increase was attributable to an increase in fat mass. Training increased $\mathrm{VO}_{2} \max$ in $\mathrm{T}$ (table 8.1), in $\mathrm{C}$ it did not change significantly from baseline $\left(30.0 \pm 7\right.$ vs. $\left.27.4 \pm 7 \mathrm{ml} \cdot \mathrm{kg}^{-1} \cdot \mathrm{min}^{-1}\right)$. Fasting glucose and insulin were 


\begin{tabular}{|lcc|}
\hline & Baseline & $12 \mathrm{mo}$ \\
\hline $\mathrm{VO}_{2} \max \left(\mathrm{ml} \cdot \mathrm{kg}^{-1} \cdot \mathrm{min}^{-1}\right)$ & $33.7 \pm 7$ & $37.8 \pm 8^{\star}$ \\
Weight $(\mathrm{kg})$ & $81.9 \pm 13$ & $83.1 \pm 11$ \\
Fat $\%$ & $28.7 \pm 7$ & $27.7 \pm 4$ \\
Fasting plasma glucose $(\mathrm{mmol} / \mathrm{l})$ & $7.3 \pm 2$ & $7.5 \pm 3$ \\
Fasting plasma insulin $(\mathrm{pmol} / \mathrm{l})$ & $55 \pm 50$ & $40 \pm 20$ \\
Insulin responsiveness $\left(\mathrm{mg} \cdot \mathrm{m}^{2} \cdot \mathrm{min}^{-1}\right)$ & $302 \pm 72$ & $385 \pm 30^{\star}$ \\
HbA1c $(\%)$ & $6.6 \pm 0.7$ & $6.9 \pm 0.9$ \\
& & \\
*significantly different from baseline $(\mathrm{p} \leq 0.01)$. & \\
\hline
\end{tabular}

Table 8.1

unchanged in either group. $\mathrm{HbA1c}$ levels remained within the well-controlled range in both groups (6.8 $\pm 0.6 \%$ in C and $6.9 \pm 0.9 \%$ in T, NS from baseline). The change from baseline in $\mathrm{HbA1c}$ levels was not significantly different between groups (table 8.2). Insulin responsiveness assessed by hyperinsulinaemic euglycaemic clamp increased $\sim 30 \%$ in $\mathrm{T}$ (table 8.1 ). Use of medication before and after the intervention period is presented in table 8.2. Subjects were ranked as either decreased, unchanged, or increased in medication. When summed ranks for subjects in both groups were compared, it was shown that there was a significant difference between $T$ and $C(p<0.05)$.

\section{Discussion}

Type 2 diabetes is a progressive disease, not only when untreated, but also when treated by diet, or intensive pharmacological therapy (10). Data from the U.K. Prospective Diabetes Study (UKPDS), have shown that in time, fasting plasma glucose and $\mathrm{HbA1c}$ levels increase $(10,11)$. This occurs despite an increase in medication requirements, regardless the mode of treatment $(10,11)$. The natural course of deteriorating glycaemic control, and the inability to reverse it with pharmacological agents or diet, probably contributes to the development of the complications (micro- and macrovascular,) associated with type 2 diabetes. These complications not only affect the quality of life, but also consume considerable health care resources (2).

Physical activity has a beneficial effect on insulin sensitivity in healthy as well as insulin resistant populations (3). It has been shown that people involved in vigorous exercise at least once weekly, have a reduced risk for the development of type 2 diabetes (9). The mechanisms by which physical exercise improves glucoregulation in insulin-resistant populations involve peripheral (mainly skeletal muscle) improvements in insulin stimulated glucose uptake, as well as decreased splanchnic glucose production (3). The present study indicates that these training-induced improvements are capable of reducing or stabilising medication requirements.

In accordance with the clinical course of type 2 diabetes, the sedentary subjects from the control group, who were sedentary, had an increased use of medication compared to the training intervention group.

Ideally, this effect would have to be established in a large scale prospective study. However, in order to increase physical exercise capacity to a substantial extend, and insulin sensitivity as a metabolic sequela, in sedentary subjects, it 


\begin{tabular}{|c|c|c|c|}
\hline Subject $n^{2}$ & $\begin{array}{l}\text { Basal } \\
\text { medication }\end{array}$ & $\mathrm{HbA1c}$ & $\begin{array}{l}12 \text { mont } \\
\text { medication }\end{array}$ \\
\hline$T$ group & & & \\
\hline 1 & None & 6.9 & None \\
\hline 2 & None & 7.5 & None \\
\hline 3 & None & 6.0 & None \\
\hline 4 & None & 6.4 & None \\
\hline 5 & Tolbutamide $3.500 \mathrm{mg}$ & 6.3 & Tolbutamide $2.500 \mathrm{mg}$ \\
\hline 6 & Tolbutamide $1.500 \mathrm{mg}$ & 5.7 & Tolbutamide $1.500 \mathrm{mg}$ \\
\hline 7 & Gliclazide $2.80 \mathrm{mg}$ & 7.5 & Glimepiride $1.6 \mathrm{mg}$ \\
\hline 8 & Gliclazide $2.80 \mathrm{mg}$ & 5.9 & None \\
\hline 9 & $\begin{array}{l}\text { Gliclazide } 3.80 \mathrm{mg} \\
\text { Metformine } 3.850 \mathrm{mg}\end{array}$ & 7.2 & $\begin{array}{l}\text { Glimepiride } 1.6 \mathrm{mg} \\
\text { Metformine } 2.850 \mathrm{mg}\end{array}$ \\
\hline $\begin{array}{c}\text { mean } \pm S D: \\
\text { C group }\end{array}$ & & $6.6 \pm 0.7$ & \\
\hline 1 & None & 6.9 & Glimepiride $1.1 \mathrm{mg}$ \\
\hline 2 & Tolbutamide $2.500 \mathrm{mg}$ & 7.8 & $\begin{array}{l}\text { Tolbutamide } 3.500 \mathrm{mg} \\
\text { Metformine } 2.850 \mathrm{mg}\end{array}$ \\
\hline
\end{tabular}

Table 8.2: Anti-hyperglycaemic medication and $\mathrm{HbA} 1 \mathrm{c}$-values before and after the 12 month intervention period. 
is imperative to prescribe and supervise exercise training on an individual basis (1). Obviously, this is infeasible in a large scale study. Nonetheless, the highly significant difference we measured in the progression of pharmacological requirements between our two groups, suggests that physical training could be regarded as an effective means to reduce the use of anti-hyperglycaemic drugs in type 2 diabetes.

Despite the increase in whole body glucose uptake as measured during the hyperinsulinaemic euglycaemic clamp, there was no improvement in $\mathrm{HbA1c}$ after training. However, of previous studies reporting on the effect of physical training on $\mathrm{HbA} 1 \mathrm{c}$, those that reported a decrease were all in subjects with much higher initial $\mathrm{HbA1c}$ values than the present study (3). Alternatively, a decrease in $\mathrm{HbA} 1 \mathrm{c}$ in the training group may have been offset by the reduction in medication in some patients. Table 8.2 shows that those patients in the Tgroup whose medication intake decreased during the training period, had increased $\mathrm{HbA} 1 \mathrm{c}$ levels at 12 months compared to basal. These patients reported that medication was reduced because episodes of hypoglycaemia occurred, especially after training sessions. The combined effects of sulfonylureas and exercise to induce hypoglycaemia in well-controlled type 2 diabetes patients has indeed been reported before (7). The reduction in medication due to the occurrence of hypoglycaemia may subsequently have caused overall glycaemic control to deteriorate. If this is true, the practical implication should be that upon recurring episodes of hypoglycaemia after exercise, it should be advised that oral anti-hyperglycaemic medication be reduced only on those days that exercise is performed.

In conclusion, physical training in type 2 diabetes patients not only improves insulin responsiveness, but also decreases anti-hyperglycaemic drug requirements. Given the implications with regard to health care costs, and in the light of the increasing prevalence of type 2 diabetes, further studies are needed to assess this effect on a larger scale. 


\section{References}

1. ACSM. American College of Sports Medicine Position Stand. The recommended quantity and quality of exercise for developing and maintaining cardiorespiratory and muscular fitness, and flexibility in healthy adults. Med Sci Sports Exerc 30: 975-91, 1998.

2. Alberti, K. G. The costs of noninsulin-dependent diabetes mellitus [editorial]. Diabet Med 14: 7-9, 1997.

3. Borghouts, L. B., and H. A. Keizer. Exercise and insulin sensitivity: a review. Int J Sports Med 20: 1-12, 1999.

4. Durnin, J. V., and J. Womersley. Body fat assessed from total body density and its estimation from skinfold thickness: measurements on 481 men and women aged from 16 to 72 years. Br J Nutr 32: 77-97. 1974.

5. Horton, E. S. Role and management of exercise in diabetes mellitus. Diabetes Care 11: 201-11. 1988.

6. IDF. A desktop guide to type-2 diabetes mellitus. Diabetic Medicine 16: 716-730, 1999.

7. Kemmer, F. W., M. Tacken, and M. Berger. Mechanism of exerciseinduced hypoglycemia during sulfo nylurea treatment. Diabetes 36 : 1178-82, 1987.

8. Lampman, R. M., and D. E. Schteingart. Effects of exercise training on glucose control, lipid metabolism, and insulin sensitivity in hypertriglyceridemia and non-insulin dependent diabetes mellitus. Med Sci Sports Exerc 23: 703-12, 1991.

9. Manson, J. E., E. B. Rimm, M. J. Stampfer, G. A. Colditz, W. C. Willett, A. S. Krolewski, B. Rosner, C. H. Hennekens, and F. E. Speizer. Physical activity and incidence of non-insulin-dependent diabetes mellitus in women. Lancet 338: 774-8, 1991.

10. Turner, R., C. Cull, and R. Holman. United Kingdom Prospective Diabetes Study 17: a 9-year update of a randomized, controlled trial on the effect of improved metabolic control on complications in non-insulin-dependent diabetes mellitus. Ann Intern Med 124: $136-$ 45, 1996.

11. UKPDS. U.K. prospective diabetes study 16 . Overview of 6 years' therapy of type II diabetes: a progressive disease. U.K. Prospective Diabetes Study Group [published erratum appears in Diabetes 1996 Nov;45(11):1655]. Diabetes 44: 1249-58, 1995. 


\section{GLUT-4 Expression in Different}

\section{Skeletal Muscle Fibre Types}

Evidence for Intermuscular Differences

\section{Chapter}

L.B. Borghouts, G. Schaart, M.K.C. Hesselink, H.A. Keizer

\section{Summary}

GLUT-4 protein levels in rat skeletal muscle have been shown to be higher in muscle consisting predominantly of oxidative muscle fibres, than in muscles consisting predominantly of glycolytic fibres. Therefore, it has been suggested that in rat muscle, oxidative fibres have an intrinsically higher level of GLUT-4 protein than glycolytic fibres. No data is available concerning human muscle. In this study, individual fibres of different types within a muscle were directly compared, with regard to their GLUT-4 protein content. Human vastus lateralis muscle and several different rat muscles were studied. The relative expression of GLUT-4 protein among fibre types varied between different muscles. We propose that factors other than solely fibre type, such as glycolytic demand, determine GLUT-4 expression in muscle. 
Skeletal muscle is responsible for the major part of insulin stimulated plasma glucose disposal (3). The insulin and contraction regulatable glucose transporter, GLUT-4, is abundantly expressed in skeletal muscle of humans and rodents. Its expression in skeletal muscle has been shown to correlate positively with insulin stimulated glucose disposal in man (13). In rat, GLUT-4 protein content is higher in muscles that are made up of predominantly oxidative fibres ("red muscle"), than in muscles that consist predominantly of glycolytic fibres ("white muscle") $(6,9,11,15,16)$. Accordingly, insulin stimulated glucose uptake is highest in red muscle of the rat in vitro $(6,9,11,15,16)$. In humans, insulin stimulated whole body glucose uptake was shown to positively correlate with the percentage of oxidative fibres in vastus lateralis muscle, and inversely correlated with the percentage of glycolytic fibres (14). This has been taken to suggest that in humans, as in rats, muscle GLUT-4 content is higher in oxidative than in glycolytic muscle fibres (10). However, in a more recent study, no correlation between oxidative fibre content and GLUT-4 protein expression was found in vastus lateralis muscle of athletes or controls (7).

Individual rat muscles often exhibit a preponderance of either glycolytic or oxidative fibres, justifying the subdivision into red and white muscles (1). In contrast, fibre type composition is much less variable between human skeletal muscles (19). Therefore, no conclusions can be drawn from comparisons of different human muscles with regard to the relation between muscle fibre type composition and GLUT-4 protein content. A direct assessment of this relation is therefore essential. In the present study, we have achieved this by concurrently determining muscle fibre type and GLUT-4 immunofluorescence staining in serial muscle sections. We investigated the hypothesis that in human skeletal muscle, the fibre type/GLUT-4 content-relationship is similar to that assumed in rats, namely a higher expression of GLUT-4 in oxidative fibres compared to glycolytic fibres. Rat muscles were investigated according to the same procedures, to confirm the observations of earlier studies which used whole muscle homogenates $(6,9,11,16)$.

\section{Materials and Methods}

Subjects were recruited and muscle biopsies taken as described in Chapter 3 . Biopsies of type 2 diabetic patients $(n=6)$ and healthy controls $(n=4)$ were analysed. Since no differences were observed between diabetic and control muscle with regard to the parameters reported here, data from these biopsies will further be referred to as "human muscle" data.

Male Wistar rats and male Lewis rats, aged 12 weeks, were used in this experiment. They were housed individually and provided with food and water ad libitum up to two hours before muscle dissection. Rats were anaesthetised with intraperitoneal injection of pentobarbital (Narcovet, $1.0 \mathrm{ml} / \mathrm{kg}$ body weight), and soleus, extensor digitorum longus (EDL), vastus lateralis, tibialis anterior, and 
medial and lateral gastrocnemius muscles were carefully dissected. All procedures were approved by the Institutional Animal Care and Use Committee of Maastricht University, and complied with the principles of laboratory animal care.

After biopsy (human) or muscle dissection (rat), muscle tissue was immediately frozen in isopenthane cooled to its melting point with liquid nitrogen. These samples were subsequently put in an aluminium cryo-vial. Biochemistry and histology muscle pieces were stored at $-70^{\circ} \mathrm{C}$. GLUT-4 content (immunofluorescence assay) and muscle fibre type (myosin ATP-ase staining (2)) were carried out on serial transverse sections. For detailed procedures of GLUT-4 SDS-Page and Immunoblotting. GLUT-4 immuno-fluorescence assay and Muscle fibre type staining, the reader is referred to chapter 3 , where these have been described.

\section{Results}

In both human and rat muscle, GLUT-4 protein was detected with Westernblotting using the GLUT4-BW antibody (for specifications see chapter 3 ) at a molecular mass of $\sim 43 \mathrm{kDa}$, in accordance with previous investigations (9-11) (figure 9.1).

Specificity of the GLUT4-BW antibody was tested by pre-incubation with the peptide against which it was raised. In addition, on several occasions GLUT-4BW antibody was omitted from the immunofluorescence labelling procedure to test for specificity of the FITCconjugated secondary antibody. Both procedures completely diminished immunofluorescence labelling, indicating that immunofluorescent signal was specific for GLUT-4 in the tissues used in this study.

GLUT-4 content in human muscle: Immunofluorescence staining of transverse muscle slides revealed a distinct "chessboard" pattern of fibres stained either strongly or weakly for GLUT-4 (figure 9.2). ATPase staining of corresponding slides showed that slow-twitch (type 1) fibres had a low expression of GLUT-4 compared to glycolytic (type 2) fibres (figure

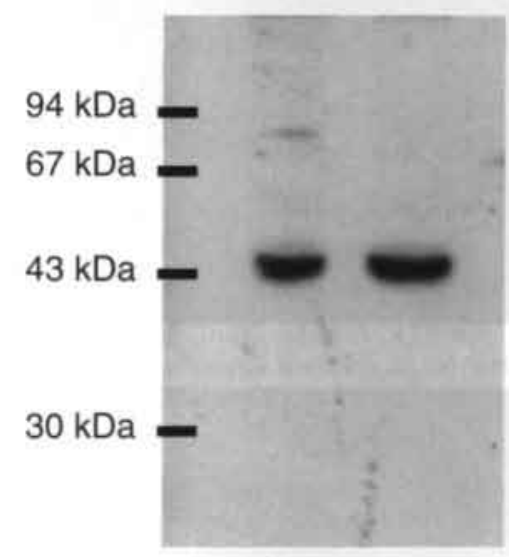

Figure 9.1: Immunoblot analysis of GLUT4 protein in human vastus lateralis muscle. Numbers on the left indicate the migration of mol wt markers.

\section{2). No consistent distinction}

could be made between type $2 a$ and type $2 b$ fibres with respect to GLUT-4 protein labelling. Fibres that were incidentally cut longitudinally to the muscle fibre-axis revealed a pattern of strings of GLUT-4 aggregates parallel to the fibre axis (figure 9.3), as has been observed before by others (17).

GLUT-4 content in rat muscle: In both the medial and lateral rat gastrocnemius muscle, GLUT-4 expression relative to fibre type was opposite to that observed 
Fig. 9.2: (A) Immunofluorescence staining of GLUT-4 in a transverse section of human vastus lateralis muscle, detected with the polyclonal antibody GLUT4-BW. (B) Myosin ATP-ase staining of a serial section of human vastus lateralis muscle. Pre-incubation was at $\mathrm{pH} 4.3$, therefore type 1 fibres appear dark, and type 2 fibres appear light. Note that GLUT-4 protein expression is highest in type 2 fibres.
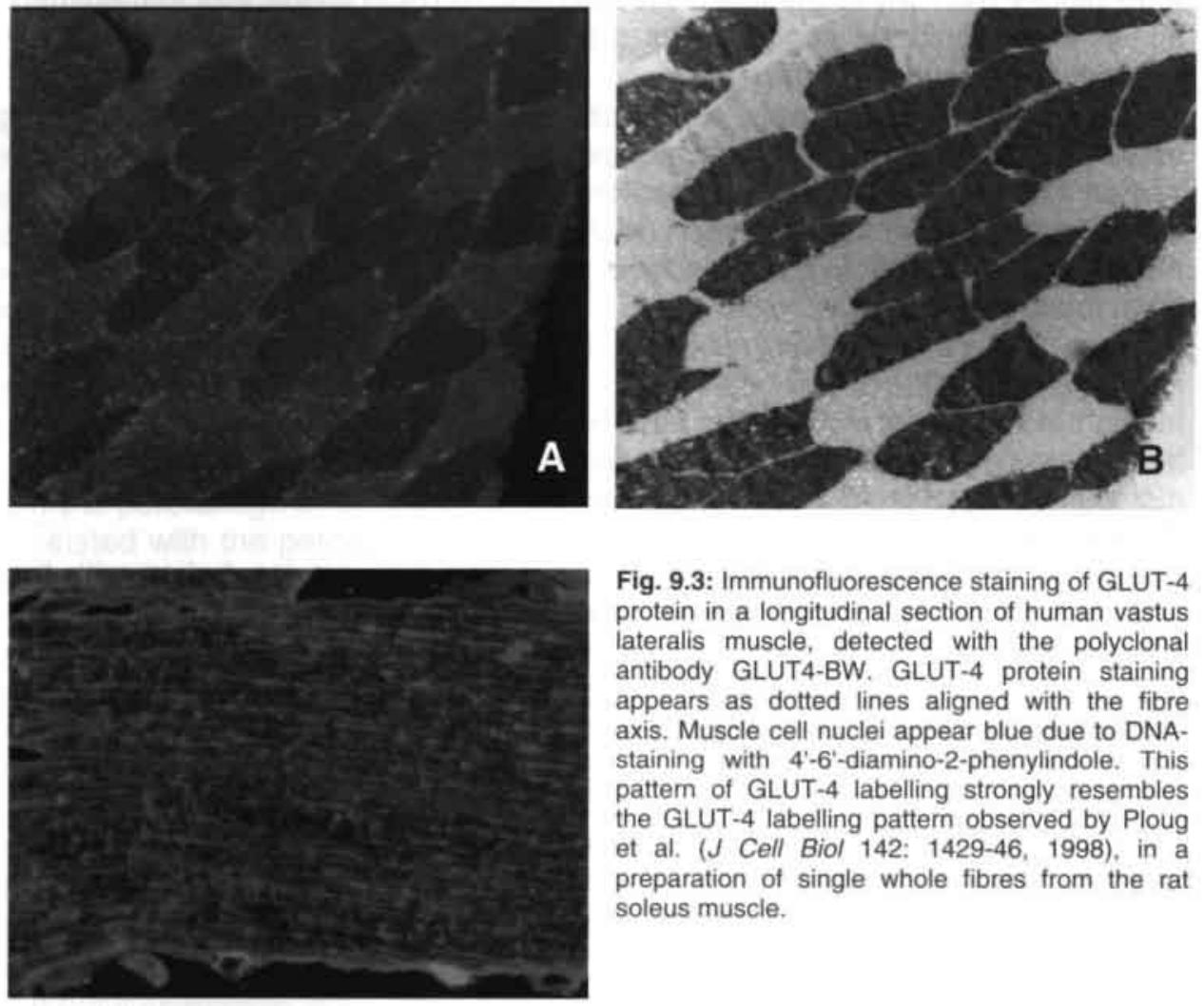

Fig. 9.3: Immunofluorescence staining of GLUT-4 protein in a longitudinal section of human vastus lateralis muscle, detected with the polyclonal antibody GLUT4-BW. GLUT-4 protein staining appears as dotted lines aligned with the fibre axis. Muscle cell nuclei appear blue due to DNAstaining with 4'-6'-diamino-2-phenylindole. This pattern of GLUT-4 labelling strongly resembles the GLUT-4 labelling pattern observed by Ploug et al. ( $J$ Cell Biol 142: 1429-46, 1998), in a preparation of single whole fibres from the rat soleus muscle.
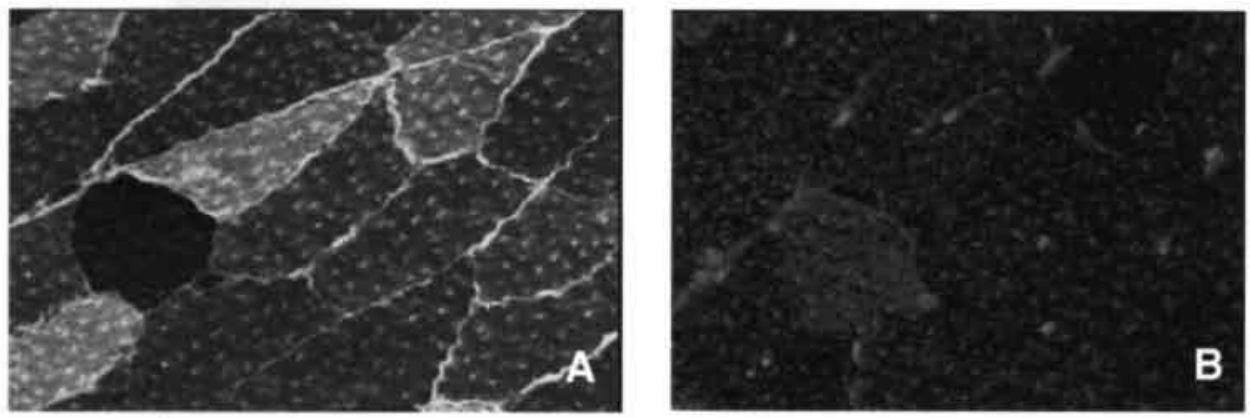

Fig. 9.4: (A) Immunofluorescence staining of GLUT-4 in a transverse section of rat gastrocnemius muscle, detected with the polyclonal antibody GLUT4-BW. (B) Myosin ATP-ase staining of a serial section of rat gastrocnemius muscle. Pre-incubation was at $\mathrm{pH} 4.45$, therefore type 1 fibres appear dark, type 2a fibres appear light, and type $2 \mathrm{~b}$ fibres appear intermediately stained.

Comparing (A) and (B), it can be seen that a single type 1 fibre is visible, which has an increased GLUT-4 protein staining. Type $2 \mathrm{a}$ and type $2 \mathrm{~b}$ fibres are not consistently differentially stained for GLUT-4 protein. 
Fig. 9.5: (A) Myosin ATP-ase staining of a transverse section of rat soleus muscle. Pre-incubation was at $\mathrm{pH} 4.45$, therefore type 1 fibres appear dark, and type 2a fibres appear light. No type $2 \mathrm{~b}$ fibres are visible. (B) Immunofluorescence staining of GLUT-4 in a serial section of rat soleus muscle, detected with the polycional antibody GLUT4-BW. Note that GLUT-4 protein expression is highest in type 2a fibres.
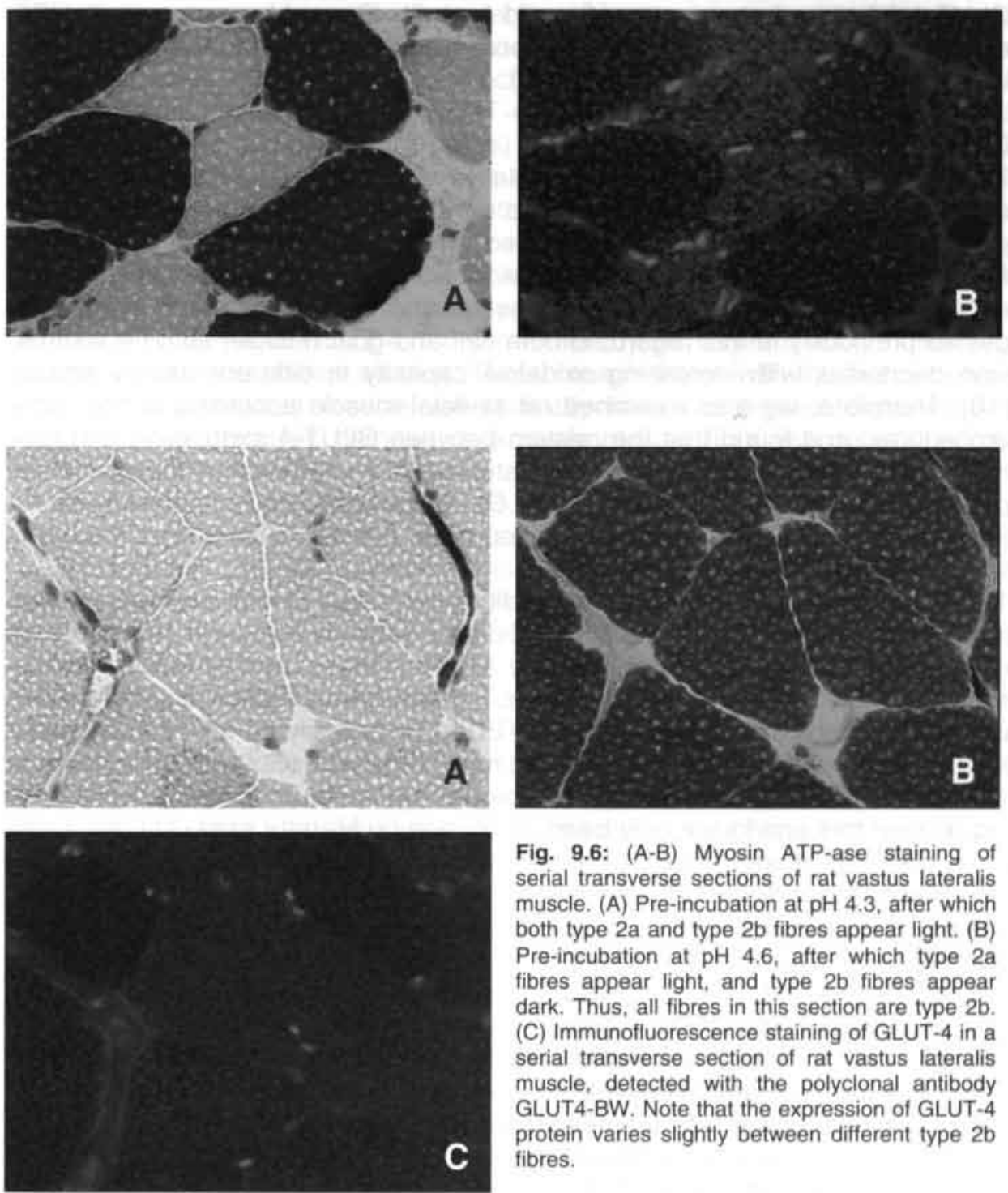

Fig. 9.6: (A-B) Myosin ATP-ase staining of serial transverse sections of rat vastus lateralis muscle. (A) Pre-incubation at $\mathrm{pH} 4.3$, after which both type $2 \mathrm{a}$ and type $2 \mathrm{~b}$ fibres appear light. (B) Pre-incubation at $\mathrm{pH} 4.6$, after which type $2 \mathrm{a}$ fibres appear light, and type 2b fibres appear dark. Thus, all fibres in this section are type $2 \mathrm{~b}$. (C) Immunofluorescence staining of GLUT-4 in a serial transverse section of rat vastus lateralis muscle, detected with the polyclonal antibody GLUT4-BW. Note that the expression of GLUT-4 protein varies slightly between different type $2 b$ fibres. 
in human vastus lateralis muscle; that is, GLUT-4 fluorescence labelling was highest in type 1 fibres (figure 9.4). In contrast, in all other rat muscles studied (soleus, extensor digitorum longus, tibialis anterior, and vastus lateralis muscle), GLUT-4 expression was highest in type 2 fibres, and lowest in type 1 fibres (figure 9.5). In none of the muscles a clear difference could be observed in GLUT-4 labelling between type $2 \mathrm{a}$ and type $2 \mathrm{~b}$ fibres. However, small differences in GLUT-4 labelling were observed between individual type 2 fibres, irrespective of their subclass (figure 9.6).

\section{Discussion}

The present study investigated the relative abundance of GLUT-4 protein in different muscle fibre types. Contrary to our hypothesis, we found that GLUT-4 protein was more abundantly expressed in glycolytic fibres than in oxidative fibres of human vastus lateralis muscle. This relationship is thought to be the opposite in rodents. However, species-specific differences have been suggested previously in this regard; in both calf and goat muscle, GLUT-4 expression decreases with increasing oxidative capacity in different muscle groups (10). Therefore, we also examined rat skeletal muscle according to the same procedures, and found that the relation between GLUT-4 expression and fibre type is dependent of the muscle group studied. In gastrocnemius muscle, which predominantly expresses type 2 fibres, GLUT-4 expression is highest in type 1 fibres, while in the other muscles studied here, this relationship was the opposite.

The abundance of GLUT-4 in different fibre types has almost exclusively been deduced from measurement of GLUT-4 protein content in muscle homogenates of different muscles of the rat $(6,8,9,11,16)$. These studies indeed conclusively showed that red muscle, such as soleus, has a higher GLUT-4 protein expression than white muscle, such as EDL. Accordingly, in vitro insulin stimulated glucose uptake is highest in red muscle groups $(6,9,16)$. However, a direct assessment of the relationship between muscle fibre type and GLUT-4 expression has previously only been performed by Marette et al (15). As a part of an elaborate study of the expression and localisation of glucose transporters in red and white muscle of the rat, they used immunofluorescence labelling to show that in the medial portion of the gastrocnemius muscle, type 1 fibres contain more GLUT-4 protein than type 2 fibres. This finding is in agreement with our data in rat gastrocnemius, but we have shown here for the first time that in a random selection of other rat muscles, as well as in human vastus lateralis muscle, type 2 fibres show the highest expression of GLUT-4 protein. This may seem incompatible with the findings of the previously cited studies using whole-muscle homogenates. However, we propose that differences in GLUT-4 content between different muscles are largely dependent on factors other than fibre type composition. Several observations from previous studies illustrate this:

1) Hardin et al. (7) showed that although marathon runners had a higher muscle GLUT-4 content than sedentary controls, insulin sensitivity and muscle GLUT-4 expression were not dependent upon muscle fibre type composition in either group. 2) Etgen et al. (5), measured GLUT-4 protein expression before and after training in epitrochlearis and soleus muscle in the obese Zucker rat. Rat epitrochlearis muscle contains $\sim 85 \%$ type 2 fibres, and rat soleus muscle con- 
tains $~ 85 \%$ type 1 fibres. GLUT-4 protein content in epitrochlearis muscle after endurance training approached the pre-training GLUT-4 levels in soleus muscle. This shows that although epitrochlearis predominantly expresses type 2 fibres, its GLUT-4 content can increase to a level found in muscle consisting almost exclusively of type 1 fibres within two weeks of exercise training. 3) Muscle fibre type composition is largely genetically determined (12). However, GLUT-4 protein expression can be upregulated within hours after acute exercise (18), a time span too short to affect fibre type composition. This suggests at least a partial independence of GLUT-4 expression and muscle fibre composition. 4) Chronic stimulation (10 days) of white rat muscle with a stimulation pattern resembling nerve activity of a nerve innervating red muscle increases GLUT-4 expression, suggesting that the activity pattern of the motor nerve is decisive for GLUT-4 expression (4).

From these observations, a strict coupling between GLUT-4 content and muscle fibre type composition seems unlikely. Therefore, it is not surprising that the relative abundance of GLUT-4 in different fibre types varies among muscles, or indeed per muscle portion studied. Those muscle fibres with the highest glycoIytic demand within a muscle will probably have the highest expression of GLUT-4. The glycolytic demand of a given muscle fibre will depend on the recruitment pattern of its motor unit, and its capacity to utilise substrates through pathways other than glycolysis. For some (or probably most) muscles, it will be the type 2 fibres that have the highest glycolytic capacity, and thus GLUT-4 protein content. However, a muscle that is activated primarily as a fasttwitch glycolytic muscle will largely derive its energy from high-energy phosphate stores such as phosphocreatine. If a few type 1 fibres are expressed within such a muscle (as seen in the medial or white portion of the gastrocnemius; figure 8.4), they will probably have to adapt to the muscle's function by upregulating their glycolytic capacity. Thus, GLUT-4 protein content within such a muscle will be highest in type 1 fibres. Although this mechanism is a putative one, it could explain the findings of our (and indeed other) studies. It may prove interesting to direct future studies toward the falsification of this theory.

In summary, the experiments described in this chapter indicate that the abundance of GLUT-4 protein varies between muscle fibres within a muscle. This differential expression is not strictly associated with fibre type: in rat gastrocnemius muscle GLUT-4 expression was highest in type 1 fibres, while in several other rat muscles, as well as human vastus lateralis, GLUT-4 expression was highest in type 2 fibres. We propose that factors other than solely fibre type, such as glycolytic demand, determine GLUT-4 expression in muscle. 


\section{References}

1. Armstrong, R. B., and R. 0. Phelps. Muscle fiber type composition of the rat hindlimb. Am J Anat 171: 259-72, 1984.

2. Brooke, M. H., and K. K. Kaiser. Muscle fiber types: how many and what kind? Arch Neurol 23: 369-79, 1970.

3. DeFronzo, R. A., E. Jacot, E. Jequier, E. Maeder, J. Wahren, and J. P. Felber. The effect of insulin on the disposal of intravenous glucose. Results from indirect calorimetry and hepatic and femoral venous catheterization. Diabetes 30 : 1000-7, 1981.

4. Etgen, G. J., Jr., R. P. Farrar, and J. L. Ivy. Effect of chronic electrical stimulation on GLUT-4 protein content in fast-twitch muscle. Am J Physiol 264: R816-9, 1993.

5. Etgen, G. J., Jr., C. M. Wilson, J. Jensen, S. W. Cushman, and J. L. Ivy. Glucose transport and cell surface GLUT-4 protein in skeletal muscle of the obese Zucker rat. AmJ-Physiol 271: E294-301, 1996.

6. Goodyear, L. J., M. F. Hirshman, R. J. Smith, and E. S. Horton. Glucose transporter number, activity, and isoform content in plasma membranes of red and white skeletal muscle. Am-J-Physiol 261: E55661, 1991.

7. Hardin, D. S., B. Azzarelli, J. Edwards, J. Wigglesworth, L. Maianu, G. Brechtel, A. Johnson, A. Baron, and W. T. Garvey. Mechanisms of enhanced insulin sensitivity in endurance-trained athletes: effects on blood flow and differential expression of GLUT 4 in skeletal muscles. J Clin Endocrinol Metab 80: 2437-46, 1995.

8. Hardin, D. S., J. H. Dominguez, and W. T. Garvey. Muscle groupspecific regulation of GLUT 4 glucose transporters in control, diabetic, and insulin-treated diabetic rats. Metabolism 42: 1310-5, 1993.

9. Henriksen, E. J., R. E. Bourey, K. J. Rodnick, L. Koranyi, M. A. Permutt, and J. O. Holloszy. Glu- cose transporter protein content and glucose transport capacity in rat skeletal muscles. Am J Physiol 259: E593-8, 1990.

10. Hocquette, J. F., F. Bornes, M. Balage, P. Ferre, J. Grizard, and M. Vermorel. Glucose-transporter (GLUT4) protein content in oxidative and glycolytic skeletal muscles from calf and goat. Biochem J 305: 46570, 1995.

11. Kern, M., J. A. Wells, J. M. Stephens, C. W. Elton, J. E. Friedman, E. B. Tapscott, P. H. Pekala, and G. L. Dohm. Insulin responsiveness in skeletal muscle is determined by glucose transporter (Glut4) protein level. Biochem-J 270: 397-400, 1990.

12. Komi, P. V., J. H. Viitasalo, M. Havu, A. Thorstensson, B. Sjodin, and J. Karlsson. Skeletal muscle fibres and muscle enzyme activities in monozygous and dizygous twins of both sexes. Acta Physiol Scand 100: 385-92, 1977.

13. Koranyi, L. I., R. E. Bourey, H. Vuorinen-Markkola, V. A. Koivisto, M. Mueckler, M. A. Permutt, and $\mathbf{H}$. Yki-Jarvinen. Level of skeletal muscle glucose transporter protein correlates with insulinstimulated whole body glucose disposal in man. Diabetologia 34: 7635, 1991.

14. Lillioja, S., A. A. Young, C. L. Culter, J. L. Ivy, W. G. Abbott, J. K. Zawadzki, H. Yki-Jarvinen, L. Christin, T. W. Secomb, and C. Bogardus. Skeletal muscle capillary density and fiber type are possible determinants of in vivo insulin resistance in man. J Clin Invest 80: 415-24, 1987.

15. Marette, A., J. M. Richardson, T. Ramlal, T. W. Balon, M. Vranic, J. E. Pessin, and A. Klip. Abundance, localization, and insulin-induced translocation of glucose transporters in red and white muscle. Am-JPhysiol 263: C443-52, 1992.

16. Megeney, L. A., P. D. Neufer, G. L. Dohm, M. H. Tan, C. A. Blewett, G. C. Elder, and A. Bonen. Effects of 
muscle activity and fiber composition on glucose transport and GLUT-4. Am J Physiol 264: E58393, 1993.

17. Ploug, T., B. van Deurs, H. Ai, S. W. Cushman, and E. Ralston. Analysis of GLUT4 distribution in whole skeletal muscle fibers: identification of distinct storage compartments that are recruited by insulin and muscle contractions. J Cell Biol 142: 1429-46, 1998.
18. Ren, J. M., C. F. Semenkovich, E. A. Gulve, J. Gao, and J. O. Holloszy. Exercise induces rapid increases in GLUT4 expression, glucose transport capacity, and insulinstimulated glycogen storage in muscle. J Biol Chem 269: 14396401, 1994.

19. Simoneau, J. A., and C. Bouchard. Human variation in skeletal muscle fiber-type proportion and enzyme activities. Am-J-Physiol 257: E567-72, 1989. 


\section{General Discussion}

\section{Chapter}

In this thesis, a number of studies concerning exercise in type 2 diabetes patients have been described. The main objective of these studies was to gain insight into the effects that prolonged endurance exercise has on patients with type 2 diabetes. The relevance of a physically active life-style for the treatment (and prevention) of type 2 diabetes has been discussed elaborately in Chapter 2. In brief, we summarised that there is ample evidence that physical exercise enhances insulin sensitivity in both healthy populations and populations with impaired insulin sensitivity or, ultimately, type 2 diabetes. A distinction should be made between the effects of acute exercise and the additive effects of prolonged physical training. The suggestion made by some researchers that the effect of physical training is merely a residual effect of the last exercise bout, that disappears within several days of detraining, can be refuted. Although the effect of a single exercise bout on insulin sensitivity indeed disappears within $\sim 24$ hours, this transient effect is stronger in the trained state. Furthermore, beneficial effects on body composition and lipoprotein-profiles, as well as pronounced alterations in the expression of enzymes and proteins involved in the oxidation and supply of substrates, occur only after prolonged physical training. This does not imply that acute effects of exercise are negligible. In Chapter 4, a study into substrate utilisation during acute exercise in type 2 diabetes patients was presented, confirming earlier observations that plasma glucose levels decline during moderate intensity exercise in these patients. In the literature, there is controversial data regarding the cause of this decline: failure to sufficiently increase hepatic glucose output (10) or, alternatively, an increased uptake of plasma glucose by exercising skeletal muscle (9). Our observations during exercise support the latter view, since the plasma glucose rate of disappearance was higher than its rate of appearance. Total rates of carbohydrate 
and fat oxidation were normal in type 2 diabetic patients. However, it has been suggested by others (4) that skeletal muscle FFA uptake and oxidation is impaired under resting conditions in type 2 diabetic patients. We hypothesised that such an impairment could cause decreased rates of whole body FFA oxidation in these patients during moderate intensity exercise. This has as yet never been shown, but failure to account for loss of FFA-carbon isotopic label in the tricarboxylic acid (TCA) cycle in all previous studies may have confounded the results. We demonstrated that during moderate intensity exercise (but not rest), the acetate recovery factor (ARF) is lower in type 2 diabetes patients than in healthy controls. The ARF is a correction factor that attempts to quantify labelloss in the TCA-cycle. Applying this correction factor, we found no significant abnormality in plasma FFA oxidation during exercise in type 2 diabetic patients. Chapter 4 reported of substrate utilisation during acute moderate intensity endurance exercise, because moderate intensity endurance exercise is the type of exercise that is generally recommended to type 2 diabetes patients. For example, the Guidelines for Diabetes Care of the European Diabetes Policy Group 1998-1999 (3) mentions 30 minutes of "brisk-walking" as an advisable means of increasing daily physical activity. However, as we already concluded in Chapter 2, little scientific evidence is available to justify such recommendations. Therefore, Chapter 5 describes a study into the influence of exercise intensity of a physical training program on insulin sensitivity. We found that, for a given exercise duration, high-intensity exercise exerts the largest increase in insulin sensitivity. This does not rule out the possibility that it is the total amount of work performed that is of prime importance in determining the effect of physical training. However, in practice it does imply that if a person must choose between 30 minutes of "brisk-walking" or 30 minutes of running, the latter is preferable. A prerequisite in this example is that this person should be free of contra-indications for intense exercise. It should be emphasised that the study described in Chapter 5 was carried out in young, healthy volunteers. Type 2 diabetes is associated with obesity, and a high prevalence of micro- and macrovascular pathologies. Therefore, it is important to evaluate the capability to participate in physical exercise on an individual basis, and to tailor exercise programs to each individual's abilities. Thus, the general conclusion from Chapter 5 is that physical activity should be intense to have an optimal impact on insulin sensitivity, but that the maximal intensity must be determined on an individual basis.

Although the data presented in Chapter 5 indicate that exercise intensity of a training program in type 2 diabetes patients should be as high as feasible, intense exercise may have adverse effects on glucose homeostasis. It has been demonstrated by others (6) that high-intensity exercise in type 2 diabetes patients can lead to an acute increase in plasma glucose levels, causing them to be elevated for $>60$ minutes after cessation of exercise. This effect was proposed to result from an increased rate of appearance of plasma glucose relative to its rate of disappearance (6). Furthermore, physical training has been shown to result in an exaggerated rate of appearance of plasma glucose during intense exercise (5), presumably caused by an increased responsiveness of the adrenal medulla. These observations have been used as an argument against the recommendation of high-intensity exercise to type 2 diabetic patients (6), since a temporal aggravation of the hyperglycaemia already present in these patients 
could result from this type of exercise. We therefore evaluated the plasma glucose response to the incremental bicycle ergometer tests in the group of diabetes patients that followed the endurance training program outlined in Chapter 3. Among other hormones, the response of plasma adrenaline and noradrenaline levels to the exercise test was measured. These experiments were compared with identical tests in healthy control subjects, and in a type 2 diabetic control group that remained sedentary. As described in Chapter 6, we found no evidence to support the notion that plasma glucose increases in type 2 diabetes patients during high-intensity exercise. In addition, we found no effect of prolonged endurance training on plasma glucose regulation during the bicycle ergometer test. Therefore, from our investigations, there seems to be no rationale to advise against high-intensity exercise training in type 2 diabetes patients because of a risk of disturbing glucoregulation.

The study outlined in Chapter 7 reports of such an exercise program of highintensity (relative to earlier investigations), applied to investigate its long-term effects in type 2 diabetes patients. From this study, we infer that it is imperative to supervise exercise in training programs aimed at these patients (or possibly this age-group), because without supervision, training duration in our study decreased to a level at which its beneficial effects were no longer sustained. These beneficial effects included a large increase in insulin responsiveness, that was associated with an increase in muscle GLUT-4 protein expression, an improvement in plasma lipoprotein-lipid profile, and a decrease in body fat percentage. However, despite its long duration and high intensity, training did not normalise glycaemic control. Very few previous training intervention studies have measured glycaemic control, and those that have reported an improvement $(11,12)$ studied patients that were much less well-controlled than the patients described in this thesis. This could explain in part why glycaemic control was unaltered in our study. However, glycaemic control in type 2 diabetes patients is often achieved through the effects of anti-hyperglycaemic medication. As has been described in Chapter 8, anti-hyperglycaemic drug requirements were decreased in the training intervention group. This could of course have offset possible improvements in glycaemic control.

The findings reported in Chapter 8 indicate that physical activity may be an important means of reducing the use of anti-hyperglycaemic medication in the increasingly large population of type 2 diabetes patients in the western society. Apart from their implications for health-care costs, these findings may be of importance to the individual type 2 diabetes patient: if physical exercise could result in decreased use of medication, this could be an important impetus for patients to commence or keep up an active life-style. However, studies on a larger scale are needed to confirm our observations in Chapter 8.

Skeletal muscle is responsible for the major part of the increase in insulin stimulated glucose uptake after physical training (Chapter 2), and the rate limiting step for insulin stimulated glucose uptake into muscle, under most physiological conditions, is glucose transport into the sarcoplasm. Skeletal muscle is heterogeneous with regard to the functional and metabolic characteristics of the muscle fibres of which it is made up. These fibres are often subdivided into slow-twitch oxidative, fast-twitch oxidative, and fast-twitch glycolytic fibres, and these sub-classes have been suggested to differ with regard to their GLUT-4 protein content. Type 2 diabetes patients have been suggested to have 
a decreased percentage of oxidative fibres (8), and therefore the relationship between muscle fibre type and muscle fibre GLUT-4 content is potentially interesting for the study of the metabolic abnormalities underlying type 2 diabetes. We investigated this relationship in both human and rat skeletal muscle. Contrary to the consensus derived from studies in which rat muscle homogenates were used, we found no evidence for a consistent association between GLUT-4 protein expression and muscle fibre type as determined by $\mathrm{pH}$ sensitive myosin ATP-ase staining. GLUT-4 protein expression was visualised for individual fibres by using immunofluorescence methods on serial transverse muscle sections, that were also stained for fibre type. We proposed that factors other than muscle fibre type composition, which is largely an inherited trait (7), account for variations in muscle GLUT-4 protein content. An important regulating factor could be muscle metabolic activity. As we (Chapter 7) and others (1, 2) have shown, exercise training can drastically increase muscle GLUT-4 content. Similarly, muscle activity throughout the day, which depends on a muscle's function, will determine muscle GLUT-4 content. Unfortunately, with the techniques used in Chapter 9, quantitation of absolute amounts of GLUT-4 is precarious, if not impossible. Otherwise, it would have been interesting to study the impact of the prolonged physical training program on the GLUT-4 content of different muscle fibre types.

In summary, this thesis has contributed to the present knowledge about exercise in type 2 diabetes. On the basis of the beneficial effects reported in our, and previous studies, those patients that are capable of participation in physical exercise should be encouraged to do so. Not only does exercise acutely decrease blood glucose levels through an increased uptake by the working muscle, exercise training also has multiple long-term benefits. Exercise intensity and duration should be as high as feasible to achieve optimal effects. However, it should be emphasised that individual assessment of exercise capability and training supervision are crucial to optimal implementation of exercise training programs in this patient group.

\section{Conclusions}

The main conclusions from the various experiments described in this thesis are:

- Plasma glucose uptake during moderate intensity exercise in type 2 diabetes is increased, due to an augmented rate of disappearance. Overall carbohydrate utilisation is normal in these patients, and thus muscle glycogen oxidation is diminished.

- Acetate recovery during moderate intensity exercise is decreased in type 2 diabetes.

- High intensity exercise is more effective in increasing insulin sensitivity than low intensity exercise, when exercise duration is kept similar.

- The insulin tolerance test can be used to evaluate the effect of interventions aimed at altering insulin sensitivity, at least in healthy subjects.

- Type 2 diabetic patients do not exhibit abnormal hormonal responses to acute exhaustive exercise, and plasma glucose does not increase during this type of exercise. 
- Physical training does not result in an augmented glucose production, leading to increased plasma glucose levels, during acute exhaustive exercise in type 2 diabetic patients.

- Long-term physical training causes a large increase insulin responsiveness in type 2 diabetes.

- The improvement in insulin responsiveness through physical training in type 2 diabetic patients is accompanied by increased levels of GLUT-4 protein and citrate synthase in skeletal muscle.

- Long-term physical training increases muscle cytosolic FABP, improves plasma lipoprotein lipid profiles, and decreases body fat percentage in type 2 diabetic patients, indicating improvements in lipid metabolism.

- Physical training in type 2 diabetic patients should be supervised, to assure that the training stimulus remains adequate to sustain training-induced improvements.

- Type 2 diabetic patients, or certain subgroups of these patients, can reduce their requirements for anti-hyperglycaemic medication by engaging in physical exercise.

- There is no strict relation between GLUT-4 protein content and muscle fibre type as determined by $\mathrm{pH}$ sensitive myosin ATP-ase activity. 


\section{Discussion}

1. Dela, F., T. Ploug, A. Handberg, L. N. Petersen, J. J. Larsen, K. J. Mikines, and H. Galbo. Physical training increases muscle GLUT4 protein and mRNA in patients with NIDDM. Diabetes 43: 862-5, 1994.

2. Etgen, G. J., Jr., J. Jensen, C. M. Wilson, D. G. Hunt, S. W. Cushman, and J. L. Ivy. Exercise training reverses insulin resistance in muscle by enhanced recruitment of GLUT-4 to the cell surface. Am-JPhysiol 272: E864-9, 1997.

3. IDF. A desktop guide to type-2 diabetes mellitus. Diabetic Medicine 16: 716-730, 1999.

4. Kelley, D. E., and J. A. Simoneau. Impaired free fatty acid utilization by skeletal muscle in non-insulindependent diabetes mellitus. J-ClinInvest 94: 2349-56, 1994.

5. Kjaer, M., P. A. Farrell, N. J. Christensen, and $\mathbf{H}$. Galbo. Increased epinephrine response and inaccurate glucoregulation in exercising athletes. J-Appl-Physiol 61: 1693-1700, 1986.

6. Kjaer, M., C. B. Hollenbeck, B. Frey Hewitt, H. Galbo, W. Haskell, and G. M. Reaven. Glucoregulation and hormonal responses to maximal exercise in non-insulin-dependent diabetes. J-Appl-Physiol 68: $2067-$ 74, 1990.

7. Komi, P. V., J. H. Viitasalo, M. Havu, A. Thorstensson, B. Sjodin, and J. Karlsson. Skeletal muscle fibres and muscle enzyme activities in monozygous and dizygous twins of both sexes. Acta Physiol Scand 100: 385-92, 1977.

8. Marin, P., B. Andersson, M. Krotkiewski, and P. Bjorntorp. Muscle fiber composition and capillary density in women and men with NIDDM. Diabetes Care 17: 382-6, 1994.

9. Martin, I. K., A. Katz, and J. Wahren. Splanchnic and muscle metabolism during exercise in NIDDM patients. Am-J-Physiol 269: E583-90, 1995.

10. Minuk, H. L., M. Vranic, E. B. Marliss, A. K. Hanna, A. M. Albisser, and B. Zinman. Glucoregulatory and metabolic response to exercise in obese noninsulindependent diabetes. Am J Physiol 240: E458-64, 1981.

11. Schneider, S. H., L. F. Amorosa, A. K. Khachadurian, and N. B. Ruderman. Studies on the mechanism of improved glucose control during regular exercise in type 2 (non-insulin-dependent) diabetes. Diabetologia 26: 355-60, 1984.

12. Trovati, M., Q. Carta, F. Cavalot, S. Vitali, C. Banaudi, P. G. Lucchina, F. Fiocchi, G. Emanuelli, and G. Lenti. Influence of physical training on blood glucose control, glucose tolerance, insulin secretion, and insulin action in non-insulindependent diabetic patients. Diabetes Care 7: 416-20, 1984. 


\section{Samenvatting "Inspanning en Type 2 Diabetes"}

In dit proefschrift worden een aantal studies beschreven naar fysieke inspanning bij patiënten met type 2 diabetes. Type 2 diabetes is een aandoeining die wordt gekenmerkt door insuline-ongevoeligheid. De ziekte komt steeds vaker voor, en kan, met name indien onbehandeld, de kwaliteit van leven sterk beperken. In Hoofdstuk 1 worden enige chronische ziekten beschreven die met type 2 diabetes samenhangen. Deze zorgen voor een hogere mortaliteit bij patiënten met type 2 diabetes dan bij gezonde leeftijdsgenoten. Epidemiologische studies hebben aangetoond dat fysiek actieve personen minder snel type 2 diabetes ontwikkelen. Hoofdstuk 2 beschrijft de rol die een fysiek-actieve leefstijl kan spelen in de behandeling en preventie van type 2 diabetes. Uit de literatuur blijkt dat acute inspanning de insulinegevoeligheid tijdelijk kan verhogen, en dat regelmatige fysieke inspanning (training) dit effect versterkt. Daarnaast zijn er nog enige lang aanhoudende effecten van training die gunstig kunnen zijn voor mensen met type 2 diabetes: o.a. verbeteringen in lichaamssamenstelling, spiermetabolisme, en normalisering van de leverglucoseproductie. De acute effecten van inspanning zijn echter niet te verwaarlozen. Hoofdstuk 4 bevestigt eerdere bevindingen dat de plasmaglucosespiegel daalt tijdens inspanning bij patiënten met type 2 diabetes, in tegenstelling tot bij gezonden. De opname van glucose uit het plasma in de spier bleek bij diabetespatiënten tijdens inspanning hoger te zijn dan de productie van plasmaglucose door met name de lever. Er werden geen afwijkingen gevonden in het vetmetabolisme tijdens inspanning. In Hoofdstuk 5 werd aangetoond, bij gezonde vrijwilligers, dat een trainingsprogramma van vier weken de insulinegevoeligheid in deze groep kan verbeteren. Hierbij is een trainingsprogramma van hoge intensiteit effectiever dan een programma van lage intensiteit, wanneer inspanningsduur en -frequentie gelijk worden gehouden. Er zijn echter aanwijzingen uit de literatuur dat uitputtende inspanning (in tegenstelling tot inspanning van lage intensiteit) de plasmaglucosespiegel van diabetespatiënten kan verhogen. Uit de bevindingen omschreven in Hoofdstuk 6 van dit proefschrift blijkt dit niet: de glucosespiegel van patiënten tijdens uitputtende inspanning was identiek aan die van gezonde controlepersonen, en ook in verscheidene hormonen die deze spiegel reguleren werden geen afwijkingen 
waargenomen. Langdurige training bracht hierin verder geen verandering. Deze langdurige training verbeterde daarentegen wel de insulinegevoeligheid van de type 2 diabetes patiënten, met zo'n 30\% na één jaar (Hoofdstuk 7). Daarnaast verhoogde onder andere het gehalte van GLUT-4 eiwit in de spier. GLUT-4 is het eiwit dat verantwoordelijk is voor het glucosetransport over de spiercelmembraan, na stimulering door insuline of spiercontractie. Een ander positief effect van het trainingsprogramma was dat de patiënten die hieraan meededen minder medicatie gebruikten dan een groep type 2 diabeten die niet aan een trainingsprogramma meededen (Hoofdstuk 8). Dit leek echter deels ten koste te gaan van de bloedsuikerregulatie. Verder werd in Hoofdstuk 7 omschreven dat, willen de verbeteringen in glucosemetabolisme gehandhaafd blijven, de trainingsduur op een zeker minimaal niveau moet blijven. Zonder regelmatige begeleiding van de training daalde dit niveau tot een peil waarop de trainingsgeïnduceerde verbeteringen weer teniet gedaan waren. Hoofdstuk 9 is een beschrijvende studie naar het gehalte van GLUT-4 eiwit in verschillende spiervezeltypen bij zowel de mens als de rat. Er wordt over het algemeen van uitgegaan dat dit gehalte hoger is in type 1 spiervezels dan in type 2 spiervezels. Dit is echter gebaseerd op studies waarbij in spierhomogenaten het totale GLUT-4 gehalte is gemeten. Met de door ons toegepaste immunofluorescentiemethoden blijkt dat deze relatie vaak omgekeerd is, en afhankelijk is van de spiergroep waarin men kijkt.

Concluderend kan worden gesteld dat, gezien de meervoudige positieve effecten, fysieke training aanbevolen zou moeten worden aan alle type 2 diabetespatiënten die hiertoe geen beperkingen hebben. Indien mogelijk, moet deze training van een hoge intensiteit zijn. Echter, het is van belang vooraf de belastbaarheid van de patiënt vast te stellen, en de training goed te begeleiden, willen er blijvende positieve effecten het gevolg zijn. 


\section{Alfabetische Dankwoordenlijst}

Wat wordt er van een proefschrift het meest gelezen? De Nederlandse samenvatting, de stellingen, en het dankwoord. Het eerste omdat je eigenlijk niet precies weet wat de promovendus in al die jaren heeft uitgevoerd, het tweede om te kijken of er nog wat te lachen valt, en het derde om te zien of je er zelf instaat. Om dit laatste te vergemakkelijken (de klant is tenslotte koning,) introduceer ik bij deze een handige noviteit: de Alfabetische Dankwoordenlijst. Zo ben je voortaan nog sneller klaar met het lezen van een proefschrift!

\section{Bedankt:}

Barendregt, Karin: Geen verontschuldigingen hier over "al die avonden dat je me hebt moeten missen," en dergelijke. Want als jij ergens voor hebt gezorgd Karin, dan is dat wel dat ik altijd liever bij jou ben dan aan het werk. We gaan binnenkort samen een half jaar door Europa fietsen, en ik kan niks verzinnen dat ik liever zou doen. Enne... ook al is dit dan een alfabetische dankwoordenlijst, de volgorde is toch niet helemaal willekeurig.

Backx, Karianne: Zonder jou was er geen hoofdstuk 5 geweest. Of althans, dan had dat het huidige hoofdstuk 6 geweest. Of misschien... Nou ja in ieder geval zijn de experimenten en trainingen in dat hoofdstuk vrijwel volledig door jou uitgevoerd, en op zodanige manier dat ik het nog steeds jammer vind dat we je naar Engeland hebben zien vertrekken. Zie ook onder "stagaires, overigen".

Bomans, Paul: Dank voor het wegwijs maken in de wondere wereld van de immuno-electronenmicroscopie, en de gezelligheid bij de koffie (of het bier) op de gang "beneden".

Borghouts, Jeroen: Omdat je mijn broer bent, en paranimf. En omdat je, na een paar jaar geleden nét voor me je doctoraaldiploma gehaald te hebben, mij wél twee weken eerder laat promoveren. Symphatiek van je. 
Brands, Désirée: Voor alle secretariële ondersteuning, met name wanneer er weer eens afspraken gemaakt moesten worden met allerlei proefpersonen. En omdat je de one-stop-shop bent voor alle vakgroepgeruchten natuurlijk.

Collega AiO's, overigen: Het AiO-volk trekt toch altijd een beetje naar elkaar toe. Enige collega AiO's die dat de moeite waard maken of hebben gemaakt: René, Gors, Reinout (Jr.), Olivier (ook soort AiO), Bolletje, Pimi, Mascha, Mariëlle, Dr. Troost, Gerard, Marco, Luuk.

Collega's, overigen: Verschillende mensen hebben de afgelopen jaren klaargestaan, soms in geval van nood, om me te helpen met van alles en nog wat. Dus dank aan: Harry, Henny, Joan, Annemie, Jos, Loek, Paul, en al die anderen die de dingen draaiende houden op de universiteit.

Frederik, Peter: Voor de gastvrijheid bij E.M. Zie verder onder Bomans.

Giessen, Heinz: Bedankt voor het mede opzetten van de clamps, helemaal in het begin. Maar ook voor die avonden in onder andere Düsseldorf (WodkaTabasco, daar heb je pas lang plezier van...) en Orlando. Hopelijk werken we in de toekomst nog eens samen.

Gool, Rein van: Voor de impuls die je aan het immuno-labelingswerk hebt gegeven. Zie verder onder Bomans en onder Frederik.

Gorselink, Marchel: Gors, bedankt voor een hoop onzin, maar ook voor serieuze en kritische gesprekken. We moeten samen nog maar eens wat consumptiebonnen eten. Zie verder onder "Collega AiO's, overigen".

Goyens, Petra: Voor al het werk dat je hebt verzet bij het uitvoeren van de studie beschreven in hoofdstuk 4. Maar niet voor het invullen van de Tour de France poule 1998. Zie verder onder "stagaires, overigen".

Groot, Patricia de: Voor de hulp bij verschillende testen. De experimenten die je hebt uitgevoerd voor je stage zijn niet in dit proefschrift beland, maar worden hopelijk nog elders gepubliceerd. Inmiddels werk je in Noorwegen, dus ik denk dat ik toch maar eens kom langlaufen. Zie verder onder "stagaires, overigen".

Heine, Rob: Dank omdat je lid wilde zijn van mijn leescommissie, en voor het zorgvuldig doornemen van mijn manuscript.

Hesselink, Matthijs: Ik denk dat ik van jou de afgelopen vijf jaar meer heb geleerd dan van wie dan ook. Bovendien hebben we als kamergenoten zoveel uren samen doorgebracht dat ik soms denk dat onze cycli gelijk zijn gaan lopen. Hesselink, Reinout: Zie zowel onder "Stagaires, overigen" als "Collega AiO's, overigen".

Jeukendrup, Asker: Want jij was tenslotte toch degenen die mij tipte voor het AiO-project waaruit dit proefschrift is voortgekomen. En ook dank voor een paar memorabele buitenland-avonturen natuurlijk.

Jong, Yvonne de: Voor al het werk dat je verzet hebt in de eerste vier jaren van ons project.

Keizer, Hans: Hans, het staat natuurlijk vaak in dankwoorden, dat een proefschrift het werk is van meerdere personen. Maar bij dit boekje is dat bij uitstek het geval. Er is nauwelijks een test geweest in het project waar je niet bij bent geweest, en ik weet niet precies hoeveel ons bioptmateriaal we samen inmiddels hebben afgenomen. Het is niet altijd van een leien dakje gegaan, zeker in het begin, maar dat ik desondanks verder wil in de wetenschap is mede aan jou te danken.

Kranenburg, Gerrit van: Omdat je als een muli-functioneel inzetbaar, duizenden-één-dingen-doekje van de vakgroep zo veel dingen voor ons hebt gedaan, 
geanalyseerd en geregeld. En omdat het zo verfrissend is om elke ochtend een welgemeend "hé eikels?" de kamer ingeslingerd te krijgen.

Kuipers, Harm: Bedankt voor je belangstelling, de steun in met name de laatste fase van mijn promotie, en omdat je de snelste levende spellingscorrector bent die ik ken.

Mensink, Marco: Dit is niet mijn eerste dankwoord waar je instaat, paranimf. Ik ben blij dat je inmiddels alweer een tijdje terug in Maastricht bent, als AiO op een onderwerp waarop onze wegen zich ongetwijfeld ook wel weer zullen kruisen. En anders zorgen we er wel voor.

Pijl, Hanno: Samenwerken op afstand is niet altijd even makkelijk, maar ik heb onze samenwerking met jou in Leiden toch heel prettig gevonden. Bovendien dank voor je kritische en snelle beoordeling van enige manuscripten, toen ik dat erg goed kon gebruiken.

Pijnappels, Mirjam: Omdat sinds je in Amsterdam zit, het binnen de vakgroep bergafwaarts is gegaan met het koffie halen voor elkaar, het ICQ-en, het squashen, het stappen, en het aantal Brabanders. Zie verder onder "Collega AiO's".

Proefpersonen: Een proefpersoon (of eigenlijk is vrijwilliger een mooier woord) die het hele project heeft meegedaan hebben we in die twee jaar tijd zo'n 13 spierbiopten afgenomen, minstens 11 catheters geprikt, en ongeveer een liter bloed afgenomen. En dat allemaal pro deo. Het moge duidelijk zij dat jullie eigenlijk nog de meeste dank toekomt.

Rietjens, Gerard: Voor hulp, een hoop plezier, maar niet voor die snelle 60 meter. Zie verder onder "Collega AiO's".

Saris, Wim: Voor je inspanningen als voorzitter van mijn leescommissie.

Schaart, Gert: Van je "transfer" naar Bewegingswetenschappen heb ik, en niet als enige, geweldig geprofiteerd. Hopelijk hou je het nog lang uit tussen al die rare $\mathrm{BW}$-ers.

Schrauwen, Patrick: Bedankt voor zinnige en onzinnige discussies, voor de (wellicht verder uitbreidende) samenwerking, en dat je de wereld hebt laten kennismaken met het spel "Demarrage".

Secretaresses, overigen: Niet alle secretaresses zijn even honkvast geweest als Désirée. Sinds ik bij BW ben gaan werken heb ik de revue zien passeren: Joke, Marion, Edith, Yvonne, Saskia. Met name de eerste twee en de laatste ben ik dank verschuldigd voor het plegen van vele telefoontjes en het versturen van talloze proefpersoonbrieven.

Sels, Jean Pierre: Voor hulp bij het keuren van vele proefpersonen, en bij het opstarten van de clamps.

Stagaires, overigen: Omdat we altijd handen tekort kwamen bij onze testen, hadden we het nooit kunnen redden zonder de hulp van vele stagaires. Bovendien maakte hun aanwezigheid het er over het algemeen een stuk gezelliger op. Dus naast de eerder genoemden ook nog bedankt: Gino, Dennis, Evelien, Kirsten, Dotje, Joris, Marc, en Ronnie.

Vusse, Ger van der: Dank omdat je lid wilde zijn van mijn beoordelingscommissie, en voor het zorgvuldig doornemen van mijn manuscript.

Wagenmakers, Ton: Dank omdat je lid wilde zijn van mijn beoordelingscommissie, en de prettige samenwerking bij met name de studie omschreven in hoofdstuk 4. 
Alfabetische Dankwoordenlijst

Wolffenbuttel, Bruce: Dank omdat je lid wilde zijn van mijn beoordelingscommissie, en je hulp bij met name de opstartfase van het project.

Zonderland, Maria: Dank omdat in de corona hebt willen plaatsnemen. 


\section{Curriculum Vitae}

Lars Borghouts werd geboren op 29 juni 1972 in Breda, alwaar hij van 1984 tot 1990 het VWO doorlopen heeft op het Newman College. In september 1990 maakte hij een aanvang met de propaedeuse Gezondheidswetenschappen aan de toenmalige Rijksuniversiteit Limburg. In november 1994 behaalde hij aldaar zijn doctoraaldiploma in de afstudeerrichting Bewegingswetenschappen. Van december 1994 tot december 1999 werd aan de vakgroep Bewegingswetenschappen van wat inmiddels de Universiteit Maastricht heet, het in dit proefschrift beschreven promotie-onderzoek uitgevoerd, dat werd gefinancierd door het Diabetes Fonds Nederland. Vanaf maart 2000 zal hij zijn inspanningsfysiologische kennis in de praktijk gaan brengen tijdens een halfjaar durende fietstocht door Europa. 


\section{Publications}

1. Borghouts L.B., A.E. Jeukendrup, W. H. M. Saris, and F. Brouns. No effect of medium chain triglyceride (MCT) ingestion during prolonged exercise on muscle glycogen utilization. Med Sci Sp Ex 27: S101, 1995. (Abstract). 2. Wagenmakers A.J.M., A.E.Jeukendrup, L.Borghouts, and W.H.M. Saris. Low oxidation rates of orally ingested glucose during exercise with low muscle glycogen. Med Sci Sp Ex 27: S206, 1995. (Abstract).

3. Jeukendrup A.E., L.B. Borghouts, W.H.M. Saris, A.J.M. Wagenmakers. Reduced oxidation rates of ingested glucose during prolonged exercise with low endogenous CHO availability. J. Appl. Physiol. 81 (5):1952-1957, 1996.

4. Borghouts L.B., H.A. Keizer. Six month endurance training program improves aerobic performance but not glycemic control in NIDDM.

The Physiologist 39 (5), 1996. (Abstract).

5. Borghouts L.B., K. Backx, G.P.J. van Kranenburg, H.A. Keizer Training intensity-specific changes in insulin sensitivity measured by insulin tolerance test. Neth. J. Med. ,1998. (Abstract).

6. Borghouts L.B., K. Backx, G.P.J. van Kranenburg, H.A. Keizer Training intensity-specific changes in insulin sensitivity measured by insulin tolerance test. Med Sci Sp Ex 30: 1104,1998. (Abstract).

7. Palmer G. S., L. B. Borghouts, T. D. Noakes, J. A. Hawley Metabolic and performance responses to constant-load vs variable-intensity exercise in trained cyclists. J. Appl. Physiol. 87 (3): 1186-1196

8. Borghouts, L.B., K. Backx, M.F. Mensink, H.A. Keizer. Effect of training intensity on insulin sensitivity evaluated by insulin tolerance test. Eur J Appl Physiol. 80 (5): 461-6, 1999

9. Borghouts L.B., G.P.J. Van Kranenburg, G. Schaart, H.A. Keizer. Longterm endurance training induced changes in insulin sensitivity, muscle enzymes and GLUT4 in NIDDM patients. Diabetologia 42 (Supp. 1): 187, 1999. (Abstract).

10. Borghouts L.B., H.A. Keizer. Exercise and insulin sensitivity: a review. Int J Sports Med 21 (1): 1-12, 2000. 
11. Schrauwen P., E.E. Blaak, D.P.C. van Aggel-Leijssen, L.B. Borghouts, A.J.M. Wagenmakers. Determinants of the acetate recovery factor: implications for estimation of ${ }^{13} \mathrm{C}$ substrate oxidation. Clinical Science (in press). 
Notes 
Notes 
Notes 
Notes 
Notes 
Notes 

